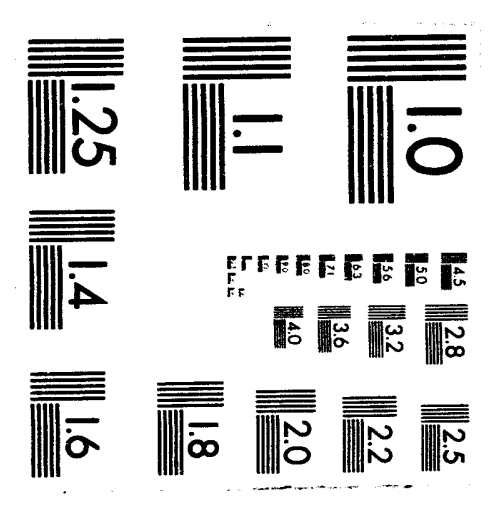



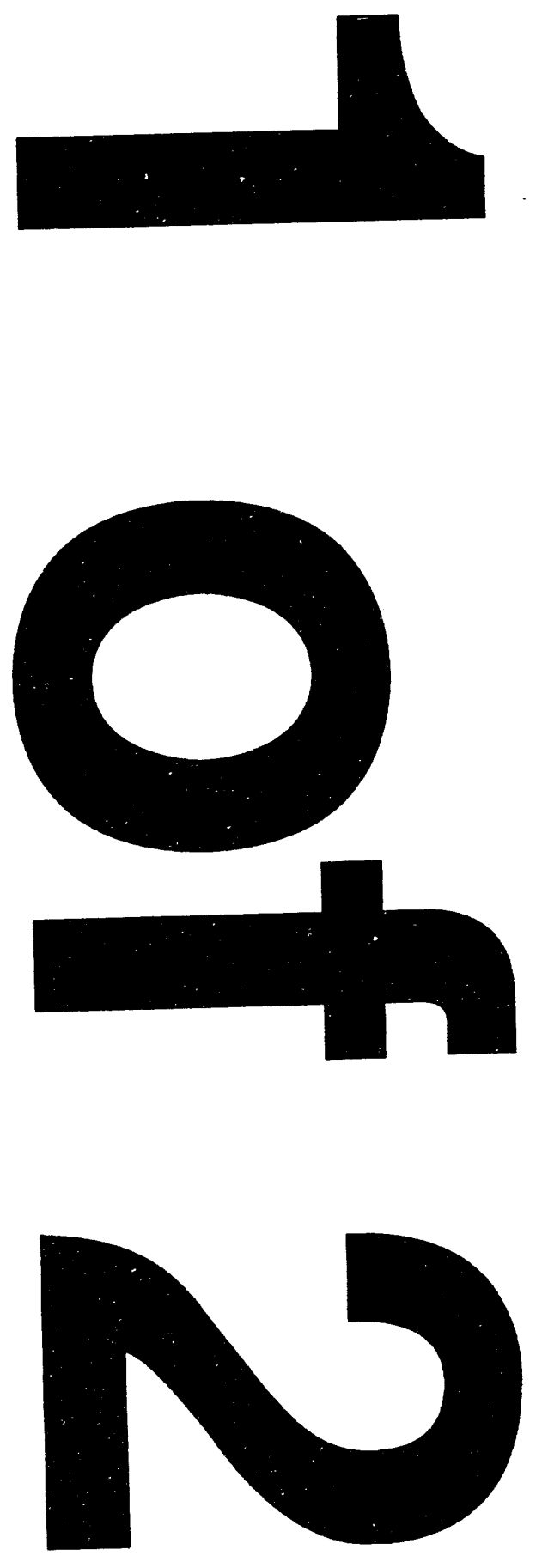


\title{
Some Light-Ion Excitation-Function Measurements on Titanium, Yttrium, and Europium, and Associated Results
}

\author{
H. I. West, Jr., Editor \\ H. I. West, Jr., R. G. Lanier, M. G. Mustafa, \\ R. M. Nuckolls, R. J. Nagle, and H. O'Brien \\ Nuclear Chemistry Division \\ University of California \\ Lawrence Livermore National Laboratory \\ Livermore, California 94550 \\ J. Frehaut, A. Adam, and C. Philis \\ Service de Physique et Techniques Nucléaires \\ Boîte Postale No. 12 \\ Centre d'Etudes Bruyeres-le-Chatel \\ 91680 Bruyeres-le-Chatel, France
}

Manuscript date: November 1993

LAWRENCE LIVERMORE NATIONAL LABORATORY

University of California - Livermore, California • 94551 


\section{Contents}

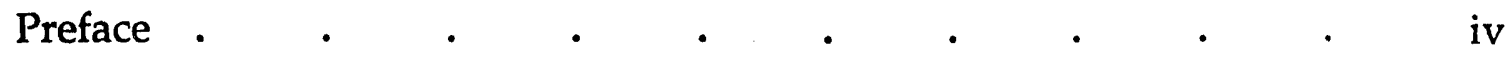

1. Fabrication of Plastic-Matrix-Encapsulated Accelerator Targets

and Their Use in Measuring Nuclear Excitation Functions

(H. I. West, Jr., R. M. Nuckolls, and R. G. Lanier) . . . . . 1-1

2. Correcting Excitation Function Data in the Low Energy Region

for Finite Thickness of the Target Foils, Including Effects of Straggling

(H. I. West, Jr.)

3. Excitation Functions for the Nuclear Reactions on Titanium

Leading to the Production of ${ }^{48} \mathrm{~V},{ }^{44} \mathrm{Sc}$ and ${ }^{47} \mathrm{Sc}$ by Proton,

Deuteron and Triton Irradiations at $0-35 \mathrm{MeV}$

(H. I. West, Ir., R. G. Lanier, and M. G. Mustafa )

4. Some Excitation Functions of Proton and Deuteron Induced

Reacti ons on ${ }^{89} \mathrm{Y}$

(H. I. West, Jr., M. G. Mustafa, H. O'Brien, and R. G. Lanier)

5. Measurements of the Excitation Functions of the Isobaric

Chain ${ }^{87} \mathrm{Y},{ }^{87} \mathrm{Ym}^{\mathrm{m}},{ }^{87} \mathrm{Yg}$, and ${ }^{87} \mathrm{Sr} \mathrm{m}$ (H. I. West, Jr., H. O'Brien,

R. G. Lanier,R. J. Nagle, and M. G. Mustafa) . . • .

6. Levels in ${ }^{87} \mathrm{Y}$ Observed in the Decay of ${ }^{87} \mathrm{Zr}$

(H. I. West IJ., and R. J. Nagle) .

6-1

7. Nuclear Reaction Excitation Functions from the Irradiation of $151,153 \mathrm{Eu}$ with Protons and Deuterons up to $35 \mathrm{MeV}$

(H. I. West, Jr., R. G. Lanier, M. G. Mustafa, R. M. Nuckolls, J. Frehaut, A. Adam, and C. Philis) 


\section{Preface}

Over the period of the last few years we have conducted a program of measuring nuclear excitation functions for protons, deuterons, and to a limited extent, tritons, for chromium, titanium, bromine, iodine, yttrium, and europium. The stacked-foil activation method was used throughout; however, the measurements were made with but a few foils in each stack, overlapping in energy, and corrections were made for effects caused by finite foil thickness. These measurements were made to fit the programmatic needs of Lawrence Livermore National Laboratory,. and care was exercised to achieve high accuracy (an error of less than $\pm 5 \%$ ).

The following results have been published: all of the chromium results

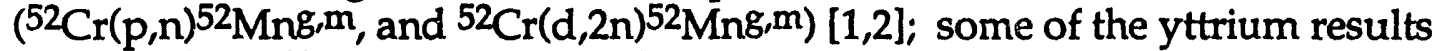
${ }^{89} \mathrm{Y}(\mathrm{p}, \mathrm{n})^{89} \mathrm{Zr},{ }^{89} \mathrm{Y}(\mathrm{p}, 2 \mathrm{n})^{88} \mathrm{Zr}$, and $\left.{ }^{89} \mathrm{Y}(\mathrm{p}, \mathrm{pn})^{88} \mathrm{Y}\right)$ [3]; all of the bromine results ${ }^{79} \mathrm{Br}(\mathrm{p}, \mathrm{n})^{79} \mathrm{Kr},{ }^{79} \mathrm{Br}(\mathrm{d}, 2 \mathrm{n})^{79} \mathrm{Kr},{ }^{81} \mathrm{Br}(\mathrm{p}, \mathrm{n})^{81} \mathrm{Kr},{ }^{81} \mathrm{Br}(\mathrm{d}, 2 \mathrm{n})^{81} \mathrm{Kr}$, and $\left.{ }^{81} \mathrm{Br}(\mathrm{d}, \mathrm{p})^{82} \mathrm{Kr}\right)$ [4]; and all of the iodine results $\left({ }^{127} \mathrm{I}(\mathrm{p}, \mathrm{n})^{127} \mathrm{Xe}\right.$ and $\left.{ }^{127} \mathrm{I}(\mathrm{d}, 2 \mathrm{n})^{127} \mathrm{Xe}\right)[4]$. The measurement of the reaction ions recoiling out the back of the target foils by means of catcher foils gives information about the reaction dynamics. We have studied this effect in detail for a number of reactions and have reported the results [5]. In studying the ${ }^{151} \mathrm{Eu}(\mathrm{p}, \mathrm{n}){ }^{151} \mathrm{Gd}$ and ${ }^{153} \mathrm{Eu}(\mathrm{p}, \mathrm{n}){ }^{153} \mathrm{Gd}$ excitation functions we discovered an enhanced cross section due to the more prolate shape of the ${ }^{153} \mathrm{Eu}$ nucleus relative to the ${ }^{151} \mathrm{Eu}$ nucleus and have reported the results [6].

The reported cross section data have all been compared to results from statistical model calculations as a minimum in the theoretical analysis. In general, for the deuteron data, we found it necessary to allow for breakup of the deuteron in the entrance channel.

In the following, we start off with work in the first two papers, essentially covering some of the details of the experimental methods that we used. These are followed by a series of papers on yttrium, titanium, and europium excitation functions that are complete as far as the data are concerned but for which only sketchy theoretical modeling has been done.

[1] H. I. West, Jr., R. G. Lanier, and M. G. Mustafa, Phys. Rev. C 35, 2067 (1987).

[2] M. G. Mustafa, T. Tamura, and T. Udagawa, Phys. Rev. C 35, 3077 (1987).

[3] M. G. Mustafa, H. I. West, Jr. H. O'Brien, R. G. Lanier, M. Benamou, and T. Tamura, Phys. Rev. C 38, 1624 (1988).

[4] H. I. West, Jr., R. M. Nuckolls, B. Hudson, B. Ruiz, R. G. Lanier, and M. G. Mustafa, Phys. Rev. C 47, 248 (1993).

[5] H. I. West, Jr., M. G. Mustafa, R. G. Lanier, and H. O'Brien, Phys. Rev. C 43, 1352 (1991).

[6] R. G. Lanier, H. I. West, Jr., M. G. Mustafa, J. Frehaut, A. Adam, and C. A. Philis, Phys. Rev. C 42, R479 (1990). 


\title{
1. Fabrication of Plastic-Matrix-Encapsulated Accelerator Targets and Their Use in Measuring Nuclear Excitation Functions
}

\author{
H. I. West, Jr., R. M. Nuckolls, and R. G. Lanier \\ Lawrence Livermore National Laboratory \\ Livermore, CA 94550
}

\begin{abstract}
We are able to make accelerator targets of material dispersed uniformly throughout the plastic Kapton. We have successfully made targets loaded with $\mathrm{TiO}_{2}, \mathrm{Eu}_{2} \mathrm{O}_{3}, \mathrm{KI}$ and $\mathrm{KBr}$ having areal densities of 5 to $20 \mathrm{mg} / \mathrm{cm}^{2}$, one third of which was the element of interest ( $\mathrm{Ti}, \mathrm{Eu}, \mathrm{I}$ or $\mathrm{Br}$ ). Here we report our experience in making and determining the elemental composition of such target foils.
\end{abstract}

\section{TARGET REQUIREMENTS}

A widely used method for measuring nuclear excitation functions involves the irradiation of a stack of target foils followed by counting off-line the activities produced. The general problem of selecting a suitable target for such experiments involves several factors. Once the element to be studied has been selected, it is important that the target foil contains sufficient material to yield activated species with a measurable level of radiation, that the target material be homogeneously distributed throughout the foil, and that none of the activated species be lost during or after irradiation. It is also desirable that such foils have good heat conductivity and/or that the heat produced in the foil does not destroy it. If the activation product has a low cross section or a low specific activity, than the irradiation times may be long if the rate of removal of heat from the target is poor. This becomes a serious concern when cross-section measurements are attempted near the reaction threshold. Finally, a target foil should be reasonably easy to handle and should be thin enough so that beam energy-loss through the foil is minimal.

Generally single metal foils make ideal targets for activation experiments. Often, however, experiments cannot be conducted with such ideal materials, and alternate techniques have been developed to fabricate targets from metal oxides or from other chemical compounds. In our program, we were confronted with the problem of making targets that would contain europium, bromine, and iodine. Metallic europium rapidly oxidizes in air and bursts into flame at relatively low temperatures $\left(150-180^{\circ} \mathrm{C}\right)$; thus, we needed to either encapsulate the europium or to use a more stable compound. The halogens, bromine and iodine, have physical properties at room temperature that are completely unsuitable for fabrication into free-standing target foils. Moreover, the $(p, n)$ and $(d, 2 n)$ activation products of both are noble gases (krypton and xenon). As a 
result, any target made from halogens must be specially protected to avoid losing those gaseous activation products.

A successful approach, for example, is that used by Colle and Kishore [1] in their studies of iodine and bromine cross sections. They used targets consisting of $\sim 2 \mathrm{mg} / \mathrm{cm}^{2}$ films of $\mathrm{KI}$ and $\mathrm{KBr}$ evaporated onto thin foils of aluminum. The foils were subsequently encapsulated in vacuum between two sheets $(\sim 12$ $\mathrm{mg} / \mathrm{cm}^{2}$ ) of heat sealable Mylar. From our own experience we find that the polyesters, such as Mylar, are readily subject to radiation damage. Nevertheless, Colle and Kishore were able to use beam current densities as high as 100$200 \mathrm{n}$ amps $/ \mathrm{cm}^{2}$.

The literature indicates the use of various other self-supporting target forms made for example by mechanical compression. However, these constructions tend to be rather thick and not very useful for work of high accuracy. In the following, we first discuss the fabrication of target foils by methods we have worked out followed by procedures we have used to determine the quantitative composition of the target foils. We then discuss the extraction of excitation functions from the experimental data. Of particular importance are the corrections for the finite energy loss of the projectiles in these foils in the sensitive rising portions of the excitation functions.

\section{METHOD OF MAKING TARGETS}

To solve the problem of making targets loaded with europium, bromine, or iodine, we developed a method of suspending suitable compounds of these materials in a plastic matrix. As a result of a suggestion by D. H. Berkebile [DuPont, private communication, (1985)], we decided to try a polyimide resin that, when polymerized, is essentially the same as Kapton, which is marketed in sheets by DuPont. Kapton, we knew, was also used for scattering-chamber windows and in many other nuclear applications, so there was already a history of its use in radiation environments. Our efforts to make foils with this resin have been quite successful. The resin contains only hydrogen, carbon, and nitrogen, and these elements have acceptable background activities when irradiated with light, charged particles.

The procedure we used for making loaded Kapton foil is presented in the Appendix. It was developed by working with the LLNL Plastic Shop by first working on loadings of $\mathrm{TiO}_{2}$. When that proved successful, we made foils loaded with $\mathrm{Eu}_{2} \mathrm{O}_{3}, \mathrm{KI}$, and $\mathrm{KBr}$.

Both $\mathrm{TiO}_{2}$ and $\mathrm{Eu}_{2} \mathrm{O}_{3}$ were ideal loadings for Kapton because they form fine powders which are chemically inert. With $\mathrm{KI}$ or $\mathrm{KBr}$, which are ionic compounds, the procedure was somewhat more complex. Since we wanted finely divided powders to mix with the resin, we tried to grind $\mathrm{KI}$ and $\mathrm{KBr}$ in ball mills only to find that the material would eventually clump together into a mass; thus the grinding could only proceed for a few minutes, after which it was necessary to sieve out the larger particles for further grinding. Also during the curing of the plastic, a small quantity of $\mathrm{H}_{2} \mathrm{O}$ was released which probably means 
that there was a small quantity of the ions $\mathrm{I}^{-}$and $\mathrm{Br}^{-}$present during polymerization. In any respect good foils were made. Mechanically, those containing $\mathrm{Eu}_{2} \mathrm{O}_{3}$ were a bit stiffer and more brittle than those containing the halogen salts.

An elemental analysis for $\mathrm{H}, \mathrm{C}, \mathrm{N}$, and $\mathrm{O}$ was done on three sets of $\mathrm{Eu}_{2} \mathrm{O}_{3}$ -Kapton foils. The average of the elemental concentrations of the plastic portion of the foils were as follows: $\mathrm{H}(3.58 \%), \mathrm{C}(64.94 \%), \mathrm{N}(8.00 \%)$, and $\mathrm{O}(23.47 \%)$. The values are in fair agreement with those published by DuPont $[2,3]$.

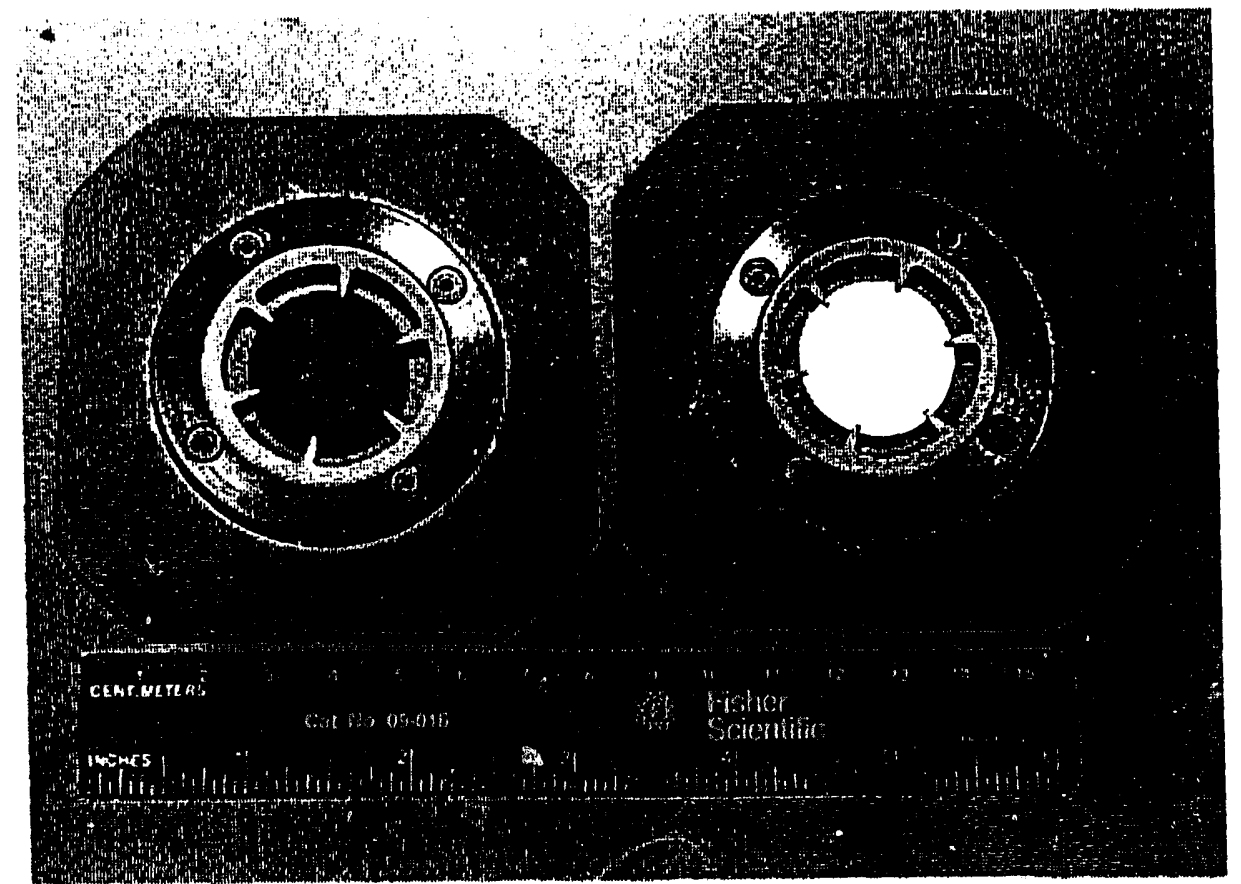

FIG. 1 Jig used to hold loaded-Kapton foils auring evaporation of aluminum onto the foil surface. The jig consists of two parts held together by screws. Left is without coating and right is with coating. A vacuum holddown is used during assembly of foils into a stack for irradiation.

\section{GAS CONTAINMENT}

Since the bombardment of $\mathrm{KI}-\mathrm{Kapton}$ and $\mathrm{KBr}$-Kapton foils produced the gaseous radioisotopes ${ }^{127} \mathrm{Xe}$ and ${ }^{79} \mathrm{Kr}$, we needed to prevent those gases from escaping the targets. To insure containment, both sides of each target foil (25.4 $\mathrm{mm}$ diam.) were covered with evaporated aluminum to an areal density of $\sim 0.3$ $\mathrm{mg} / \mathrm{cm}^{2}$. The foils tended to curl around the edges; thus, to hold the individual foils flat during coating, we used specially constructed jigs which held the foils at six points around their periphery. Figure 1 is a picture of an assembled jig with foil. The jig is made of two parts held together by four screws. During assembly 
the foil is held flat by vacuum using an auxiliary jig. With these aluminum coatings we found that we could dissipate $\sim 0.5$ watts in a foil during irradiation and still contain the noble gases. The area of irradiation of the targets was about $1 \mathrm{~cm}^{2}$ produced by electrostatically rastering the beam over the target. Whether or not more heat could be dissipated by using a larger area has not been determined. The problem here is not the breakdown of the Kapton, since we have successfully irradiated $\mathrm{Eu}_{2} \mathrm{O}_{3}$-Kapton foils at $1 \mu$ amp for two hours, but rather in the breakdown in bonding of the aluminum to the target foil. Our halogen targets were $5-20 \mathrm{mg} / \mathrm{cm}^{2}$, one third of which was elemental halogen. Typical irradiation currents were $300 \mathrm{n}$ amps.

\section{FOIL CALIBRATION}

It is necessary to accurately determine the areal density of the target element loaded into each of the plastic foils. It is desirable that this be a nondestructive, easily applied, and highly accurate method. The method we finally developed makes use of $x$-ray fluorescence analysis spectrometry and is based on the fact that the number of fluorescent $x$-rays $\left(K_{\alpha}\right.$ and $\left.K_{\beta}\right)$ produced when irradiating a foil is proportional to both the intensity of the excitor gamma-ray source and the total amount of element to be analyzed. Physically, the spectrometry assembly consists of a ring of excitor sources located around the axis of the system so as to irradiate the target on axis. The fluorescent $x$-ray spectrometer is located on the axis so as to intercept the back-scattered. fluorescent $x$-rays.

By using the appropriate self-absorption coefficients, we can correct for the absorption in the targets of both the excitor gamma-rays and the emitted x-rays. The number of $x$-rays detected due to the interacting of the excitor $\gamma$-rays in the foil at $x$ to $x+d x$ can be written

$$
d N=N_{\gamma} g_{\gamma} g_{x} w_{x}^{E} 0.8 \frac{\sigma_{P E}}{\Sigma \sigma_{T}} \mu_{\gamma}^{E} \rho^{E} d x \operatorname{Exp}\left(-\sum_{\gamma} \frac{\mu \rho x}{\cos \theta}-\sum_{x} \mu \rho x\right)
$$

$$
\text { Here, } \begin{aligned}
N_{\gamma} & =\gamma \text {-ray source strength } \\
g_{\gamma} & =\gamma \text {-source }- \text { foil geometry } \\
g_{x} & =\text { foil }- \text { detector geometry } \\
w_{x}^{E} & =\text { x-ray fluorescent yield } \\
\sigma_{P E} & =\text { photoelectric cross section }\left(\sim 0.8 \text { of } \sigma_{P E} \text { excites the } \mathrm{K} \text {-shell }\right) \\
\Sigma \sigma_{T} & =\text { total } \gamma \text {-ray cross section } \\
\sum_{\gamma} \frac{\mu \rho x}{\cos \theta} & =\text { total } \gamma \text {-ray absorption at } x, \text { including, e.g., } \mathrm{HCNO}+\mathrm{Eu}_{2} \mathrm{O}_{3}, \\
\sum_{x} \mu \rho x & =\text { total } x \text {-ray absorption at } x, \text { assuming obliquity } \sim 1.00 \\
k & =\text { first six terms in equation }
\end{aligned}
$$




$$
D(x) \quad=\text { argument of Exp }
$$

We integrate over the foil thickness $X$ and rearrange terms, whence

$$
\rho x^{E}=N_{x} \frac{1}{k \mu_{\gamma}^{E}}\left(\frac{D(X)}{1-e^{-D(X)}}\right) \mathrm{mg} / \mathrm{cm}^{2}
$$

Here the term $1 / k \mu_{\gamma}^{E}$ is considered a calibration constant for the experimental setup which must be evaluated using foils of known areal density. The only problem in using Eq. 2 for the determination of $\rho x^{E}$ is the fact that $D(X)$ is a function of $\rho x^{E}$. Thus, one must use an iterative procedure in evaluating the equation; but the solution converges rapidly.

We try to keep D small so that the self-absorption correction, $D /\left(1-e^{-D}\right)$, will be close to 1.0, since this minimizes the need for highly accurate absorption coefficients. For absorption coefficients we, of course, used those in the literature. A major influence in our considerations was the energy of the excitor $\gamma$-ray, which should be conveniently larger than the K-edge but not too much so. For evaluating $\mathrm{Eu}_{2} \mathrm{O}_{3}$ and $\mathrm{KI}$-Kapton foils, we used the $60-\mathrm{keV} \gamma$-rays from ${ }^{241} \mathrm{Am}$. For $\mathrm{TiO}_{2}$ and $\mathrm{KBr}$, we used the $22.5-\mathrm{keV} \mathrm{Ag} x$-rays following the decay of ${ }^{109} \mathrm{Cd}$.

After the foils were counted by means of fluorescent $x$-ray spectrometry, a selected subset of these foils was assayed and those results used to calibrate the density equation so that the target thickness, $\rho x$, could be obtained. For $\mathrm{Eu}_{2} \mathrm{O}_{3}$, the procedure was especially simple. Ten foils were burned individually to ash and the ash weighed as $\mathrm{Eu}_{2} \mathrm{O}_{3}$. For the halogens, standard gravimetric analysis was carried out by Analytical Chemistry (LLNL) on several samples. In all cases the calibration constants determined for a given element agreed to better than $1 \%$.

Since we worked with stacks of target foils interspersed with aluminum energy-degrader foils, it was necessary to calculate the energy loss of the projectiles in the foils. Our calculations relied upon the compilation of Janni [4]. For the Kapton part of the foil, we use the HCNO results quoted earlier. One note of precaution: Kapton can pick up moisture, as much as $1 \%$ by weight, and hence it must be dried in vacuum before weighing.

Some of our europium work was done using the Van de Graaff at Centre d'Etudes, Bruyeres-le-Chatel, France [5]. We were concerned about the accuracy with which we could do the energy-loss calculations. We measured results using single foils and stacks of foils with both protons and deuterons and found the typical uncertainty in determining, e.g., a $3 \mathrm{MeV}$ energy loss was less than $3 \%$. We point out that in our work, absolute accuracy was paramount; thus, cross section runs were made with but a few (1-5) target foils in a stack. In addition, all the data runs overlapped in energy. Even though we had to calculate the energy loss in a stack of foils, the uncertainty in assigned energies was less than $0.1 \mathrm{MeV}$. 


\section{ACKNOWLEDGMENTS}

We wish to thank David H. Berkebile of DuPont for suggesting the use of the polyimide resin and for providing us with the initial materials. We are grateful to Gordon Spellman (Plastics Chemical Engineering, LLNL) for encouragement of this work and for his advice and guidance during all stages of the target manufacture. We also wish to thank Mark Pearson and Wayne Jensen of the LLNL Plastics Shop for their help with developing the procedure to fabricate the targets and in making the targets. Finally, we thank Barbara Frazier of the Vacuum Deposition Laboratory, LLNL, for Providing aluminum coatings for the iodine and bromine targets.

This work was performed under the auspices of the U. S. Department of Energy by Lawrence Livermore National Laboratory under contract W-7405-Eng-48.

\section{REFERENCES}

[1] R. Collé and R. Kishore, Phys. Rev. 9, 2166 (1974)

[2] DuPont, Kapton Polyimide Filter - Summary of Properties, Technical Information Bulletin H-1 (A-37474) (No date).

[3] Introduction to Industrial Polymers, Henry Ulrich, Ed., Hanser Verlag Pub., Munich (1982).

[4] J.F. Janni, Technical Report No. AFWL-TR-65-150, Air Force Weapons Laboratory, Air Force Systems Command, Kirtland Air Force Base, New Mexico (1966), Atomic Data Nucl. Data Tables, 27, 147 (1982)

[5] See Paper 7 of this Report

\section{APPENDIX}

Procedure for making Kapton foils loaded with $\mathrm{TiO}_{2}$.

1. Thoroughly mix $300 \mathrm{~g}$ of DuPont RC5057 with $37.5 \mathrm{~g}$ of $\mathrm{TiO}_{2}$. (This is enough material for a number of cured sheets.) We have used a paint 'roller mill' for the mixing.

2. Evacuate in vacuum a few minutes to remove entrapped gases.

3. Add $30 \%$ by weight, thinner (1-methyl-2 pyrolidinone).

4. Repeat (2). 
5. Using a flat Pyrex plate $(30 \mathrm{~cm} \times 30 \mathrm{~cm})$ prepare a channel $(\sim 0.4 \mathrm{~mm}$ deep) using polyimide tape. Pour a quantity of the mixture onto the glass and spread within the channel using a straight-edged blade which spans the channel. Place in an oven, keeping level. (Refrigerate mixture not used for use at a later time.)

6. Heat at $\sim 80^{\circ} \mathrm{C}$ for at least one hour.

Heat at $\sim 140^{\circ} \mathrm{C}$ for 15 minutes.

Heat at $\sim 190^{\circ} \mathrm{C}$ for 15 minutes.

Heat at $\sim 260^{\circ} \mathrm{C}$ for 15 minutes.

7. Let cool. Peel film from glass. By starting with $0.4 \mathrm{~mm}$ deep channel, we end up with a film $\sim 0.05 \mathrm{~mm}$ thick. 
2. Correcting Excitation Function Data in the Low Energy Region for Finite Thickness of the Target Foils, Including Effects of Straggling

\author{
H. I. West, Jr. \\ Lawrence Livermore National Laboratory \\ Liivermore, CA 94550
}

\title{
ABSTRACT
}

We have developed a procedure to correct excitation function data in the rising portion of an excitation function at low energies, where the finite thickness of the target foils causes a possible error. The procedure involves the evaluation of an integral equation by a process of repeated trial solutions. Since the projectiles are subject to considerable straggling in energy, one must examine the effect of straggling on the cross section measurement; usually it is negligible.

\section{THE PROCEDURE}

When making measurements in the rising part of the distribution, the finite thickness of the target foil can yield an apparent cross section considerably different from the true cross section. Even the thinnest of foils yield data in the rising portion of the excitation function that need correction. Our approach has

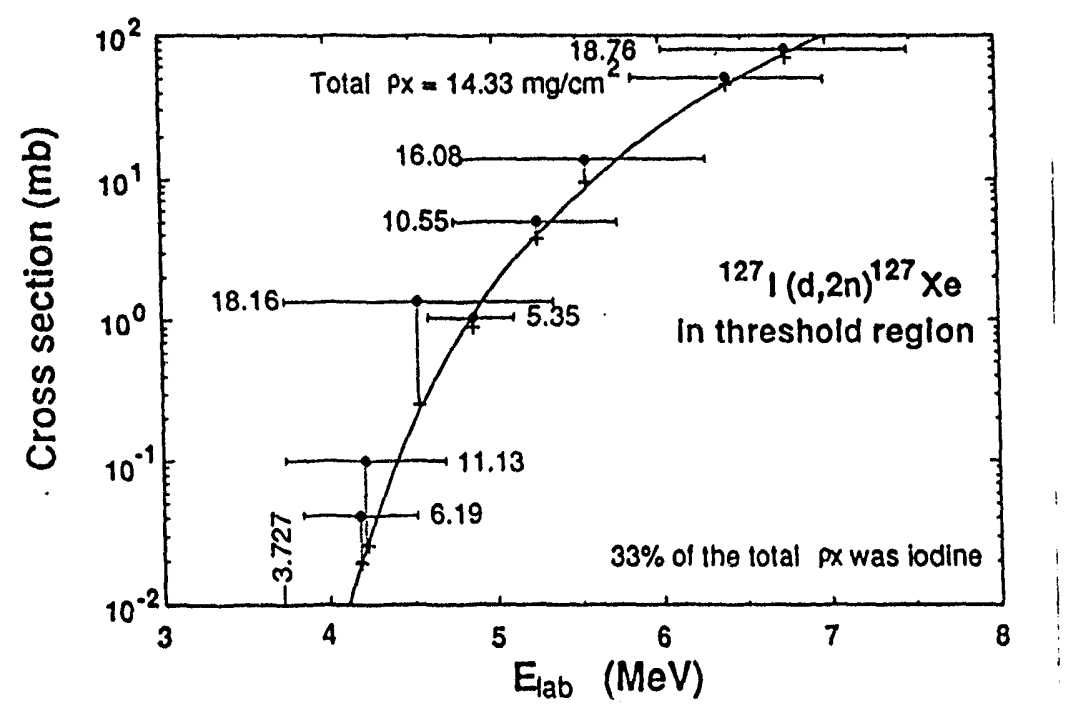

FIG. 1 Energy resolution corrections applied to ${ }^{127} I(d, 2 n){ }^{127} X e$ data in the rising portion of the excitation function. The horizontal bars show the energy range in the respective foils $\left(E_{\text {in }}\right.$ to $\left.E_{\text {out }}\right)$ labeled with the total areal densities $\rho x$. The data are plotted at $E_{\text {average }}$. The pluses are the final corrected data obtained by deconvoluting the data as described in the text. 
been to calculate the average energy of the projectile in the target foil and then to correct the cross section accordingly. Fig 1 shows a particularly bad situation encountered with some ${ }^{127} \mathrm{I}(\mathrm{d}, 2 \mathrm{n})^{127} \mathrm{Xe}$ data. Here we see results using foils of total thickness $\rho x$ as labeled. The areal density of the iodine was about $1 / 3$ of the total $\rho x$. The ends of the horizontal error bars represent the energy of the incoming and the outgoing projectiles. Underneath each of the initially measured data points, i.e., $\sigma$ measured at $E_{a v}$ is a plus mark showing the corrected results. The solid curve is the result of fitting a polynomial to the final corrected data points.

The procedure for correcting the data has been described briefly before [1]. Here we amplify on the procedure. For a given foil, by definition

$$
\sigma_{a v}=\frac{1}{\Delta x} \int \sigma(x) d x
$$

Here $\sigma_{a v}$ is equivalent to the observed cross section, $\Delta x$ is the foil thickness, and $\sigma(x)$ is to be determined (given as $\sigma_{\text {corrected }}$ in later work). Implicit in Eq. 1 is the assumption of a smoothly varying cross section. Johnson et al. [2] present the formal solution to this integral equation in the analysis of experimental data. Our approach is much more direct than theirs. Since we are working with energy variables, we rewrite the above as

$$
\sigma_{a v}=\frac{1}{\Delta E} \int \frac{\sigma(E) d E}{\frac{d E}{d x} /\left(\frac{d E}{d x}\right)_{a v}}
$$

Note that the ratio of differentials in the denominator inside the intigral correct for the fact that as $d E / d x$ increases, less of the foil thickness is subject to irradiation for a given $d E$.

To obtain a quick solution to Eq. 2 we expand the cross section around its value $\sigma_{0}$ at $E_{a v}$ in terms of $\delta=E-E_{a v}$, that is,

$$
\sigma=\sigma_{0}\left(1+b \delta+c \delta^{2}+d \delta^{3}+e \delta^{4}\right)
$$

In addition, we set the denominator equal $(1-f \delta)^{-1}$. Thus for a foil of energy loss $\Delta E$, the value of the integral $\sigma_{a v}$ becomes

$$
\sigma_{a v}=\sigma_{o}\left(1-(c-f b) \Delta E^{2} / 12+(e-f d) \Delta E^{4} / 80 \ldots . .\right)
$$

To use this equation in correcting the experimental data, we identify $\sigma_{a v}$ with $\sigma_{\text {exp }}$. Thus 


$$
\sigma_{\text {correceded }}=\sigma_{\text {exp }} \frac{\sigma\left(E_{a v}\right)}{\sigma_{a v}}
$$

One iterates Eq. 2 to obtain the best values for $\sigma_{\text {corrected }}$. We find that a better polynomial to fit the experimental values is $\ln \sigma(E)=A+B \ln E+C(\ln E)^{2}$ or $\ln \sigma(E)=A+B E+C E^{2}$. (Note that at times it is preferable to use $E-E_{T}$ rather than $E$, in the expansion if $Q$ is negative.)

\section{Straggling}

It does not follow a priori that we can use a square distribution of projectile energy loss in a foil (after factoring out the denominator in Eq. 2) when energy straggling is significant, as it can be after passage of the projectiles through several foils. In such a case, we can estimate the effect using a theoretical expression for straggling such as the r.m.s. value determined by an equation given in Segre. [3]. We call this $\Delta E_{s}$. With this value(determined by the square root of the sum of such terms) and assuming a very thin foil we can represent the straggling at $E_{s}$ as a probability integral

$$
\begin{aligned}
N\left(E_{s}\right) & =\frac{1}{\Delta E_{s} \sqrt{2 \pi}} \int_{E_{0}-\Delta E / 2}^{E_{0}+\Delta E / 2} \exp \left(-1 / 2\left(E-E_{s}\right)^{2} / \Delta E_{s}^{2}\right) d E \\
& =\frac{1}{\sqrt{\pi}} \int_{t_{t}}^{t_{t}} \exp \left(-t^{2}\right) d t
\end{aligned}
$$

where

$$
\begin{aligned}
& t_{l}=\frac{1}{\Delta E_{s}}\left(E_{0}-E_{p}-\Delta E / 2\right) \\
& t_{u}=\frac{1}{\Delta E_{s}}\left(E_{0}-E_{p}+\Delta E / 2\right)
\end{aligned}
$$

The error function

$$
\operatorname{erf}(x)=\frac{2}{\sqrt{\pi}} \int_{0}^{x} \exp \left(-t^{2}\right) d t
$$

is used to evaluate Eq. 7 The error function can be evaluated by means of rational approximations [4] Whence

$$
\begin{aligned}
& N\left(E_{p}\right)=1 / 2 \operatorname{sgn}_{u} \operatorname{erf}\left(t_{u}\right)+1 / 2 \operatorname{sgn} n_{l} \operatorname{erf}\left(t_{l}\right) \\
& \text { If } t_{k} \text { is }+\& t_{l} \text { is - then } s g n_{u}=+1 \& s g n_{t}=-1 \\
& +\quad-\quad+1+1 \\
& -1 \quad+1
\end{aligned}
$$


Although $\Delta E_{s}$ is considered a constant, we define a $\Delta E_{s}(i n)$ at the input to the foil and a $\Delta E_{s}$ (out) at the output which serves as a good approximation to the real process. This is the approach that was used to calculate the titanium results in Fig. 2. In general, our coding for the evaluation of Eq.2 is set up to carry out the calculations requiring as input $E_{0}, \Delta E, \Delta E_{s}\left(\right.$ in), and $\Delta E_{s}(o u t)$. Usually, the inclusion of the effects of straggling are not significant.

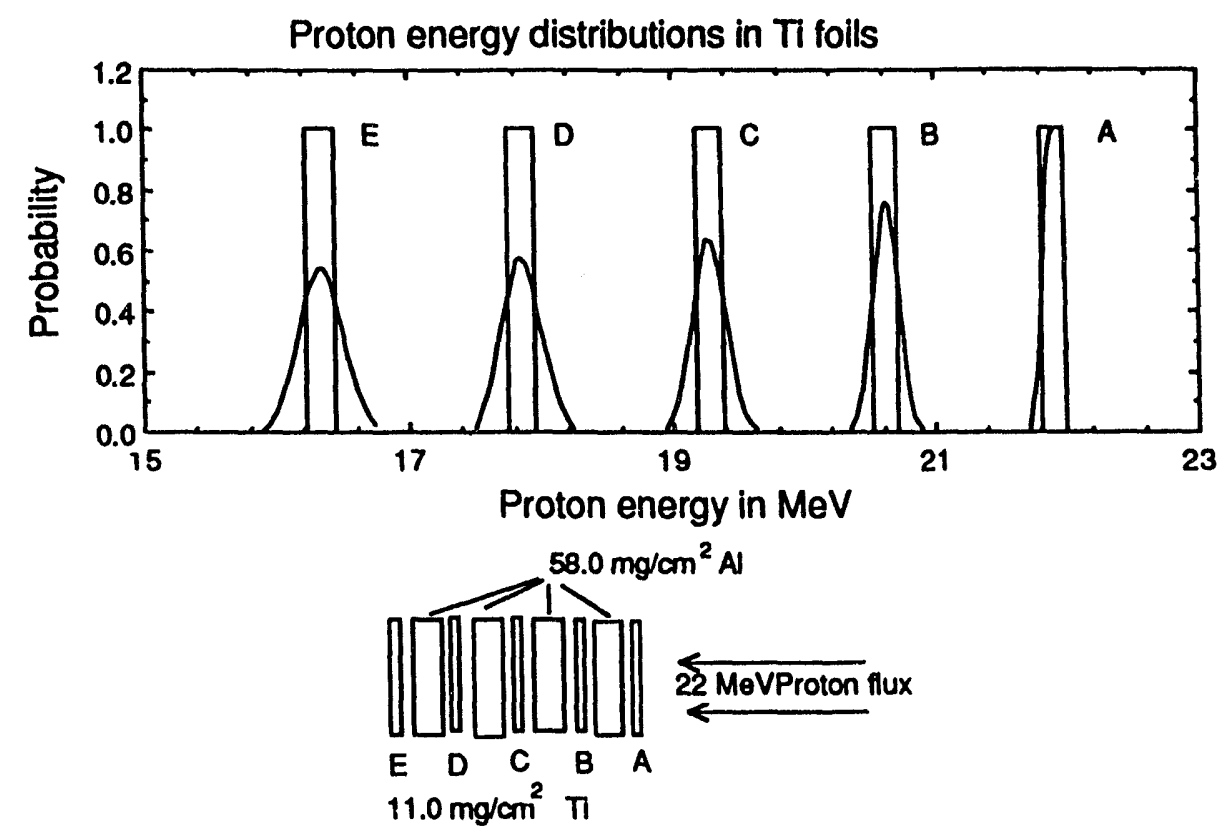

FIG. 2 Results of calculating straggling of $22 \mathrm{MeV}$ protons in a stack of titanium and aluminum foils.

\section{Results in Fig. 1}

Fig. 1 is a good example of the application of our procedures to correct data in the rising portion of the an excitation function. The values of $\Delta E_{s}(i n)$, and $\Delta E_{s}(o u t)$ for each foil were used in the calculations. For the data above about 6 $\mathrm{MeV}$, the results of the first iteration were adequate. For lower energies, the $\sigma_{\text {corrected }}$ values were used as inputs to the polynomial and the process repeated until the $\sigma_{a v}$ values were sufficiently close to $\sigma_{\text {exp }}$ or no longer changed significantly between iterations. The data near the bottom of the figure were run four times. Our coding is set up to run piece-wise continuous; that is, we choose any contiguous set of data points for the fit. It is important that the results from the polynomial be well behaved over the range of the projectiles in the foil. This 
can cause a problem in analyzing the data for the foil at the lowest energy and may require some educated guessing, such as help from theory. The results shown here are for a rather extreme case. Interestingly, these results agree well with results from statistical model calculations.

Note that although $\sigma(E)$ is a smoothly varying function, the corrected values of $\sigma$ will still reflect the fluctuations in the original data set. The assignment of errors to the results is not immediately obvious. The error in $E_{a v}$ is clear, but the error in $\sigma\left(E_{a v}\right)$ is not as clear. Least-square codes usually provide a goodness of fit; however, in principle, a formal analysis such as that of Johnson et al. [2] is needed. Our error estimate, however, has relied upon parameter studies during the fit procedure, noting the variations in $\sigma_{\text {corrected }}$ in the last few iteractions.

\section{ACKNOWLEDGMENTS}

This work was performed under the auspices of the U. S. Department of Energy by Lawrence Livermore National Laboratory under contract W-7405-Eng-48.

\section{REFERENCES}

[1] M. G. Mustafa, H. I. West, Jr., H. O'Brien, R. G. Lanier, M. Benhamou and T. Tamura, Phys. Rev. C 38, 1624 (1988)

[2] M. L. Johnson, J. L. Romero, T. S. Subramanian and F. P. Brady, Nucl. Instrum. Meth., 169179 (1980).

[3] E. Segrè, editor, Experimental Nuclear Physics, John Wiley \& Sons, Inc., N.Y. (1953), Eq. 36, p. 243.

[4] M. Abromowitz and I. A. Stegun, Eds., Handbook of Mathematical Functions with Formulas, Graphs, and Mathematical Tables, Dover Publishing Co., Inc. (1965), Eq. 7.1.25. 


\title{
3. Excitation Functions for the Nuclear Reactions on Titanium Leading to the Production of ${ }^{48} \mathrm{~V},{ }^{44} \mathrm{Sc}$, and ${ }^{47} \mathrm{Sc}$, by Proton, Deuteron and Triton Irradiations at 0-35 MeV.
}

\author{
H. I. West, Jr., R. G. Lanier, and M. G. Mustafa \\ Lawrence Livermore National Laboratory \\ Livermore, CA 94550
}

\section{INTRODUCTION}

We have studied the production of $48 \mathrm{~V}$ from proton, deuteron, and triton irradiations of titanium. Of particular interest has been the measurement of accurate cross sections in the rising portions of the excitation functions near threshold. The reactions studied for the production of $48 \mathrm{~V}$ were ${ }^{48} \mathrm{Ti}(\mathrm{p}, \mathrm{n})^{48} \mathrm{~V}$, ${ }^{48} \mathrm{Ti}(\mathrm{d}, 2 \mathrm{n})^{48} \mathrm{~V},{ }^{47} \mathrm{Ti}(\mathrm{d}, n)^{48} \mathrm{~V},{ }^{49} \mathrm{Ti}(\mathrm{p}, 2 \mathrm{n}){ }^{48} \mathrm{~V}$, and $\mathrm{Ti}[(\mathrm{t}, \mathrm{n}) \&(\mathrm{t}, 2 \mathrm{n})]{ }^{48} \mathrm{~V}$. Targets used were of natural titanium $(73.94 \%)$ [1] and isotopically separated ${ }^{47} \mathrm{Ti}$ and ${ }^{48} \mathrm{Ti}$. In the course of these measurements, data were obtained on a number of scandium isotopes ${ }^{44} \mathrm{Sc},{ }^{46} \mathrm{Sc},{ }^{47} \mathrm{Sc}$, and ${ }^{48} \mathrm{Sc}$. Those for ${ }^{46} \mathrm{Ti}(\mathrm{d}, \alpha)^{44} \mathrm{Sc} \mathrm{m}, \mathrm{g},{ }^{47} \mathrm{Ti}(\mathrm{d}, \alpha \mathrm{n}){ }^{44} \mathrm{Scm}, \mathrm{g}$, and $\mathrm{Ti}(t, x)^{47} \mathrm{Sc}$ were of sufficient quality to be reported here. The reactions pertaining to our study, along with their respective $Q$ values, are listed in Table 1. The experimental procedure used was the well-known stacked-foil method, in which target foils are interspersed with aluminum energy-degrader foils. The stack is irradiated and the induced activities counted off line. Each data set is the result of a number of data runs, each one covering only a few $\mathrm{MeV}$ in projectile energy to insure accuracy.

Significant earlier work for ${ }^{48} \mathrm{Ti}(\mathrm{p}, \mathrm{n})^{46} \mathrm{~V}$ is that of Tanaka and Furukawa [3], Michel et al. [4], Michel and Brinkman [5], and Gadioli et al. [6] Early ${ }^{48} \mathrm{Ti}(\mathrm{d}, 2 \mathrm{n})^{48} \mathrm{~V}$ measurements are those of Burgess et al. [7] where targets of natural titanium (natTi) were used. The most significant prior measurements available for deuterons on separated titanium $(46,47,48,49,50 \mathrm{Ti})$ are those of Chen and Miller [8]. Not only did they study ${ }^{47} \mathrm{Ti}(\mathrm{d}, n)^{48} \mathrm{~V},{ }^{48} \mathrm{Ti}(\mathrm{d}, 2 \mathrm{n}){ }^{48} \mathrm{~V}$, but also a number of scandium isotopes including the ones we present. No prior measurements were found in the literature for tritons on titanium.

Early reports of our work are to be found in the Nuclear Chemistry Division Annual reports [9,10]. Those reports also cover our initial attempts at modeling the data using the Hauser-Feshbach statistical model code STAPRE [11]. With high-quality data, careful modeling becomes worthwhile. From earlier work [12], we found that allowance must be made to include the probability of deuteron break-up in the entrance channel of the reaction [13]. Also, for tritons one must consider the break-up of the triton as well. 
TABLE 1. Rections pertaining to our studies. ${ }^{a}$

\begin{tabular}{|c|c|}
\hline Reaction & $\mathrm{Q}(\mathrm{MeV})$ \\
\hline${ }^{48} \mathrm{Ti}(\mathrm{p}, \mathrm{n})^{48} \mathrm{~V}$ & -4.797 \\
\hline${ }^{48} \mathrm{Ti}(\mathrm{d}, 2 \mathrm{n})^{48} \mathrm{~V}$ & -7.021 \\
\hline${ }^{49} \mathrm{Ti}(\mathrm{p}, 2 \mathrm{n})^{48} \mathrm{~V}$ & -12.939 \\
\hline${ }^{47} \mathrm{Ti}(\mathrm{d}, \mathrm{n})^{48} \mathrm{~V}$ & +4.605 \\
\hline${ }^{46} \mathrm{Ti}(\mathrm{d}, \alpha)^{44} \mathrm{Sc}$ & +4.400 \\
\hline${ }^{47} \mathrm{Ti}(\mathrm{d}, \alpha \mathrm{n})^{44} \mathrm{Sc}$ & -4.477 \\
\hline${ }^{46} \mathrm{Ti}(\mathrm{t}, \mathrm{n})^{48} \mathrm{~V}$ & +7.225 \\
\hline${ }^{47} \mathrm{Ti}(\mathrm{t}, 2 \mathrm{n})^{48} \mathrm{~V}$ & -1.652 \\
\hline${ }^{48} \mathrm{Ti}(\mathrm{t}, 3 \mathrm{n})^{48} \mathrm{~V}$ & -13.278 \\
\hline${ }^{49} \mathrm{Ti}(\mathrm{t}, 4 \mathrm{n})^{48} \mathrm{~V}$ & -21.420 \\
\hline${ }^{46} \mathrm{Ti}(\mathrm{t}, 2 \mathrm{p})^{47} \mathrm{Sc}$ & +0.577 \\
\hline${ }^{47} \mathrm{Ti}(\mathrm{t}, 2 \mathrm{pn}){ }^{47} \mathrm{Sc}$ & -8.300 \\
\hline${ }^{48} \mathrm{Ti}(\mathrm{t}, \alpha)^{47} \mathrm{Sc}$ & +8.369 \\
\hline${ }^{48} \mathrm{Ti}(\mathrm{t}, 2 \mathrm{p} 2 \mathrm{n})^{47} \mathrm{Sc}$ & -19.926 \\
\hline${ }^{49} \mathrm{Ti}(\mathrm{t}, \propto \mathrm{n}){ }^{47} \mathrm{Sc}$ & +0.227 \\
\hline${ }^{50} \mathrm{Ti}(t, \alpha 2 n){ }^{47} \mathrm{Sc}$ & -10.712 \\
\hline${ }^{49} \mathrm{Ti}(\mathrm{p}, 2 \mathrm{p}){ }^{48} \mathrm{Sc}$ & -11.354 \\
\hline${ }^{48} \mathrm{Ti}(\mathrm{d}, 2 \mathrm{p}){ }^{48} \mathrm{Sc}$ & -5.436 \\
\hline${ }^{49} \mathrm{Ti}(\mathrm{d}, 2 \mathrm{pn}){ }^{48} \mathrm{Sc}$ & -13.578 \\
\hline${ }^{50} \mathrm{Ti}(\mathrm{d}, \alpha){ }^{48} \mathrm{Sc}$ & 3.778 \\
\hline${ }^{47} \mathrm{Ti}(t, 2 p){ }^{48} \mathrm{Sc}$ & -0.067 \\
\hline${ }^{48} \mathrm{Ti}(\mathrm{t}, 2 \mathrm{pn}){ }^{48} \mathrm{Sc}$ & -11.693 \\
\hline${ }^{49} \mathrm{Ti}(t, \alpha){ }^{48} \mathrm{Sc}$ & 8.46 \\
\hline${ }^{50} \mathrm{Ti}(\mathrm{t}, \alpha \mathrm{n}){ }^{48} \mathrm{Sc}$ & -2.479 \\
\hline
\end{tabular}

${ }^{\mathrm{a}} \mathrm{Q}$ values were calculated using Nuclear Wallet Cards [2].

\section{EXPERIMENTAL PROCEDURE}

The targets of natural titanium we used were free-standing metal foils $~ 11$ $\mathrm{mg} / \mathrm{cm}^{2}$, and foils $\sim 6 \mathrm{mg} / \mathrm{cm}^{2}$ evaporated onto aluminum backings. The isotopic abundances [1] used for natural titanium were ${ }^{46} \mathrm{Ti}(7.93 \%),{ }^{47} \mathrm{Ti}(7.28 \%), 48 \mathrm{Ti}$ $(73.94 \%),{ }^{49} \mathrm{Ti}(5.51 \%)$, and ${ }^{50} \mathrm{Ti}(5.34 \%)$. We used two sets of isotopically separated foils, $5-6 \mathrm{mg} / \mathrm{cm}^{2}$, consisting nominally of (1) $48 \mathrm{Ti}(99.81 \%)$ and (2) ${ }^{46} \mathrm{Ti}(0.347 \%),{ }^{47} \mathrm{Ti}(94.55 \%),{ }^{48} \mathrm{Ti}(4.74 \%),{ }^{49} \mathrm{Ti}(0.190 \%)$, and ${ }^{50} \mathrm{Ti}(0.175 \%)$. These 
yields must be adjusted because apparently, in the process of making the istopically separated foils (reduction from the oxide) the manufacturer allowed the addition of some tungsten (2\%), as we found from $x$-ray fluorescent analysis. $X$-ray fluorescent analysis was also, used in the intercomparison of foil densities and to check the foil uniformities. In such an analysis, one must be careful to correct for the absorption in the foils of the excitor radiations and the $x$-rays that are produced and counted. Foil uniformities and densities were known to $\sim 2 \%$.

Foil stacks consisted of one to four target foils, depending upon the region of the excitation function in which we were working. Near threshold, at times, we could use only one foil because of the relatively large range in cross section covered in even our thinnest foils. Data acquired under such conditions needed corrections for energy resolution as brought out later.

During irradiations, the foil stacks were mounted inside a Faraday cup designed to insure complete trapping of the delta-ray electrons produced in the reactions. The charge accumulation was measured digitally by means of an ORTEC Model 439 integrator. This unit had an absolute accuracy of $0.2 \%$.

Currents up to 1 ramp were used. Target cooling was provided. Irradiations at Lawrence Livermore National Laboratory (LLNL) were carried out on the Cyclograph covering the range 0 to 12 and 15 to $27 \mathrm{MeV}$ for protons, and 0 to 20 $\mathrm{MeV}$ for deuterons. Since ther this accelerator has been dismantled. For higher energy deuterons up to $25 \mathrm{MeV}$, we used the Crocker Nuclear Laboratory Cyclotron at the University of California at Davis. For triton measurements and some proton measurements up to $17 \mathrm{MeV}$ we used the Van de Graaff at the Los Alamos National Laboratory (LANL).

All counting of the decay $\gamma$-rays from the targets were made using germanium spectrometers. The major part of the counting was carried out using our automated $\gamma$-counters in the Nuclear Chemistry building at LLNL. Measurements made at LANL went through preliminary counting at the LANL Nuclear Chemistry facility, with a follow up at LLNL. The counting of rapidly decaying activities, i.e., ${ }^{44} \mathrm{Scg}$, was carried out using spectrometers located close to the accelerator. The residual ions produced during the irradiations often had sufficient energy to escape out the rear of the target foils. We have studied these effects [14] in detail. Ions picked up in the catcher foils were included in the counts. Data acquired at LANL were analyzed using a computer routine they call RAGUN. At LLNL we used GAMANAL [15].

\section{Resolution Corrections}

At the lower energies, especially in the rising portion of the excitation functions, the energy loss of the projectiles over the target thickness meant that a significant variation in cross section was encountered in the target so that just using the average energy $\left(E_{a v}\right)$ in association with the apparent cross section $\left(\sigma_{a v}\right)$ would have been in significant error. To obtain the corrected cross sections we need to solve the integral equation so as to return $\sigma_{a v}$ the measured cross section. By definition, 


$$
\sigma_{a v}=\frac{1}{\Delta x} \int \sigma(x) d x
$$

in which $\Delta x$ is the foil thickness, and $\sigma(x)$ the cross section to be found. In effect one uses a series of trial solutions in energy variables that finally return a consistent set of $\sigma_{a v}$. Further details of the procedure are reported elsewhere $[16,17]$. and in detail in Paper 2 of this report. Although curve fitting is used, the corrected $\sigma_{a v}$ values do not reflect the result of smoothing the data. However, implicit in the procedure is the assumption that all structure in the excitation function has been averaged out. The procedure works quite well, as we have been able to show, in the rising portion of the excitation functions, where in some cases, as with deuterons and tritons, we have had to correct for $\Delta E$ values of 0.5 to $1.2 \mathrm{MeV}$. In some cases, as e.g., near threshold, the corrected $\sigma_{a v}$ was only 0.5 of the measured $\sigma_{a v}$.

\section{${ }^{48} \mathrm{~V}$ Counting}

A decay scheme [18] for ${ }^{48} \mathrm{~V}$ and ${ }^{48} \mathrm{Sc}$ showing the details important to this study is shown in Fig. 1. To localize the decay of the positrons and minimize $x-$ ray absorption, an aluminum absorber $1.275 \mathrm{gm} / \mathrm{cm}^{2}$ was used during radiation counting. The ${ }^{48} \mathrm{~V}$ decay was determined through the measurement of the 1312.1- and 983.5-keV $\gamma$-rays (the I $\gamma$ 's used are shown in Fig. 1). Above $11.6 \mathrm{MeV}$ protons $(Q=-11.354),{ }^{48} \mathrm{Sc}$ is formed from the ${ }^{49} \mathrm{Ti}(\mathrm{p}, 2 \mathrm{p})^{48} \mathrm{Sc}$ reaction. Thus, for targets of nat Ti to obtain the ${ }^{48} \mathrm{~V}$ production, we must correct for the ${ }^{48} \mathrm{Sc}$ production through measurement of the $1037.5-\mathrm{keV} \gamma$-ray unless, of course, the 48Sc had already decayed to negligible level. For deuterons, in which we were measuring ${ }^{47} \mathrm{Ti}(\mathrm{d}, \mathrm{n})^{48} \mathrm{~V}$ and ${ }^{48} \mathrm{Ti}(\mathrm{d}, 2 \mathrm{n})^{48} \mathrm{~V}$, we had possible contamination from ${ }^{48} \mathrm{Ti}(\mathrm{d}, 2 \mathrm{p}){ }^{48} \mathrm{Sc}(\mathrm{Q}=-5.436),{ }^{49} \mathrm{Ti}(\mathrm{d}, 2 \mathrm{pn})^{48} \mathrm{Sc}(\mathrm{Q}=-13.578)$ and ${ }^{50} \mathrm{Ti}(\mathrm{d}, \alpha)^{48} \mathrm{Sc}$

$(\mathrm{Q}=+3.778)$. For tritons we had contributions from ${ }^{47} \mathrm{Ti}(t, 2 \mathrm{p})^{48} \mathrm{Sc}(\mathrm{Q}=-0.067)$, ${ }^{48} \mathrm{Ti}(t, 2 \mathrm{pn}){ }^{48} \mathrm{Sc}(\mathrm{Q}=-11.693),{ }^{49} \mathrm{Ti}(t, \alpha)^{48} \mathrm{Sc}(\mathrm{Q}=+8.46)$, and ${ }^{50} \mathrm{Ti}(t, \alpha n)^{48} \mathrm{Sc}$.

Fortunately, it was easy to eliminate these contaminants through measuring the $1037.5-\mathrm{keV} \gamma$-ray and by making use of the difference in decay times.

\section{${ }^{48} \mathrm{Ti}(\mathrm{p}, \mathrm{n})^{48} \mathrm{~V}$}

Most of the measurements of ${ }^{48} \mathrm{Ti}(\mathrm{p}, \mathrm{n})^{48} \mathrm{~V}$ were made using nat $\mathrm{Ti}$ targets. There was no interference from other isotopes until the protons were above 13.20 MeV where the ${ }^{49} \mathrm{Ti}(\mathrm{p}, 2 \mathrm{n})^{48} \mathrm{~V}$ reaction begins to contribute. For the higher energies ( $>15.90 \mathrm{MeV}$ ), we made measurements using the separated ${ }^{48} \mathrm{Ti}$ targets. We made a least-squares fit to these data, including a fit to the unseparated data at and below threshold for the ${ }^{49} \mathrm{Ti}$ reaction. The differences between the fitted data and the natural target data (isotopically corrected) are reported here as ${ }^{49} \mathrm{Ti}(\mathrm{p}, 2 \mathrm{n})^{48} \mathrm{~V}$ in Table 2 and Fig. 2 . The ${ }^{48} \mathrm{Ti}(\mathrm{p}, \mathrm{n})^{48} \mathrm{~V}$ results are given in Table 3 and shown in Fig. 3. We also show earlier data in Fig. 3. The results of Tanaka 
and Furukawa [3] were obtained from a photographic enlargement of their published data. They used nat $\mathrm{Ti}$ so we divided their results by the ${ }^{48} \mathrm{Ti}$ isotopic abundance 0.7394. The results shown for Michel et al. [4] and Michel and Brinkman [5] were also made using natTi. The results by Gadioli et al. [6] are for separated ${ }^{48} \mathrm{Ti}$. The results of Tanaka and Furukawa agree especially well with our results.

A data point for ${ }^{48} \mathrm{~V}$ at $4.63-4.80 \mathrm{MeV}$ (not shown in Table 3) was observed below the reaction threshold of $4.90 \mathrm{MeV}$. It is attributed to ${ }^{47} \mathrm{Ti}(\mathrm{p}, \gamma)^{48} \mathrm{~V}$. Correcting for isotopic abundance, we obtain $0.042 / 0.0728=0.58 \mathrm{mb}$. This value is in good agreement with that of Kennett et al. [19]. The low-energy data in Table 3 are corrected $(0.057 \mathrm{mb})$ for this effect.

\section{${ }^{47} \mathrm{Ti}(\mathrm{d}, \mathrm{n})^{48} \mathrm{~V}$ and ${ }^{48} \mathrm{Ti}(\mathrm{d}, 2 \mathrm{n})^{48} \mathrm{~V}$}

Our first measurements were made using targets of natTi. Below 7.317 $\mathrm{MeV}$ only the ${ }^{47} \mathrm{Ti}(\mathrm{d}, \mathrm{n})^{48} \mathrm{~V}$ reaction occurred. In the rising portion of this excitation function we made extensive use of our evaporated targets ( 6 $\mathrm{mg} / \mathrm{cm}^{2}$ ). Later, targets of separated ${ }^{47} \mathrm{Ti}$ and ${ }^{48} \mathrm{Ti}$ were acquired. The ${ }^{47} \mathrm{Ti}(\mathrm{d}, \mathrm{n})^{48} \mathrm{~V}$ excitation function was then extended above $7.3 \mathrm{MeV}$. These higher energy data were fit to a polynomial by least-squares and subtracted from the nat $\mathrm{Ti}(\mathrm{d}, \mathrm{xn})^{48} \mathrm{~V}$ results to give a measure of ${ }^{48} \mathrm{Ti}(\mathrm{d}, 2 \mathrm{n})^{48} \mathrm{~V}$. Runs were also made with separated ${ }^{48} \mathrm{Ti}$ and the results combined. Both the ${ }^{47} \mathrm{Ti}(\mathrm{d}, \mathrm{n})^{48} \mathrm{~V}$ and ${ }^{48} \mathrm{Ti}(\mathrm{d}, 2 \mathrm{n})^{48} \mathrm{~V}$ excitation functions were carefully corrected in the rising portions of the excitation functions. The results for ${ }^{47} \mathrm{Ti}(\mathrm{d}, \mathrm{n})^{48} \mathrm{~V}$ are given in Table 4 and Fig. 4. The results for ${ }^{48} \mathrm{Ti}(\mathrm{d}, 2 \mathrm{n})^{48} \mathrm{~V}$ are given in Table 5 and Fig. 5 . For the ${ }^{47} \mathrm{Ti}$ data we find the results of Chen and Miller [8] in the literature. Their highenergy data are reasonable but their two points below $7 \mathrm{MeV}$ seem questionable. For the ${ }^{48} \mathrm{Ti}$ data, the results of Chen and Miller, although lower than ours, have the same general trend. The ${ }^{48} \mathrm{Ti}$ data of Burgess et al.[7] using ${ }^{\text {nat }} \mathrm{Ti}$ taken at face value, are considerably lower than ours. However, we noted that they did beta counting and thus, making the correction to a more recent branching ratio results (changed $58 \%$ to $49.6 \%$ ), we find that their data fits ours reasonable well. The outlying point at low energy would seem to be from ${ }^{47} \mathrm{Ti}$.

\section{${ }^{\text {nat }} \mathrm{Ti}(\mathrm{t}, \mathrm{xn})^{48} \mathrm{~V}$}

The measurements of the production of ${ }^{48} \mathrm{~V}$ from tritons on $\mathrm{Ti}$ were made using foils of nat $\mathrm{Ti}$ and separated ${ }^{48} \mathrm{Ti}$. The ${ }^{48} \mathrm{Ti}$ reaction has a threshold at 14.11 $\mathrm{MeV}$. Three data points were obtained for ${ }^{48} \mathrm{Ti}$; the results including threshold, were fit to a polynomial, and subtracted from the nat Ti data. The residual data given in $\mathrm{T}$ able 6 and Fig. 6 are due to ${ }^{46} \mathrm{Ti}(\mathrm{Q}=7.225)$ and ${ }^{47} \mathrm{Ti}(\mathrm{Q}=-1.652)$, the latter by far giving the major contribution, as shown by modeling. Unfortunately, at the time these measurements were made, we did not have targets of separated ${ }^{47} \mathrm{Ti}$. Careful resolution corrections wero made in the rising 
portion of the excitation function. We have found no data in the literature to use for comparison.

$\operatorname{Ti}(t, x)^{47} \mathrm{Sc}$

In the course of the preceding triton measurements, we measured the production of ${ }^{47} \mathrm{Sc}$. We counted the $159-\mathrm{keV} \gamma$-ray in the decay ${ }^{16}$ of ${ }^{47} \mathrm{Sc}$ and used $I \gamma=0.685$. The results are given in Table 7 and Fig. 7. The results for natTi are corrected by $1 / 0.7394$. The results are treated as if entirely due to ${ }^{48} \mathrm{Ti}(t, \alpha)^{47} \mathrm{Sc}(\mathrm{Q}=$ +8.369) but there may be some small contribution below $10 \mathrm{MeV}$ from ${ }^{46} \mathrm{Ti}(\mathrm{t}, 2 \mathrm{p})^{47} \mathrm{Sc}(\mathrm{Q}=0.577),{ }^{47} \mathrm{Ti}(\mathrm{t}, 2 \mathrm{pn})^{47} \mathrm{Sc}(\mathrm{Q}=-8.300)$ and ${ }^{49} \mathrm{Ti}(\mathrm{t}, \alpha \mathrm{n}){ }^{47} \mathrm{Sc}(\mathrm{Q}=0.227)$. We expect the contribution from ${ }^{47} \mathrm{Ti}$ to be negligible.

${ }^{46} \mathrm{Ti}(\mathrm{d}, \alpha)^{44} \mathrm{Sc}^{\mathrm{m}, \mathrm{B}}$ and ${ }^{47} \mathrm{Ti}(\mathrm{d}, \alpha \mathrm{n})^{44} \mathrm{Sc} \mathrm{c}^{\mathrm{m}, \mathrm{g}}$

The decay [18] of ${ }^{44} \mathrm{Sc}$ is shown in Fig. 8. Here we are interested in the production of the 2.44-d isomer at $271 \mathrm{keV}$ and the 3.93-hr ground state. It would also be interesting to acquire data from the other two isomeric states at 146 and 68 $\mathrm{keV}$, but that would require us to perform an inbeam accelerator experiment.

For the metastable state we used the equation

$$
N_{10}=\frac{A_{1}}{\lambda_{1}} e^{-\lambda_{1} l}
$$

For the ground state we had

$$
N_{20}=\frac{A_{2}}{\lambda_{2}} e^{-\lambda_{2} t}-N_{10} f \frac{\lambda_{1}}{\lambda_{2}-\lambda_{1}} e^{\lambda_{2} t}\left(e^{-\lambda_{1} t}-e^{-\lambda_{2} t}\right)
$$

Here $f$ is the IT branch to the ground state (98.6\%). For $A_{1}$ we counted the $271-\mathrm{keV} \gamma$-ray with an $\mathrm{I} \gamma=0.866$. For $A_{2}$ we counted the $1157-\mathrm{keV} \gamma$-ray with an $I \gamma$ $=0.9899$.

The irradiations consisted of targets of ${ }^{n a t} \mathrm{Ti}^{47} \mathrm{Ti}$, and ${ }^{48} \mathrm{Ti}$. The results for ${ }^{47} \mathrm{Ti}(\mathrm{d}, \alpha \mathrm{n}){ }^{47} \mathrm{Sc}{ }^{\mathrm{m}, \mathrm{g}}$ are given in Table 8 and Fig. 9. Also shown are the results of Chen and Miller [8] which are in fair agreement with our results. To obtain the ${ }^{46} \mathrm{Ti}(\mathrm{d}, \alpha)^{44} \mathrm{Sc}^{\mathrm{m}, \mathrm{g}}$ results, we corrected the runs of nat Ti using the ${ }^{47} \mathrm{Ti}$ results. The results are given in Table 9 and Fig. 10. The large error bars near $20 \mathrm{MeV}$ are due to uncertainties in correcting for a contribution at high energies from ${ }^{48} \mathrm{Ti}$. In Fig. 10 we also show results of Chen and Miller [8] which are in fair agreement with our results. 


\section{MODELING}

Preliminary efforts at modeling the data, using the statistical model code STAPRE [11] are to be found in our earlier reports [9,10]. Our final excitation functions presented here should yield to the modeling approach that we used in our study of the excitation functions produced by protons and deuterons on bromine and iodine [20]. There we used the preequilibrium model and for level densities we relied on the back-shifted prescription. For the $(p, n)$ data, with adequate level densities and correct preequilibrium-parameter $K$, the modeling should go smoothly. For the deuterons, and probably to a lessor extent for tritons, there is the problem of breakup of the projectile in the entrance channel of the reaction. Also, for the $(d, n)$ reaction there may be a strong direct (pickup) component. Again, we refer to our work on the halides for guidance.

Comparing the excitation functions of the ${ }^{44} \mathrm{Sc}, g$ pairs has the potential of being interesting and may make use of concepts we developed in our study of ${ }^{52} \mathrm{Cr}$,g $[12,13]$.

\section{ACKNOWLEDGMENTS}

This work was performed under the auspices of the U. S. Department of Energy by Lawrence Livermore National Laboratory under contract W-7405-Eng-48.

\section{REFERENCES}

[1] D. T. Goldman, Amer. Inst. Phys. Handbook 8, 14 (1972).

[2] J. K. Tuli, Nuclear Wallet Cards, National Nuclear Data Center (1985), based on A.H. Wapstra and G. Audi; Nucl. Phys. 432A, 55 (1985).

[3] S. Tanaka and M. Furukawa, J. Phys. Soc. Japan 14, 1269 (1969).

[4] R. Michel, G. Brinkman, H. Weigel, and W. Herr, J. Inorg. Chem. 40, 1845 (1978).

[5] R. Michel and G. Brinkman, J. Rad. Chem 59, 467 (1980).

[6] E. Gadioli, E. Gadioli-Erba, J. J. Hogan, and K. I. Burns, Z. Phys. A301, 289 (1981)

[7] W. H. Burgess, G. A. Cowan, J. W. Hadley, W. Hess, T. Schull, M. L. Stevenson, and H. F. York, Phys. Rev. 95, 750 (1954).

[8] K. L. Chen and J. Miller, Phys. Rev. B 134, 1269 (1964).

[9] M. G. Mustafa, R. G. Lanier, H. I. West, Jr., and R. A. Meyer, Predictive limits of Statistical Theory of Charged-Particle Reactions in the $A=50$ Region, Nucl. 
Chem. Div. Ann. Report, UCAR 10062/85-1, p. 2-20, Lawrence Livermore National Laboratory (1985).

[10] H. I.West, Jr., R.G. Lanier, M. G. Mustafa, and H. O'Brien, Excitation Functions for Nuclear Reactions Produced by Triton Irradiation of Titanium, Nucl. Chem. Div. Ann. Report, UCAR 10062/87, p. 2-31, Law. Liv. Nat. Lab. (1987)

[11] D. G. Gardner, Livermore version of a statistical model code STAPRE originally written by B. Strohmaier and M. Uhl, Institut für Radium Forschung und Kernphysik, Vienna, Austria, Report No. IRK-76/01, Livermore version updated 1981.

[12] H. I. West, Jr., R. G. Lanier, and M. G. Mustafa, Phys. Rev. C 35, 2067 (1987).

[13] M. G. Mustafa, T. Tamura, and T. Udagawa, Phys. Rev. C 35, 2077 (1987).

[14] H. I. West, Jr., M. G. Mustafa, R. G. Lanier, and H. O'Brien, Phys. Rev. C 43, 1352 (1991).

[15] R. Gunnink and J. B. Niday, Lawrence Livermore National Laboratory, Livermore, Calif. Report No. UCRL-51061 (1972).

[16] M. G. Mustafa, H. I. West, Jr., H. O'Brien, R. G. Lanier, M. Benhamau, and T. Tamura, Phys. Rev. C 38, 1626 (1988).

[17] H. I. West, Jr., R. G. Lanier, M. G. Mustafa, and H. O'Brien, The Excitation Function for ${ }^{48} \mathrm{~V}$ from Tritons on Natural Titanium, Univ. of Calif. Report, Lawrence Livermore National Laboratory, UCID-21063 (1987).

[18] C. M. Lederer, V. S. Shirley, E. Browne, J. M. Dairiki, R. E. Doebler, A. A. Shihab-Eldin, L. J. Jardine, J. K. Tuli, and A. B. Buyrn, Table of Isotopes, Wiley and Sons, Inc., New York, (1978).

[19] S. R. Kennett, L. W. Mitchell, M. R. Anderson, and D. G. Sargood, Nucl. Phys. A368, 337 (1981).

[20] H. I. West, Jr., R. M. Nuckolls, B. Hudson, B. Ruiz, R. G. Lanier, and M. G. Mustafa, Phys. Rev. C 47, 245 (1993). 
TABLE 2. Excitation function for ${ }^{49} \mathrm{Ti}(\mathrm{p}, 2 \mathrm{n})^{48} \mathrm{~V}$

$\begin{array}{cc}E(\mathrm{MeV}) & \sigma\left(\mathrm{mb}^{\mathrm{a}}\right. \\ 13.20^{\mathrm{b}} & 0 \\ 13.51 & 113 \pm 130 \\ 14.56 & 267 \pm 127 \\ 15.29 & 91 \pm 140 \\ 15.89 & 196.140 \\ 16.33 & 283 \pm 125 \\ 16.91 & 215 \pm 103 \\ 17.85 & 357 \pm 99 \\ 19.20 & 326 \pm 70 \\ 20.55 & 39 . \pm \ldots \ldots .55 \\ 21.11 & 312 \pm 48 \\ 22.53 & 404 \pm 42 \\ 22.61 & 396 \pm 40 \\ 24.08 & 351 \pm 35 \\ 24.60 \ldots \ldots \ldots \ldots \ldots . .326 . \pm 32 \\ 24.81 & 337 \pm 34 \\ 25.92 & 267 \pm 30 \\ 26.47 & 253 \pm 28 \\ 28.21 & 181 \pm 25 \\ 29.93 & \ldots \ldots \ldots \ldots . .146 . \pm 23\end{array}$

a $\sigma(49)$ derived from $\sigma$ (nat) - $\sigma$ (48 sep)

$b$ Reaction threshold
TABLE 3. Excitation function for ${ }^{48} \mathrm{Ti}(\mathrm{p}, \mathrm{n})^{48} \mathrm{~V}$

$\begin{array}{lc}E(\mathrm{MeV}) & \sigma(\mathrm{mb})^{\mathrm{a}, \mathrm{e}} \\ 4.96^{\mathrm{a}} & 1.60 \pm 0.17 \\ 5.11^{\mathrm{a}} & 4.64 \pm 0.48 \\ 5.27^{\mathrm{a}} & 31.04 \pm 1.0 \\ 5.37^{\mathrm{a}} & 63.1 \pm 2.0 \\ 5.66^{\mathrm{a}} & .134 .3 .4 .4 .0 \\ 5.86 & 171.3 \pm 5.1 \\ 6.37 & 276 . \pm 8 \\ 6.94 & 309 . \pm 9 \\ 7.07 & 323 . \pm 10 \\ 7.48 & 36 . \pm 11 \\ 8.05 & 399 . \pm \ldots \ldots \ldots . .12(2)^{\mathrm{b}} \\ 8.26 & 424 . \pm 13 \\ 8.89 & 451 . \pm 14 \\ 9.56 & 463 . \pm 14(2) \\ 10.82 & .508 . \pm 15 .(5) \\ 11.68 & 508 . \pm 15(2) \\ 13.20 & 504 . \pm 16^{\mathrm{d}} \\ 15.00 & 371 . \pm 12^{\mathrm{d}} \\ 15.90 & 290.7 \pm 9.2^{\mathrm{c}} \\ 17.72 \ldots \ldots \ldots \ldots \ldots . .165 .1 \pm 5.2 \\ 19.37 & 105.8 \pm 3.3 \\ 20.95 & 74.8 \pm 2.4 \\ 22.65 & 58.0 \pm 1.8 \\ 24.05 & 45.8 \pm 1.5 \\ 25.41 \ldots \ldots \ldots \ldots \ldots . .42 .0 \pm 1.3 \\ 26.71 & 39.3 \pm 1.3\end{array}$

${ }^{a}$ Foil energy resolution corrected. Lowest energy points were corrected for contribution from ${ }^{47} \mathrm{Ti}(\mathrm{p}, \gamma){ }^{48 \mathrm{~V}}$

$b()$ is number of averaged data points.

c Below this energy data are due to $\sigma($ nat) $/ 0.7394$. At and above this energy, data were obtained from separated ${ }^{48} \mathrm{Ti}$. d Derived from the two sets of data.

e Statistical error $\leq 1 \%$. A systematic error of $\pm 3 \%$ was added. 
TABLE 4. Excitation function for ${ }^{47} \mathrm{Ti}(\mathrm{d}, \mathrm{n}){ }^{48} \mathrm{~V}$

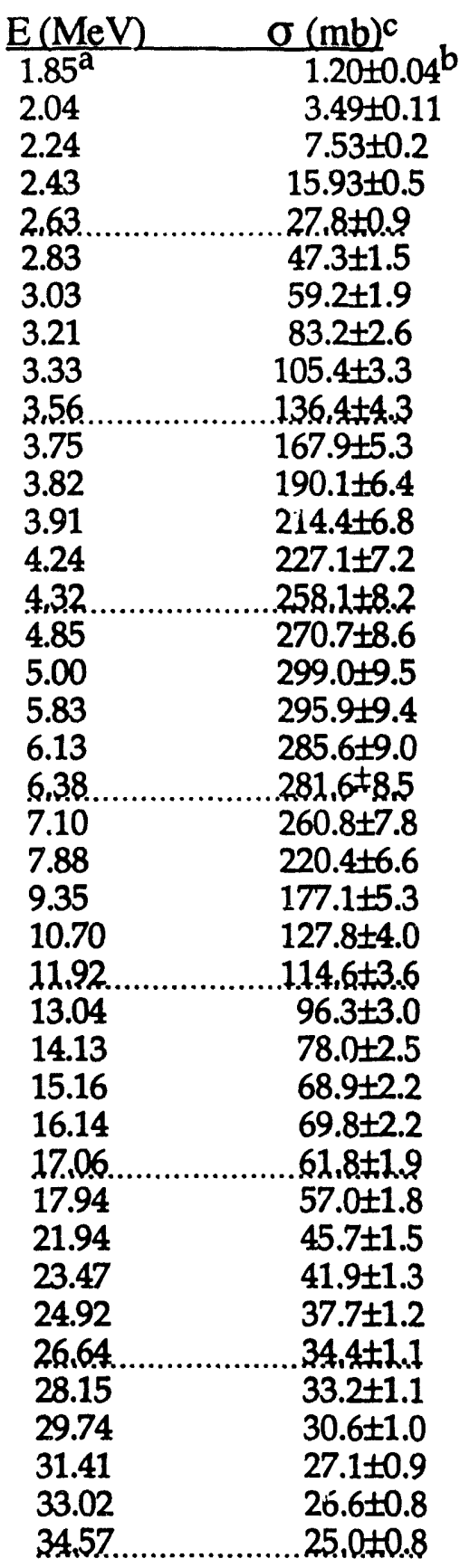

${ }^{2}$ For $\mathrm{E} \leq 7.10 \mathrm{MeV}$, except $3.91 \& 6.13 \mathrm{MeV}$, $\sigma(47)$ was derived from measurements on natural Ti corrected for ${ }^{47} \mathrm{Ti}$ isotopic abundance. The rest of the measurements came from foils $95 \%$ ${ }^{47} \mathrm{Ti}$ and $5 \%{ }^{48} \mathrm{Ti}$.

${ }^{b}$ The measurements at low energy were corrected for finite energy loss in the foils.

c Stat. error less than $1 \%$. A systematic error of $\pm 3 \%$ was added in quadrature.
TABLE 5. Excitation function for ${ }^{48} \mathrm{Ti}(\mathrm{d}, 2 \mathrm{n}){ }^{48} \mathrm{~V}$

\begin{tabular}{|c|c|}
\hline $\mathrm{E}(\mathrm{MeV})$ & $\sigma(\mathrm{mb})^{c}$ \\
\hline 7.317 & 0 \\
\hline 7.459 & $0.666 \pm 0.021^{b}$ \\
\hline $7.60^{a}$ & $3.70 \pm 0.12^{b}$ \\
\hline 7.82 & $5.43 \pm 0.17^{b}$ \\
\hline $8.10^{\mathrm{a}}$. & $15.50 \pm 0.49^{b}$ \\
\hline $8.23^{a}$ & $19.85 \pm 0.63^{b}$ \\
\hline 8.24 & $19.35 \pm 0.61^{b}$ \\
\hline $8.69^{a}$ & $53.6 \pm 1.7^{\mathrm{b}}$ \\
\hline 8.84 & $58.1 \pm 1,8^{\mathfrak{b}}$ \\
\hline $9.26^{\mathrm{a}}$. & $93.9+3 k$ \\
\hline 9.33 & $100.4 \pm 3$ \\
\hline $9.74^{\mathrm{a}}$ & $162.2 \pm 5$ \\
\hline 10.01 & $164.9 \pm 5$ \\
\hline 10.56. & $202.8 \pm 6$ \\
\hline 10.86 & $230 . \pm 7$ \\
\hline $11.00^{\mathrm{a}}$ & $263.8 \pm 8$ \\
\hline $11.75^{\mathrm{a}}$ & $287 . \pm 9$ \\
\hline 11.95 & $303 . \pm 10$ \\
\hline $12.49^{\mathrm{a}}$ & $348 . \pm 11$ \\
\hline $13.93 \ldots$ & $391, \pm 12$ \\
\hline $14.29^{\mathrm{a}}$ & $412 . \pm 13$ \\
\hline 15.50 & 431.土14 \\
\hline 15.99 & $420.6 \pm 13$ \\
\hline $17.04^{\mathrm{a}}$ & $450 . \pm 14$ \\
\hline $17.95 \ldots$ & $.434 . \pm 14$ \\
\hline $18.48^{\mathrm{a}}$ & $440 . \pm 14$ \\
\hline $19.84^{\mathrm{a}}$ & $417 . \pm 13$ \\
\hline 19.92 & $400 . \pm 13$ \\
\hline 21.73 & $368 . \pm 12$ \\
\hline 23.35. & $318 . \pm 10$ \\
\hline 24.89 & $260.8 \pm 8.3$ \\
\hline 26.54 & $221.2 \pm 7.0$ \\
\hline 28.09 & $188.8 \pm 6.0$ \\
\hline 29.70 & $158.3 \pm 4.7$ \\
\hline 31.31.. & $.132 .7 . \pm 4.2$ \\
\hline 32.97 & $118.4 \pm 3.7$ \\
\hline 34.56 & $106.5 \pm 3.4$ \\
\hline
\end{tabular}

a $[\sigma$ (nat) $-\sigma(47)] / 0.7394$. The rest are from separated ${ }^{48} \mathrm{Ti}$.

$b$ Data in rising portion of excitation function corrected for deuteron energy, loss in target foils.

c Stat. error $<1 \%$. A systematic error of $\pm 3 \%$ was added in quadrature. 
TABLE 6. Excitation function for natTi(t,xn) ${ }^{48} \mathrm{~V}$

\begin{tabular}{ll}
$E(\mathrm{MeV})$ & $\sigma(\mathrm{mb})^{\mathrm{a}, \mathrm{d}}$ \\
\hline 1.67 & $0.010 \pm 0.001$ \\
2.03 & $0.155 \pm 0.023$ \\
2.21 & $0.199 \pm 0.010$ \\
2.73 & $1.05 \pm 0.04$ \\
3.25 & 4.01 .0 .13 \\
3.77 & $8.46 \pm 0.26$ \\
4.59 & $16.5 \pm 0.5^{\mathrm{c}}$ \\
6.62 & $31.4 \pm 1.0$ \\
8.13 & $37.3 \pm 1.1$ \\
9.50 & $\ldots \ldots .5 .1 .2$ \\
10.91 & $42.8 \pm 1.3$ \\
12.45 & $41.9 \pm 1.3$ \\
13.88 & $40.4 \pm 1.3$ \\
15.32 & $37.7 \pm 1.2^{\mathrm{b}}$ \\
16.54 & 33.9 .1 .1 .3 \\
17.71 & $29.4 \pm 1.8$
\end{tabular}

a Target ${ }^{\text {nat }} \mathrm{Ti}$. Results mostly due to ${ }^{47} \mathrm{Ti}$. Some contribution at low energy due to ${ }^{46} \mathrm{Ti}$. b Highest three points were corrected for ${ }^{48} \mathrm{Ti}$ contribution. $\mathrm{Q}=-13.278 \mathrm{MeV}$

c All data at this and lower energies were corrected for triton energy loss in target foils. Known stat. error plus $3 \%$ systematic error were added in quadrature. d Values are for natTi. No isotopic corrections were made.
TABLE 7. Excitation function for ${ }^{48} \mathrm{Ti}(t, \alpha){ }^{47} \mathrm{Sc}$, with smail contributions from ${ }^{46} \mathrm{Ti}(t, 2 \mathrm{p})$ and ${ }^{49} \mathrm{Ti}(\mathrm{t}, \alpha \mathrm{n})$

\begin{tabular}{|c|c|}
\hline $\mathrm{E}(\mathrm{MeV})$ & $\sigma(\mathrm{mb})^{e}$ \\
\hline 1.67 & $0.014 \pm 0.001^{n}$ \\
\hline 2.21 & $0.27 \pm 0.010^{n}$ \\
\hline 2.04 & $0.152 \pm 0.008^{n}$ \\
\hline 2.60 & $1.144+0.036^{\mathrm{S}}$ \\
\hline 2.73. & $.1 .56+0.05^{n}$ \\
\hline 3.08 & $3.71 \pm 0.12^{\mathrm{s}}$ \\
\hline 3.25 & $4.79 \pm 0.15^{n}$ \\
\hline 3.62 & $8.21 \pm 0.26^{s}$ \\
\hline $3.77^{c}$ & $9.59 \pm 0.3^{n}$ \\
\hline $4.28 \ldots$ & $.15 .7 .5 \pm 0.5^{\mathrm{s}}$ \\
\hline 4.59 & $18.24 \pm 0.6^{n}$ \\
\hline 5.73 & $28.7 \pm 0.9^{s}$ \\
\hline 6.63 & $37.1 \pm 1.2^{n}$ \\
\hline 7.23 & $42.5 \pm 1.3^{s}$ \\
\hline 8.15. & $.48 .4 \pm 1,5^{n}$ \\
\hline 8.87 & $50.6 \pm 1.6^{\mathrm{S}}$ \\
\hline 9.50 & $55.1 \pm 1.7^{n}$ \\
\hline 10.30 & $53.1 \pm 1.7^{\mathrm{s}}$ \\
\hline 12.47 & $44.3 \pm 1.4^{\mathrm{S}}$ \\
\hline $13,61$. & $.40,3 \pm 1,3^{5}$ \\
\hline 15.19 & $34.2 \pm 1.0^{\mathrm{s}}$ \\
\hline 16.55 & $33.1 \pm 1.0^{5}$ \\
\hline 17.83 & $32.6 \pm 1.0^{\mathrm{s}}$ \\
\hline
\end{tabular}

c All $\sigma$ 's at this and lower energy were corrected for triton energy loss in target foils.

e Except for first three points, stat. error $<1 \%$. A systematic error of $\pm 3 \%$ was added in quadrature. 
TABLE 8. Excitation function for ${ }^{47} \mathrm{Ti}(\mathrm{d}, \alpha \mathrm{n}){ }^{44} \mathrm{Sc}{ }^{\mathrm{m}, \mathrm{g}}$

\begin{tabular}{|c|c|c|}
\hline $\mathrm{E}(\mathrm{MeV})$ & $\sigma_{m}(m b)^{a, b}$ & $\sigma_{g}(m b)^{a, b}$ \\
\hline 9.35 & $0.004 \pm 0.007$ & $0.036 \pm 0.010$ \\
\hline 10.70 & $0.277 \pm 0.016$ & $0.50 \pm 0.03$ \\
\hline 11.92 & $2.35 \pm 0.07$ & $4.6 \pm 0.14$ \\
\hline 11.92 & $2.60 \pm 0.1$ & $4.17 \pm 0.14$ \\
\hline $13,04$. & ...35. \pm .0 .2 & 12.8.\$.0.4 \\
\hline 14.13 & $12.1 \pm 0.4$ & $22.0 \pm 0.7$ \\
\hline 15.16 & $17.3 \pm 0.5$ & $32.7 \pm 0.9$ \\
\hline 16.14 & $23.6 \pm 0.7$ & $44.8 \pm 1.5$ \\
\hline 17.06 & $26.4 \pm 0.8$ & $52.8 \pm 1.5$ \\
\hline 17.94. & $.30,2 \pm 0.9$ & $.58,4 \pm .1 .8$ \\
\hline
\end{tabular}

a Measurements made using ${ }^{47} \mathrm{Ti}$ foils. Effects due to ${ }^{46} \mathrm{Ti}$ contaminants had to be removed at low energies ( $\$ 10.7 \mathrm{MeV}$ ).

b Stat. error plus $3 \%$ systematic error added in quadrature. Error in I $\gamma$ not included.

TABLE 9. Excitation function for ${ }^{46} \mathrm{Ti}(\mathrm{d}, \alpha)^{44} \mathrm{Sc} \mathrm{c}^{\mathrm{m}, \mathrm{g}}$

\begin{tabular}{|c|c|c|}
\hline $\mathrm{E}(\mathrm{MeV})$ & $\sigma_{m}(m b)^{a}$ & $\sigma_{g}(m b)^{a}$ \\
\hline 4.85 & $1.01 \pm 0.1$ & \\
\hline 5.06 & $1.99 \pm 0.14$ & $19.8 \pm 0.7$ \\
\hline 5.36 & $2.38 \pm 0.1$ & $23.9 \pm 0.8$ \\
\hline 5.92 & $2.95 \pm 0.14$ & $31.6 \pm 1.1$ \\
\hline $6,38 \ldots$ & $3,35 . \pm 0.2$ & \\
\hline 7.67 & $6.91 \pm 0.3$ & $48.5 \pm 1.6$ \\
\hline 8.10 & $7.38 \pm 0.4$ & \\
\hline 9.20 & $11.9 \pm 0.7$ & $62.0 \pm 2.1$ \\
\hline 9.74 & $13.5 \pm 0.5$ & \\
\hline 10.41. & $12.9+0.5$ & \\
\hline 10.54 & $15.1 \pm 0.6$ & $63.4 \pm 2.0$ \\
\hline 11.00 & $15.1 \pm 0.6$ & \\
\hline 11.51 & $16.9 \pm 0.7$ & $57.7 \pm 2.0$ \\
\hline 11.75 & $15.1 \pm 0.7$ & \\
\hline 12.49. & 16.8 . +0.7 . & \\
\hline 13.37 & $15.9 \pm 0.8$ & $46.4 \pm 2.0$ \\
\hline 14.29 & $15.9 \pm 1.1$ & \\
\hline 15.10 & $14.1 \pm 1.1$ & $33.0 \pm 2.1$ \\
\hline 16.63 & $10.2 \pm 1.2$ & $23.5 \pm 2.6$ \\
\hline 18.26. & $. .6 .94 \ldots+1.4 \ldots$ & $19.0 \pm .4 .0$ \\
\hline & & \\
\hline
\end{tabular}

a Measurements were made with ${ }^{\text {nat }} \mathrm{Ti}$ with contributions from ${ }^{47} \mathrm{Ti}$ subtracted at $\mathrm{E} \geq 9.7 \mathrm{MeV}$. Error estimates increase at high energies due to the differences of the two measurements. Brror estimates of original $\sigma$ 's before subtraction were stat. plus $3 \%$ systematic error added in quadrature. No estimates of errors in $I \gamma$ are included. 


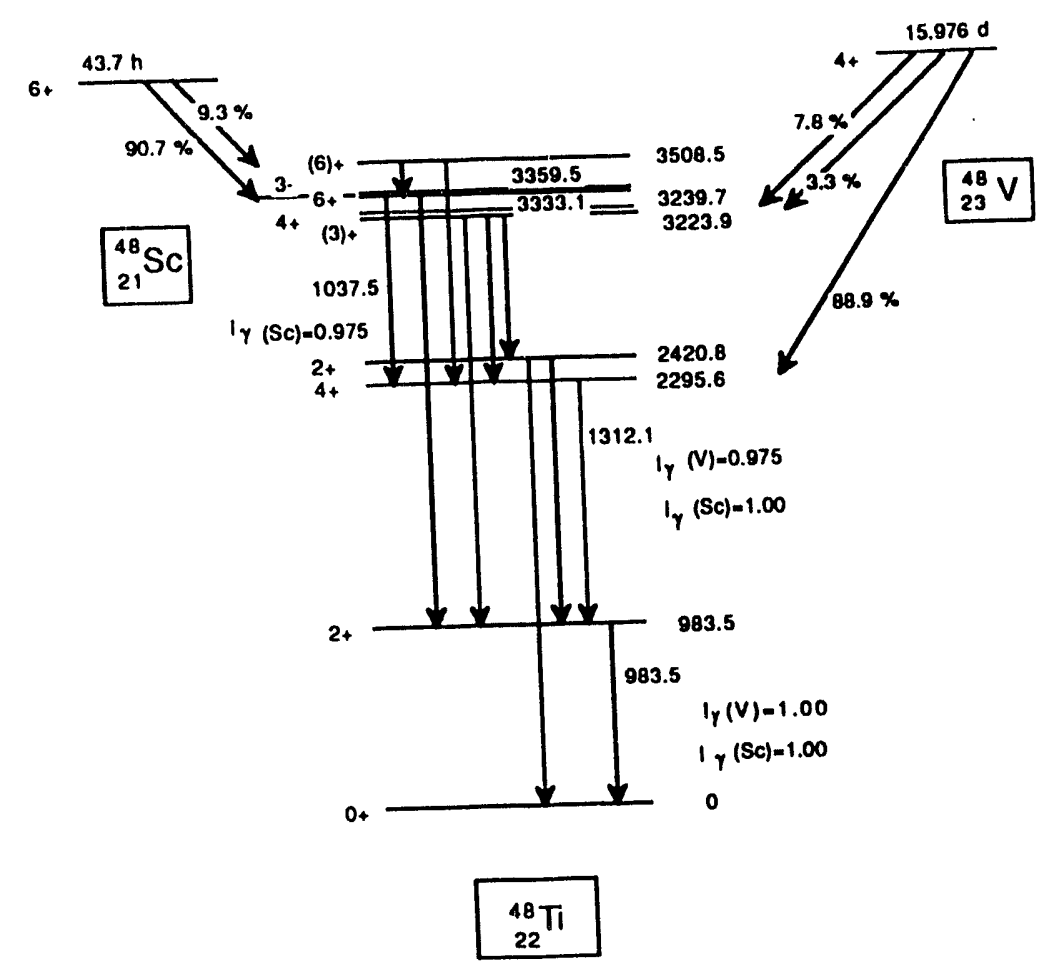

FIG.1 The decay of ${ }^{48 \mathrm{~V}}$ and ${ }^{48} \mathrm{Sc}$.

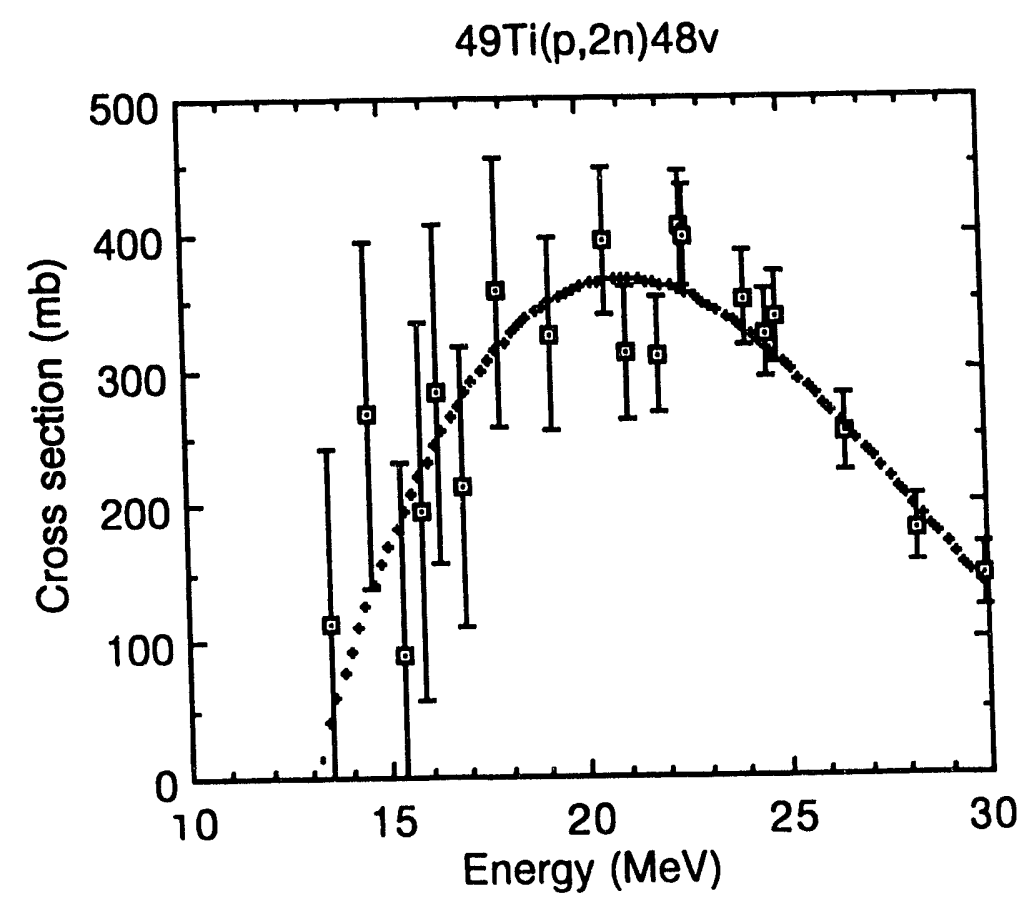

FIG. 2. Excitation function for ${ }^{49} \mathrm{Ti}(p, 2 n)^{48} \mathrm{~V}$. See Table 2 for data. 


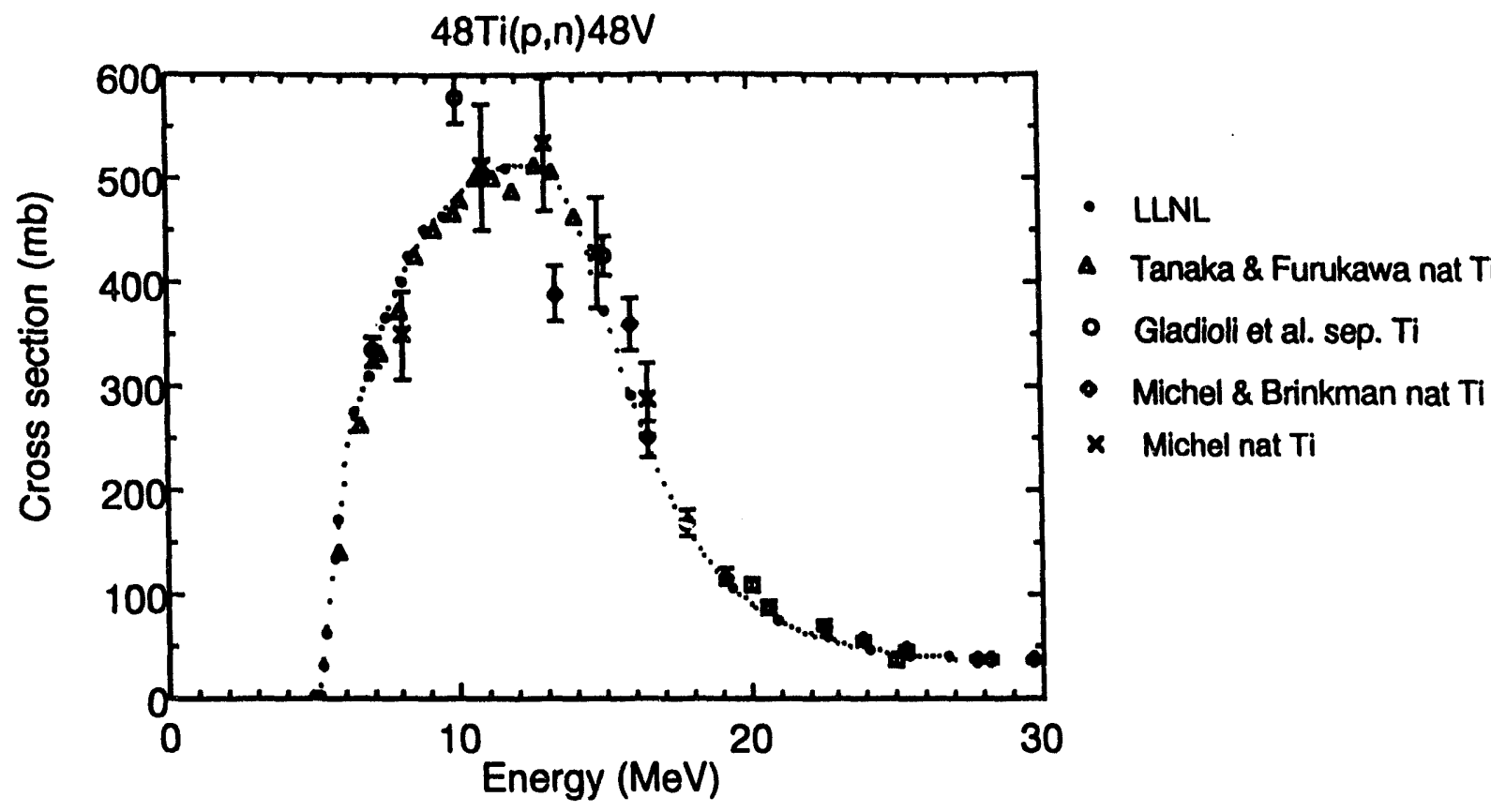

FIG. 3 Excitation function for ${ }^{48} \mathrm{Ti}(p, n)^{48} \mathrm{~V}$. See Table 3 for data.

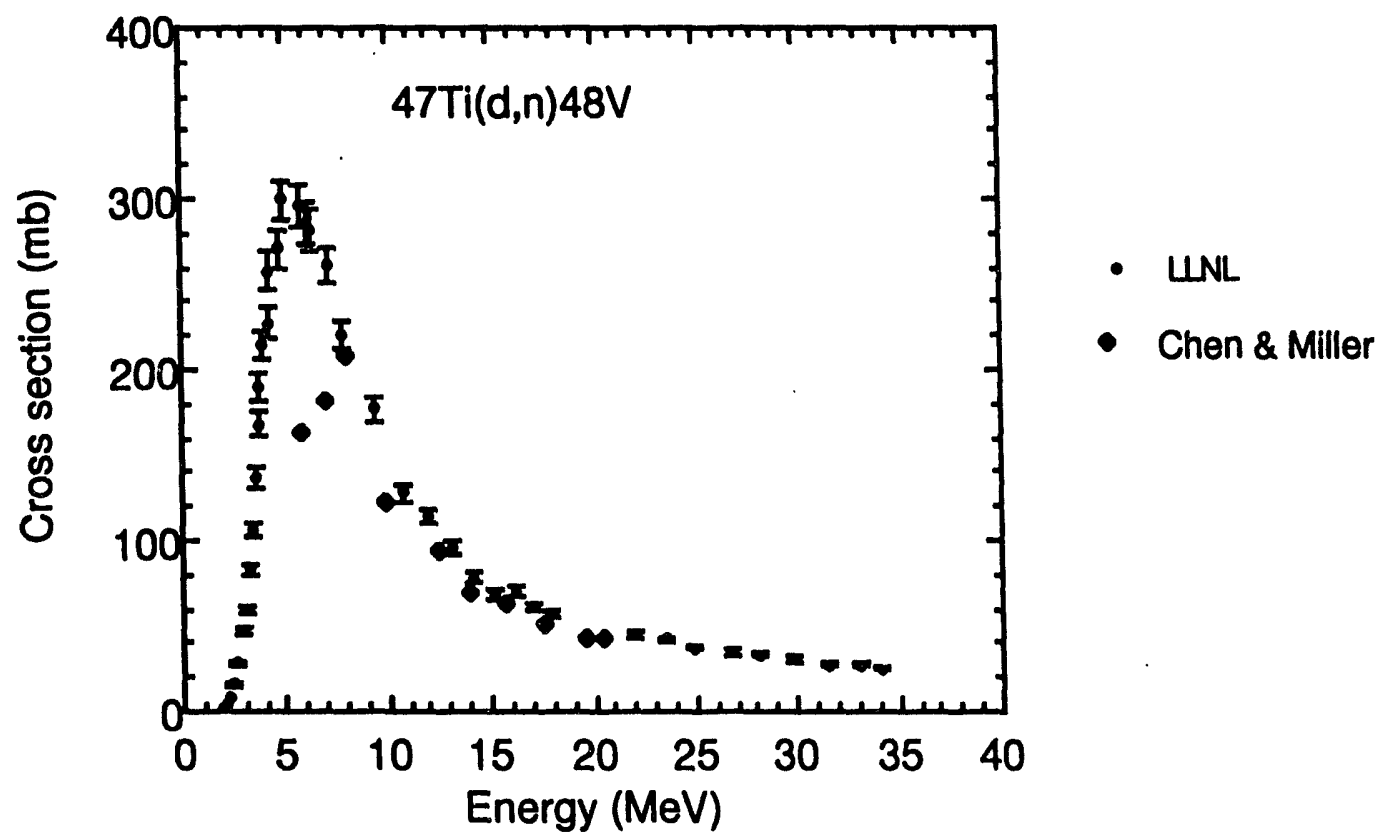

FIG. 4 Excitation function for ${ }^{47} \mathrm{Ti}(d, n)^{48} \mathrm{~V}$. See Table 4 for data. 


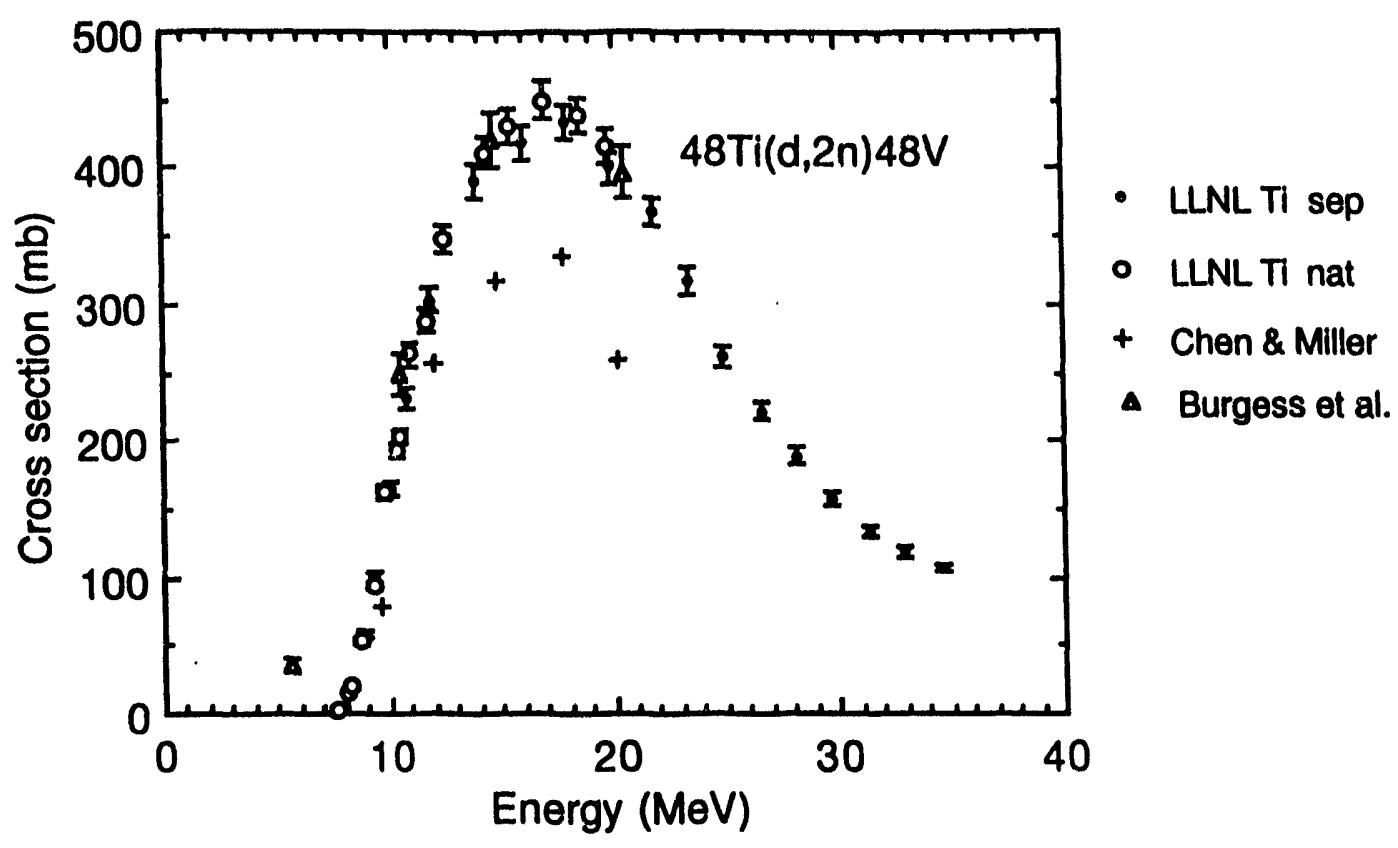

FIG. 5 Excitation function for ${ }^{48} \mathrm{Ti}(\mathrm{d}, 2 \mathrm{n})^{48} \mathrm{~V}$. See Table 5 for data.

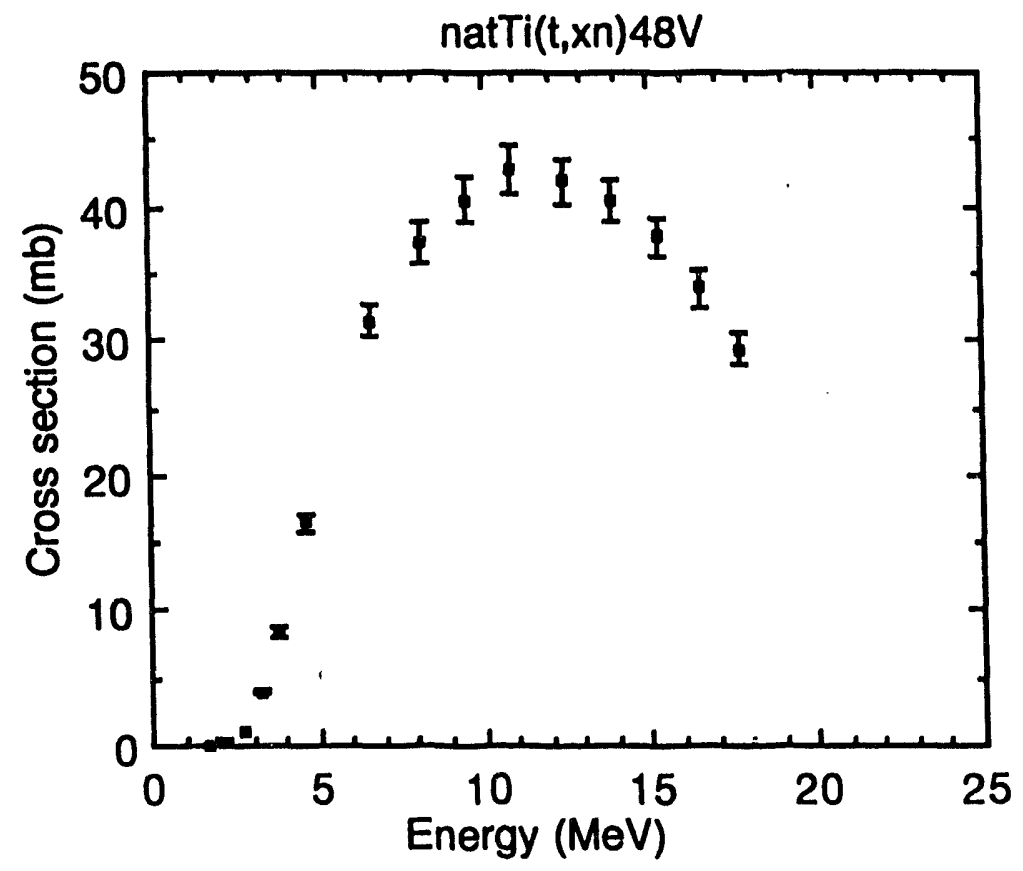

FIG. 6 Excitation function for $\operatorname{nat}^{T}(t, x n)^{48} \mathrm{~V}$. See Table 6 for data. The major contribution is from ${ }^{47} \mathrm{Ti}(t, n)$. The rest is from ${ }^{46} \mathrm{Ti}(t, 2 \mathrm{n})$. 


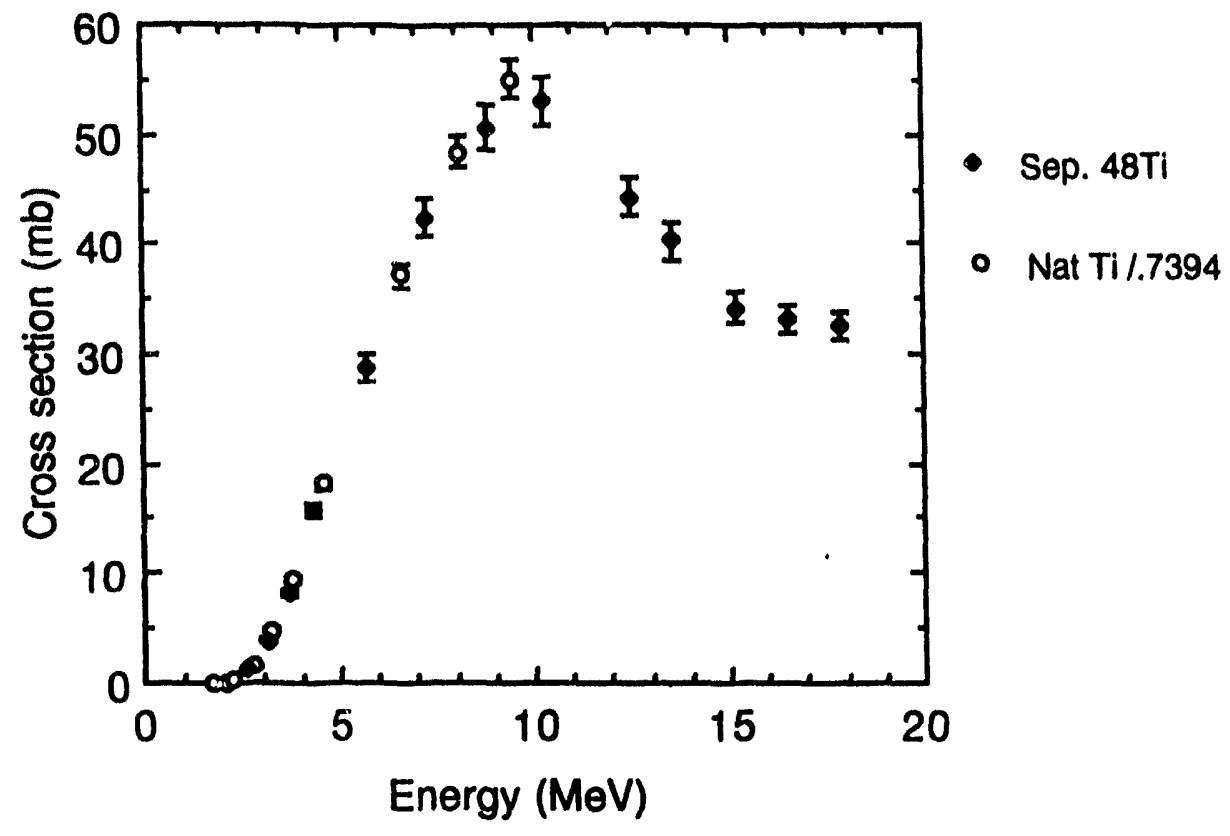

FIG. 7. Excitation function for $\mathrm{Ti}(t, x)^{47} \mathrm{Sc}$. See Table 7 for data. The data are treated as due from ${ }^{48} \mathrm{Ti}(t, \alpha)$ and are corrected for the ${ }^{48} \mathrm{Ti}$ abundance. However, there are small contributions from ${ }^{46} \mathrm{Ti}(t, 2 p)$ and ${ }^{49} \mathrm{Ti}(t, \alpha \mathrm{n})$.

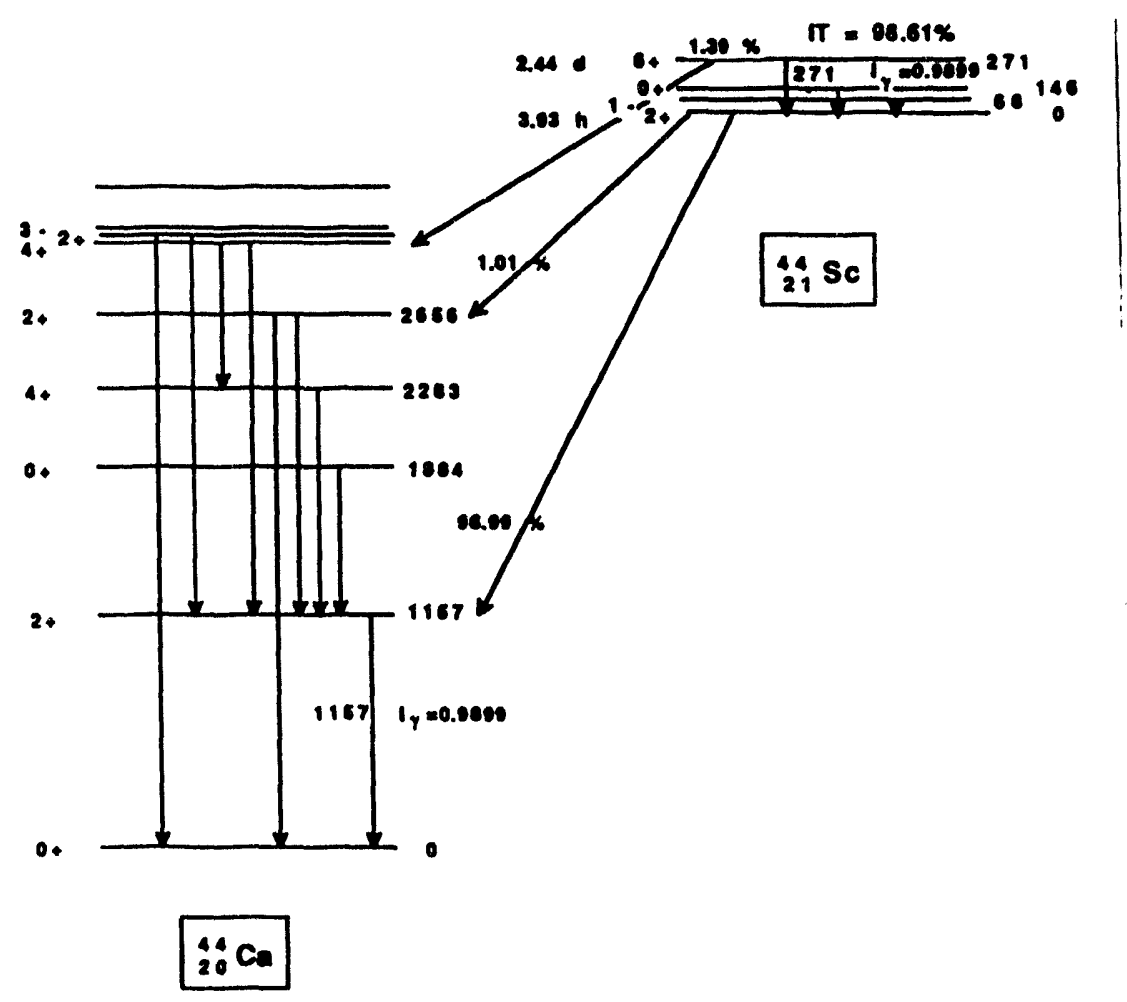

FIG. 8 The Decay of ${ }^{44}$ Sc. 


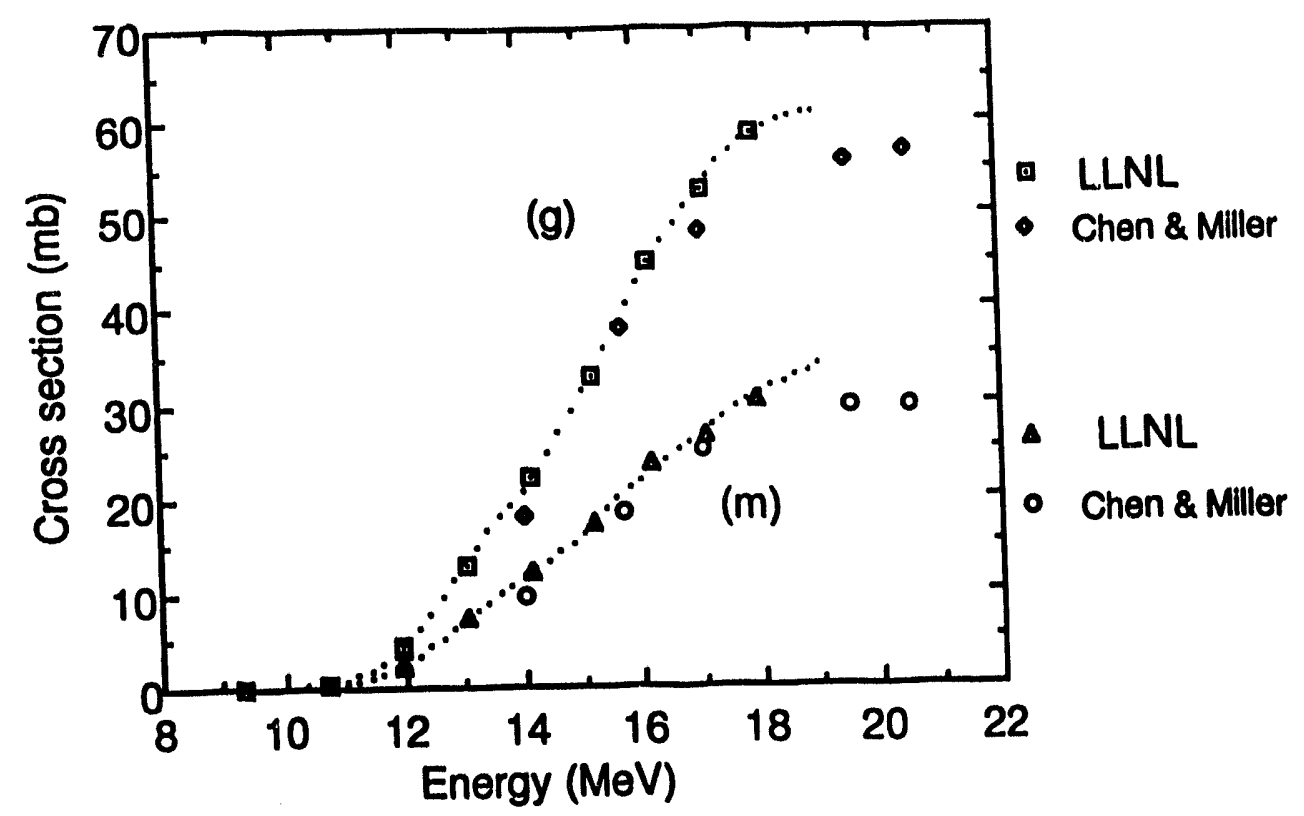

FIG. 9 Excitation functions for ${ }^{47} \mathrm{Ti}(\mathrm{d}, \alpha \mathrm{n})^{44} \mathrm{Sc}^{\mathrm{m}, g}$. See Table 8 for data.

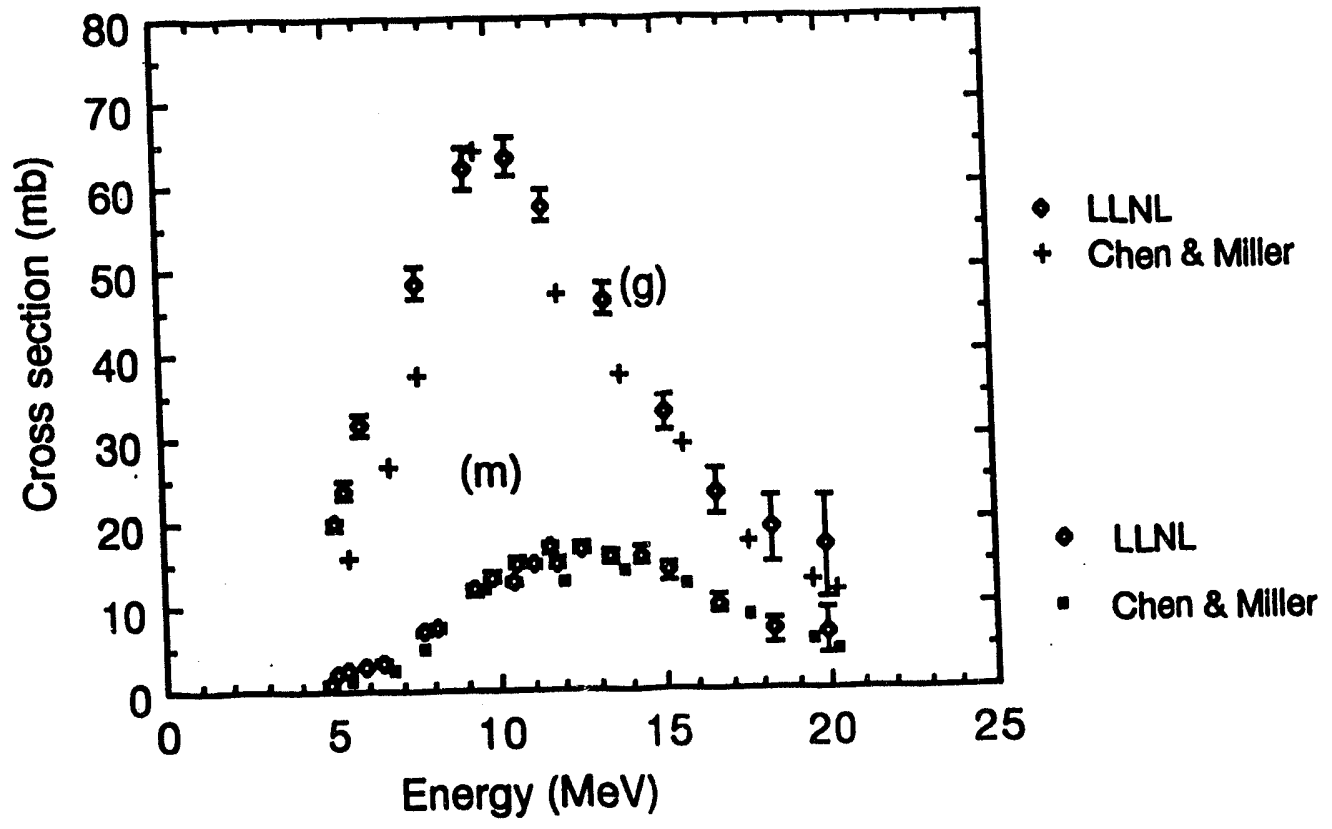

FIG. 10 Excitation functions for ${ }^{46} \mathrm{Ti}(\mathrm{d}, \alpha)^{44} \mathrm{Sc} \mathrm{c}^{\mathrm{m}, \mathrm{g}}$. See Table 9 for data. 


\title{
4. Some Excitation Functions of Proton and Deuteron Induced Reactions on $89 \mathrm{Y}$
}

\author{
H. I. West, Jr., M. G. Mustafa, H. O'Brien and R. G. Lanier \\ Lawrence Livermore National Laboratory \\ Livermore, CA 94550
}

INTRODUCTION

We have measured the cross sections for the reactions induced in ${ }^{89} \mathrm{Y}$ by the irradiation of protons and deuterons from 0 to $40 \mathrm{MeV}$ using the stacked-foil activation method. Excitation functions for ${ }^{89} \mathrm{Y}(\mathrm{p}, \mathrm{n})^{89} \mathrm{Zr},{ }^{89} \mathrm{Y}(\mathrm{p}, 2 \mathrm{n}){ }^{88 \mathrm{Zr}}$ and ${ }^{89} \mathrm{Y}(\mathrm{p}, \mathrm{pn})^{88} \mathrm{Y}$ were published elsewhere [1]. Here we report results for ${ }^{89} \mathrm{Y}(\mathrm{d}, 2 \mathrm{2n})^{89} \mathrm{Zr}$, ${ }^{89} \mathrm{Y}(\mathrm{d}, 3 \mathrm{n}){ }^{88} \mathrm{Zr},{ }^{89} \mathrm{Y}(\mathrm{d}, \mathrm{p} 2 \mathrm{n}){ }^{88} \mathrm{Y},{ }^{89} \mathrm{Y}(\mathrm{p}, \alpha \mathrm{n}){ }^{85} \mathrm{~S} \mathrm{r}^{\mathrm{m}, \mathrm{g},}{ }^{89} \mathrm{Y}(\mathrm{d}, \alpha 2 \mathrm{n}){ }^{85} \mathrm{Srm}, \mathrm{g}$, and ${ }^{89} \mathrm{Y}(\mathrm{d}, \mathrm{p})^{90} \mathrm{Ym}$. Some results of our measurements of ${ }^{89} \mathrm{Y}(\mathrm{d}, 2 \mathrm{n}){ }^{89} \mathrm{Zr}$ were published earlier [2]. A major goal of our work was to achieve a high degree of accuracy (errors $\leq \mathrm{a}$ few percent).

Bissem et al. [3] have studied the ${ }^{89} \mathrm{Y}(\mathrm{d}, \mathrm{p}){ }^{90} \mathrm{Ym}^{89}{ }^{89} \mathrm{Y}(\mathrm{d}, 2 \mathrm{n})^{89} \mathrm{Zrg}, \mathrm{m}$, and ${ }^{89} \mathrm{Y}(\mathrm{d}, \mathrm{p} 2 \mathrm{n}){ }^{88} \mathrm{Y}$, excitation functions. They used $25.9 \mathrm{MeV}$ deuterons directed into a stack of foils. The thick stack of foils they used degraded the beam quality considerably. The beam spread at $10 \mathrm{MeV}$ was calculated to be $\pm 0.95 \mathrm{MeV}$ full width at one half maximum and would affect the measurements of the rising portions of the excitation functions. However, they did not attempt to make corrections for this. They used their data as part of an extensive modeling study. The numerical cross sections are not given in the paper. These were obtained from Prof. Scobel [private communication, 1993].

Degering et al. [4] have measured the ${ }^{89} \mathrm{Y}(\mathrm{d}, 2 \mathrm{n}){ }^{89} \mathrm{Zr}$ excitation function below 13.5 MeV. Their results are in good agreement with the Keller, Lange, Munzel [5] tables.

For previous work for ${ }^{89} \mathrm{Y}(\mathrm{d}, \mathrm{p}){ }^{90} \mathrm{Ym}$, a pick-up reaction, we cite the work of Corazza and Nassiff [6] and Riley and Linder [7]. It would have been desirable for us to have also measured the production of $64.1 \mathrm{~h} 90 \mathrm{Yg}$, but we have not done so. Studies of isomeric pairs illuminate spin dependent features of reaction mechanisms

\section{EXPERIMENTAL METHODS AND RESULTS}

The targets consisted of Yttrium foils varying in density from 5 to $11 \mathrm{mg} / \mathrm{cm}^{2}$ and were $25.4 \mathrm{~mm}$ in diameter. Aluminum foils were used as projectile energydegraders and recoil-ion catchers. The activities in the catcher foils were counted separately for use in range-ion measurements [2]. Irradiations were carried out using the Cyclograph at LLNL (the Cyclograph is now dismantled), the Van de Graaff at Los Alamos National Laboratory, and the Crocker Cyclotron at the University of California at Davis. The Cyclograph was used for most work up to 
$28 \mathrm{MeV}$. In the interest of accuracy the foil stacks contained no more than four yttrium foils and the energy range in the stacks covered but a few $\mathrm{MeV}$. In addition the energy ranges in the stacks overlapped.

TABLE 1. Possible nuclear reactions and their $Q$ values.

\begin{tabular}{|c|c|}
\hline Reaction & $\mathrm{e}(\mathrm{MeV})^{\mathrm{a}}$ \\
\hline${ }^{89} Y(d, p)^{90} Y m$ & 3.95 \\
\hline$(\mathrm{d}, \mathrm{p})^{90} \mathrm{Yg}$ & 4.63 \\
\hline${ }^{89} Y(d, 2 n)^{89} Z r$ & -5.839 \\
\hline${ }^{89} \mathrm{Y}(\mathrm{d}, 3 \mathrm{n})^{88} \mathrm{Zr}$ & -15.154 \\
\hline$(d, p 2 n)^{88 Y}$ & -13.703 \\
\hline$(d, d n)^{88 Y}$ & -11.479 \\
\hline$(d, t)^{88 Y}$ & -4.622 \\
\hline${ }^{89} \mathrm{Y}(\mathrm{p}, 2 \mathrm{p} 3 \mathrm{n})^{85} \mathrm{Srg}$ & -38.105 \\
\hline$(p, 2 d n)$ & -33.657 \\
\hline$(\mathrm{p}, \mathrm{tpn})$ & -29.624 \\
\hline$(\mathrm{p}, \mathrm{td})$ & -27.400 \\
\hline$(p, \alpha n)$ & -9.81 \\
\hline${ }^{89} \mathrm{Y}(\mathrm{d}, 2 \mathrm{p} 4 \mathrm{n})^{85} \mathrm{Srg}$ & -40.329 \\
\hline (d,dp3n) & -38.105 \\
\hline$(d, t p 2 n)$ & -31.848 \\
\hline$(d, t d n)$ & -29.624 \\
\hline$(\mathrm{d}, 2 \mathrm{t})$ & -23.367 \\
\hline$(d, \alpha 2 n)$ & -12.034 \\
\hline
\end{tabular}

a $Q$ was calculated using masses listed in Nuclear Wallet Cards [8]

The $\gamma$-ray decay rates were measured using the carefully calibrated germanium $\gamma$-ray spectrometers at the Nuclear Chemistry Division of LLNL with the spectra analyzed by use of the code GAMANAL [9]. We routinely used aluminum absorbers of $1.275 \mathrm{gm} / \mathrm{cm}^{2}$ to absorb $x$-rays, and thus largely eliminate loss due to $x-y$ coincidence summing. In addition the counter efficiencies were low enough to make $\gamma-\gamma$ summing insignificant. The target foils were of a th' $k$ kness that the resultant excitation functions had to be corrected for energy loss $(\Delta \mathrm{E})$ of the projectiles at low energies in the rising portion of the excitation functions. The details of the procedure are discussed in [1]. Briefly one expands the excitation function in a log series, piece-wise continuous. The corrected results are obtained by itteratively solving an integral equation, starting with the experimental data as the first trial solution. 
Systematic errors are estimated as follows: For the foil density measurements we have $\pm 2 \%$. Counter measurements were good to $\pm 2 \%$. Charge integration accuracy was $\pm 0.2 \%$. Energy errors at low energies were about $50 \mathrm{keV}$. For the cyclotron energy, the uncertainties were $\pm 100 \mathrm{keV}$ at $20 \mathrm{MeV}$ to $\pm 200 \mathrm{keV}$ at $40 \mathrm{MeV}$. Finally, the decay schemes are well measured and appear to offer no inconsistencies and thereby introduce negligible errors.

${ }^{89} \mathrm{Y}(\mathrm{d}, 2 \mathrm{n}){ }^{89} \mathrm{Zr}$

The decay scheme for ${ }^{89} \mathrm{Zr}$ is shown in Fig. 1 . We determined the decay of ${ }^{89} \mathrm{Zr}$ through the measurement of the $909-\mathrm{keV} \gamma$-ray. This procedure misses a small part of the cross section because of the decay from the $588-\mathrm{keV}$ isomeric state in the ${ }^{89} \mathrm{Zr}$ to ${ }^{89} \mathrm{Y}$ decay with a $4.18 \mathrm{~min}$ half life. Bissen et al. [3] have measured the groundstate and the isomeric yields separately and their ratio $\sigma_{s} / \sigma_{m}$ are taken from their Fig. 15. From our paper [1] we have

$$
\sigma_{g}=\sigma_{s a}-f \frac{\lambda_{m}}{\lambda_{m}-\lambda_{g}} \sigma_{m}
$$

where

$$
\begin{aligned}
& \sigma_{g a}=\text { measured cross section } \\
& f=\text { the fraction going by isomeric transition }=0.938
\end{aligned}
$$

Now

$$
\lambda_{m} \gg \lambda_{8}
$$$$
\sigma_{\mathrm{g}}=\sigma_{\mathrm{ga}}-f \sigma_{m}
$$

Let

$$
R_{s m}=\frac{\sigma_{s}}{\sigma_{m}}
$$

and

$$
\sigma_{T}=\sigma_{m}+\sigma_{g}
$$

so that

$$
\sigma_{\tau}=\frac{R_{g m}+1}{R_{g m}+f} \sigma_{g a}
$$

where

$$
\sigma_{T}=\text { total cross section }
$$

We find that $\sigma_{T}$ is increased by about $2 \%$ near threshold, $1.7 \%$ at $10 \mathrm{MeV}, 1.3 \%$ at 15 $\mathrm{MeV}$, and $0.7 \%$ at $25 \mathrm{MeV}$. Above $25 \mathrm{MeV}$ the correction appears to increase again. The experimental results, $\sigma_{g a}$, are given in Table 2 and plotted in Fig. 2.

\section{${ }^{89} \mathrm{Y}(\mathrm{d}, 3 \mathrm{n}){ }^{88} \mathrm{Zr}$ \& ${ }^{89} \mathrm{Y}(\mathrm{d}, \mathrm{p} 2 \mathrm{n}){ }^{88} \mathrm{Y}$}

The radioactive decay of ${ }^{88} \mathrm{Zr} \rightarrow{ }^{88 \mathrm{Y}} \rightarrow{ }^{88 \mathrm{Sr}}$ is shown in Fig. 3, updated as described in [1]. The decay of ${ }^{88} \mathrm{Zr}$ was determined through the measurement of the 392.9-keV $\gamma$-ray. The decay of $88 Y$ was determined through the measurement of the $898.03-\mathrm{keV}$ and $1836.03-\mathrm{keV} \gamma$-rays. For the amount of $88 \mathrm{Zr}$ formed during the irradiation we have 


$$
N_{10}=\frac{A_{1}}{\lambda_{1}} e^{\lambda_{1}}
$$

For the amount of ${ }^{88} Y$ formed during irradiation we have

$$
N_{20}=\frac{A_{2}}{\lambda_{2}} e^{\lambda_{2} t}-\frac{N_{10} \lambda_{1} e^{-\lambda_{1} t}}{\lambda_{2}-\lambda_{1}}\left(e^{\lambda_{2} t}-e^{\lambda_{1} t}\right)
$$

The equations are readily solved. The results for ${ }^{89} \mathrm{Y}(\mathrm{d}, 3 \mathrm{n}){ }^{88} \mathrm{Zr}$ are given in Table 3 and Fig. 4. The results for ${ }^{89} \mathrm{Y}(\mathrm{d}, \mathrm{p} 2 \mathrm{n})^{88} \mathrm{Zr}$ are given in Tables 4 and 5.

${ }^{89} \mathrm{Y}(\mathrm{p}, \alpha \mathrm{n}){ }^{85} \mathrm{Sr}^{\mathrm{m}, 8}$ and ${ }^{89} \mathrm{Y}(\mathrm{d}, \alpha 2 \mathrm{n}){ }^{85} \mathrm{Sr} \mathrm{r}^{\mathrm{m}, \mathrm{g}}$

The essential parts of the decay scheme we used are given in Fig. 6. The data are from Lederer et al. [10] and Nuclear Data Sheets. We determined the excitation functions for $85 \mathrm{Sr}$ for the metastable state at $238.61 \mathrm{keV}$ and for the ground state. In the course of our work we observed both the early decay of the 231.67- and 151.99$\mathrm{keV} \gamma$-rays and the long term decay of the 513.99-keV $\gamma$-ray. For the latter case, care was taken to use only late data relatively free of $511.00-\mathrm{keV}$ annihilation radiation from the decay of other isotopes present. Our observation of the 231.67- and 151.99$\mathrm{keV} \gamma$-rays allowed us to make a reevaluation of the isomeric decay. From our earlydecay data we found the ratio of the counting rates $C(231) / C(151)=6.809 \pm 0.068$ in which the resultant statistical error is just about the detector's relative-energyefficiency uncertainty. By equating ${ }^{85} \mathrm{Sr}$ decay activity, as determined by the respective $\gamma$ counting rates, and using the total conversion coefficients and branchings given in Fig. 6 , we obtained $I T=87.04 \pm 0.13 \%$. This is in good agreement with that previously published.

To extract the cross sections we proceed as follows: The population of the metastable state at the end of bombardment is given by:

$$
N_{10}=\frac{A_{1}}{\lambda_{1}} e^{\lambda_{1} t}
$$

The population of the ${ }^{85} \mathrm{Sr}$ ground state at the end of bombardment is given by:

$$
N_{20}=\frac{A_{2}}{\lambda_{2}} e^{\lambda_{2} t}-f_{b} \frac{N_{10} \lambda_{1} e^{-\lambda_{1} t}}{\lambda_{2}-\lambda_{1}}\left(e^{\lambda_{2} t}-e^{\lambda_{1} t}\right)
$$

Here $f_{b}=I T$ and the other terms are standard notation. We have $\lambda_{1}=14.75 \mathrm{~d}^{-1}$ and $\lambda_{2}=1.070 \times 10^{-2} \mathrm{~d}^{-1}$ and thus $\lambda_{1} \gg \lambda_{2}$. As the first step in data reduction, $N_{10}$ was obtained using averaged results. Then using data obtained from the $513.99-\mathrm{keV}$ decay for $A_{2}$, the equation for $N_{20}$ becomes: 


$$
N_{20}=\frac{A_{2}}{\lambda_{2}} e^{\lambda_{2} t}-f_{6} \frac{N_{10} \lambda_{1}}{\lambda_{2}-\lambda_{1}}
$$

The resultant cross sections are listed in Tables 5 and 6 and plotted in Figs. 7 and 8. The errors on the cross sections are predominantly statistical. The energy loss in the reported energies are the average values of the projectiles in the respective targets. No effort was made to make a correction for the finite energy loss in the foils, as we usually do at lower energies, since the corrections would be small relative to the uncertainty in energy of the particles from the accelerator.

${ }^{89} Y(d, p){ }^{90} Y^{m}$

The decay scheme [10] is given in Fig. 9. We determined the decay of the $3.19 \mathrm{~h} 7+$ state of $90 \mathrm{Y}$ through the measurement of the $479.5-$ and $202.5-\mathrm{keV} \gamma$-rays using I $\gamma=0.899$ and 0.963 respectively. The decay of $90 \mathrm{Yg}$ could be determined from the measurement of beta-decay electrons or possibly mass spectrometry, but we have not done so. The isomeric ratio $\sigma_{\mathrm{m}} / \sigma_{\mathrm{g}}$ is of some interest in nuclear modeling [6,7] and would be of interest in future work. Our results for $90 \mathrm{Ym}$ are given in Table 7 and plotted in Fig. 10 along with the results of Corazza and Nassiff [6] and Riley and Linder [7]. We note that the latter two sets of data are low with respect to ours. We expect that the difference is due to their treatment of their counting data. Riley and Linder counted their targets directly on the face of a $3 \times 3$ inch NaI(Tl) scintillation counter. They do not mention $\gamma-\gamma$ coincidence corrections; also they appear to use the decay scheme without correcting for internal electron conversion. Carazza and Nassiff also do not seem to correct for internal conversion.

\section{DISCUSSION}

We note in Fig. 2, 4, and 10 that the data of Bissem et al. are about 0.74 of ours. We attempted to find the source of this difference. The problem is important to us since our goal was to obtain data of high accuracy. Exactly the same procedures that were used for our measurement of ${ }^{89} \mathrm{Y}(\mathrm{p}, \mathrm{n})^{89} \mathrm{Zr}$ were used for ${ }^{89} \mathrm{Y}(\mathrm{d}, 2 \mathrm{n})^{89} \mathrm{Zr}$ including the same equations for analyzing the counting data. Our $(p, n)$ data [1] are supported by the work of Birattari et al. [12] and at low energies by that of Johnson et al. [13] Where could Bissem et al. have incurred an error? They used a cyclotron and thus may have had an appreciable amount of $\mathrm{H}_{2}+$ in the beam. However, any absorber before the current measurement would have made them aware of the problem. There is always the possibility that the yttrium foils were not of sufficient purity. Finally we look at the counting procedures. The irradiations were rather short, only a few minutes. Thus we expect that they counted in close geometry to their germanium $\gamma$-counter. This can introduce large error unless one is very careful, and calibrating with other source will not necessarily be adequate. Unless an absorber is used, $x$-ray $\gamma$-ray coincidence can occur and can easily reduce the efficiency by $30 \%$. 
Some preliminary modeling studies using the statistical-model code STAPRE have been carried out. The modeling follows our earlier work [1] and that on Bromine and Iodine [14] In our modeling work we take into account the breakup of the deuteron in the reaction entrance channel. Modeling of ${ }^{89} \mathrm{Y}(\mathrm{d}, 2 \mathrm{n})^{89} \mathrm{Zr}$ shows an excitation function about $30 \%$ larger than our measurements. The difference is handled using the procedures discussed in [1] and [14].

\section{ACKNOWLEDGMENTS}

This work was performed under the auspices of the U. S. Department of Energy by Lawrence Livermore National Laboratory under contract W-7405-Eng-48.

\section{REFERENCES}

[1] M. G. Mustafa, H. I. West, Jr., H. O'Brien, R. G. Lanier, M. Benamou, and T. Tamura, Phys. Rev. C 38, 1628 (1988), \& paper Two of this report.

[2] H. I. West,Jr., M. G. Mustafa, R. G. Lanier, and H. O'Brien, Phys. Rev. C 43, 1352 (1991).

[3] H. H. Bissem, R. Georgi, W. Scobel, J. Ernst, M. Kaba, J. Rama Rao, and H. Strohe, Phys. Rev. C 22, 1468 (1980).

[4] D. Degering, S. Unterricker, and W. Stolz, J. Radioanal. Chem., Lett. 127, 1 (1988).

[5] K. A. Keller, J. Lange, and H. Munzel, Q-values and excitation functions of nuclear reactions, Landolt-Bornstein, New Ser. 1, 5 (Springer-Verlag, Berlin 1973).

[6] C. Corazza and S. J. Nassiff, Rad. Chem. Acta 15, 7 (1971).

[7] C. Riley and B. Linder, Phys. Rev. 134, B559 (1964).

[8] J. K. Tuli, Nuclear. Wallet Cards, National Nuclear Data Center, Brookhaven National Laboratory, Jan (1985). Based on the mass table of A. H. Wapatra and G. Audi, Nucl. Phys. A (1984).

[9] R. Gunnink and J. B. Niday, Lawrence Livermore National Laboratory Report No. UCRL-51061, 1972 .

[10] C. M. Lederer, V. S. Shirley, E. Brown, J. N. Dairiki, R. E. Doebler, A. A. ShihabEldin, L. J. Jardine, J. K. Tuli, and A. B. Buyrin, Table of Isotopes, 7th ed. (Wiley, New York, 1978).

[11] M. Uhl and B. Ströhmaier, Institut für Radiumforschung und Kernphysik, Vienna, Report No. IRK 76/01 with Addenda, 1976 (unpublished) 
[12] C. Birattari, E. Gadioli, E. Gadioli Erba, A. M. Grassi Strini, G. Strini, and G. Tagliaferri, Nucl. Phys. A201, 579 (1973).

[13] C. H. Johnson, R. L. Kernell, and S. Ramavataram, Nucl. Phys. A107, 21 (1968).

[14] H. I. West, Jr., R. M. Nuckolls, B. Hudson, B. Ruiz, R. G. Lanier, and M. G. Mustafa, Phys. Rev. C 47, 248 (1993). 
TABLE 2. The ${ }^{89} \mathrm{Y}(\mathrm{d}, 2 \mathrm{2n}){ }^{89} \mathrm{Zr}$ excitation function

\begin{tabular}{|c|c|}
\hline E(MeV)s & ${ }^{\mathrm{a}, \mathrm{d}} \boldsymbol{g}(\mathbf{m b})_{g}$ \\
\hline 2.90 & $(7.70 \pm 0.65) \times 10^{-3}(\mathrm{a})$ \\
\hline 4.44 & $\left(1.09 \pm 0.077 \times 10^{-2}\right.$ \\
\hline 5.69 & $(8.63 \pm 0.95) \times 10^{-3}$ \\
\hline 6.62 & $15.88 \pm 050^{b}$ \\
\hline 6.67 & $19.9 \pm 0.61$ \\
\hline 7.27 & $77.3 \pm 2.3$ \\
\hline 8.08 & $190.1 \pm 5.8$ \\
\hline 8.40 & $248.7 \pm 7.5$ \\
\hline 9.38 & $400.2 \pm 12$ \\
\hline 9.89 & $478.8 \pm 14$ \\
\hline 10.49 & $555.0 \pm 17$ \\
\hline 11.37 & $664.5 \pm 21$ \\
\hline 13.08 & $800.2+25$ \\
\hline 14.64 & $921.9+29$ \\
\hline 15.97 & $982.1 \pm 31$ \\
\hline 16.29 & $952.0 \pm 41$ \\
\hline 16.67 & $944.5 \pm 41$ \\
\hline 17.50 & $951.5 \pm 41$ \\
\hline 18.14 & $976.4 \pm 43$ \\
\hline 19.84 & $907.9 \pm 39$ \\
\hline 21.10 & $780.8 \pm 34$ \\
\hline 22.78 & $611.0 \pm 27$ \\
\hline 24.36 & $478.8 \pm 15$ \\
\hline 25.74 & $399.8 \pm 14$ \\
\hline 27.57 & $231.4 \pm 8.1$ \\
\hline 29.29 & $262.8 \pm 8.2$ \\
\hline 31.13 & $225.0 \pm 8.2$ \\
\hline 32.77 & $197.0 \pm 6.3$ \\
\hline 34.23 & $180.0 \pm 5.6$ \\
\hline 35.99 & $160.9 \pm 5.3$ \\
\hline 37.73 & $145.6 \pm 5.9$ \\
\hline 39.41 & $133.6 \pm 4.5$ \\
\hline
\end{tabular}

${ }^{2}$ The first three data points below $\mathrm{E}_{\mathrm{T}}$ at 5.975 $\mathrm{MeV}$ are possibly due to breakup of the deuteron in the entrance channel with only the breakup proton being captured in a $(p, \gamma)$ reaction.

b Resolution corrections (small) were applied to this and the next three o's. A systematic error of $\pm 3 \%$ was added in quadrature to the errors on all $\sigma$ 's.
C Error in $\mathrm{E}$ at 6-10 $\mathrm{MeV} \sim \pm 0.05 \mathrm{MeV}$, at 20 $\mathrm{MeV} \sim \pm 0.10 \mathrm{MeV}$, and at $40 \mathrm{MeV} \sim \pm 0.25$ $\mathrm{MeV}$

$\mathrm{d}_{\sigma(\mathrm{mb})} \mathrm{ga}_{\mathrm{a}}$ is the measured cross section. For oT need to increase $\sigma(\mathrm{mb})$ ga by 0.7 to $2 \%$. See text.

TABLE 3. The ${ }^{89} \mathrm{Y}(\mathrm{d}, 3 \mathrm{n}){ }^{88} \mathrm{Zr}$ excitation function

\begin{tabular}{ll}
$E(\mathrm{MeV})$ & \multicolumn{1}{c}{$\sigma(\mathbf{m b})^{\mathbf{b}}$} \\
\cline { 1 - 2 } 15.496 & 0.0 \\
15.99 & $0.071 \pm 0.20$ \\
16.29 & $0.521 \pm 0.030$ \\
16.67 & $1.67 \pm 0.064$ \\
17.50 & $9.18 \pm 0.35$ \\
18.14 & $20.6 \pm 0.70$ \\
19.84 & $91.6 \pm 2.8$ \\
21.10 & $211.4 \pm 8.6$ \\
22.78 & $371.0 \pm 12$ \\
24.36 & $499.2 \pm 15$ \\
25.74 & $595.7 \pm 19$ \\
27.57 & $676.3 \pm 21$ \\
29.29 & $687.1 \pm 21$ \\
31.13 & $711.0 \pm 22$ \\
32.77 & $688.8 \pm 21$ \\
34.23 & $631.5 \pm 19$ \\
35.99 & $578.8 \pm 18$ \\
37.73 & $505.7 \pm 16$ \\
39.41 & $426.1 \pm 13$
\end{tabular}

a The data points below $20 \mathrm{MeV}$ are due to measurements at LLNL and LANL with $E$ known to about $0.05 \mathrm{MeV}$. Above $20 \mathrm{MeV}$ the measurements were made at $\mathrm{CNL}$ with $\mathrm{E}$ known to about $\pm 0.25 \mathrm{MeV}$.

b The first three data points required a small resolution correction for finite $\Delta E$. A systematic error of $\pm 3 \%$ was added in quadrature to each data point. 
TABLE 4. The ${ }^{89} Y[(d, p 2 n) \&(d, d n)]^{89} Y$ excitation function

\begin{tabular}{cc}
$\mathrm{E}(\mathrm{MeV})$ & ${ }^{\mathrm{a} \sigma}(\mathrm{mb})$ corr. \\
\hline 10.49 & $0.546 \pm 0.046$ \\
11.37 & $1.655 \pm 0.064$ \\
13.08 & $4.42 \pm 0.15$ \\
14.64 & $7.48 \pm 0.24$ \\
15.97 & $10.23 \pm 0.33$ \\
16.29 & $9.82 \pm 0.30$ \\
16.67 & $10.90 \pm 0.34$ \\
17.50 & $12.49 \pm 0.41$ \\
18.14 & $15.75 \pm 0.5$ \\
19.84 & $36.4 \pm 1.1$ \\
21.10 & $67.4 \pm 2.1$ \\
22.77 & $106.9 \pm 3.3$ \\
24.36 & $145.2 \pm 4.4$ \\
25.74 & $181.8 \pm 5.5$ \\
27.57 & $236.2 \pm 7.2$ \\
29.29 & $277.1 \pm 8.4$ \\
31.13 & $323.2 \pm 10$ \\
32.71 & $360.9 \pm 11$ \\
34.23 & $380.0 \pm 11$ \\
35.99 & $396.6 \pm 12$ \\
37.73 & $404.3 \pm 12$ \\
39.41 & $399.9 \pm 12$
\end{tabular}

a A systematic error of $\pm 3 \%$ was added in quadrature to each data point.

TABLE 5. The ${ }^{89} \mathrm{Y}(\mathrm{p}, \alpha \mathrm{n}){ }^{85} \mathrm{Sr} \mathrm{m}, \mathrm{g}$ excitation function

\begin{tabular}{llr}
$\mathrm{E}(\mathrm{MeV})$ & \multicolumn{1}{c}{${ }^{\mathrm{a}} \mathrm{\sigma}_{\mathrm{m}}$} & ${ }^{\mathrm{a}} \mathrm{\sigma}_{\mathrm{g}}$ \\
\hline 19.92 & $0.56 \pm 0.017$ & $1.07 \pm 0.15$ \\
20.87 & $0.348 \pm 0.011$ & $1.51 \pm 0.08$ \\
20.91 & $0.526 \pm 0.032$ & $2.44 \pm 0.13$ \\
22.34 & $1.62 \pm 0.078$ & $5.22 \pm 0.19$ \\
22.38 & $1.42 \pm 0.043$ & $5.04 \pm 0.17$ \\
23.85 & $2.94 \pm 0.16$ & $9.29 \pm 0.29$ \\
23.85 & $3.11 \pm 0.54$ & $8.99 \pm 0.30$ \\
25.25 & $4.06 \pm 0.12$ & $12.21 \pm 0.37$ \\
25.29 & $4.28 \pm 0.14$ & $12.67 \pm 0.40$ \\
26.67 & $5.12 \pm 0.18$ & $16.42 \pm 0.51$
\end{tabular}

$\begin{array}{lll}26.86 & 5.30 \pm 0.16 & 17.25 \pm 0.52 \\ 30.8 & 6.77 \pm 0.70 & 28.81 \pm 0.87 \\ 31.21 & 7.61 \pm 0.25 & 29.38 \pm 0.89 \\ 32.52 & 6.23 \pm 0.83 & 30.92 \pm 0.93 \\ 32.86 & 6.89 \pm 0.23 & 30.44 \pm 0.92 \\ 34.15 & 6.08 \pm 1.05 & 29.99 \pm 0.90 \\ 34.44 & 5.68 \pm J .30 & 30.10 \pm 0.91 \\ 35.73 & 4.97 \pm 0.86 & 26.78 \pm 0.81 \\ 36.47 & 3.86 \pm 0.50 & 23.01 \pm 0.70 \\ 36.72 & 4.42 \pm 0.23 & 24.18 \pm 0.74 \\ 37.93 & 2.94 \pm 0.56 & 19.24 \pm 0.58 \\ 38.17 & 3.11 \pm 0.21 & 19.36 \pm 0.60 \\ 39.37 & 2.46 \pm 0.35 & 15.85 \pm 0.48 \\ 39.56 & 2.71 \pm 0.24 & 16.54 \pm 0.52\end{array}$

a A systematic error of $\pm 3 \%$ was added in quadrature to each data point.

TABLE 6. The ${ }^{89} \mathrm{Y}(\mathrm{d}, \alpha 2 \mathrm{n}){ }^{8 \mathrm{i}} \mathrm{Sr} \mathrm{m}, \mathrm{g}$ excitation function

\begin{tabular}{lll}
$\mathrm{E}(\mathrm{MeV})$ & ${ }^{\mathrm{a}} \sigma_{\mathrm{m}}(\mathrm{mb})$ & ${ }^{\mathrm{a}}{ }^{\mathrm{a}} \sigma_{\mathrm{g}}(\mathrm{mb})$ \\
\hline 22.77 & & $0.78 \pm .31$ \\
24.36 & $0.239 \pm 0.008$ & $1.86 \pm 0.11$ \\
25.74 & $0.831 \pm 0.028$ & $6.10 \pm 0.30$ \\
27.57 & $2.236 \pm 0.073$ & $14.64 \pm 0.48$ \\
29.29 & $3.72 \pm 0.13$ & $24.37 \pm 0.76$ \\
31.13 & $5.44 \pm 0.18$ & $35.83 \pm 1.1$ \\
32.71 & $6.48 \pm 0.20$ & $44.46 \pm 1.4$ \\
34.23 & $7.16 \pm 0.24$ & $51.54 \pm 1.6$ \\
35.99 & $7.66 \pm 0.25$ & $57.79 \pm 1.8$ \\
37.73 & $7.51 \pm 0.31$ & $62.15 \pm 1.9$ \\
39.41 & $7.45 \pm 0.26$ & $62.54 \pm 1.9$
\end{tabular}

a A systematic error of $\pm 3 \%$ was added in quadrature to each data point. 
TABLE 7. The ${ }^{89} Y(d, p){ }^{90} Y^{m}$ excitation function

\begin{tabular}{cc}
$\mathrm{E}(\mathrm{MeV})$ & ${ }^{\mathrm{a}} \mathrm{\sigma}_{\mathrm{m}}(\mathrm{mb})$ \\
\hline 2.90 & $0.00974 \pm 0.00050$ \\
4.44 & $0.527 \pm 0.017$ \\
5.69 & $3.17 \pm 0.14$ \\
6.62 & $7.09 \pm 0.24$ \\
8.08 & $14.87 \pm 0.99$ \\
9.38 & $19.79 \pm 2.6$ \\
10.49 & $22.54 \pm 1.96$ \\
11.37 & $20.35 \pm 0.72$ \\
13.08 & $20.19 \pm 0.83$ \\
14.64 & $20.33 \pm 0.75$ \\
15.97 & $20.09 \pm 0.76$ \\
16.28 & $18.59 \pm 0.87$ \\
16.67 & $17.03 \pm 0.70$ \\
17.50 & $17.74 \pm 0.76$ \\
18.14 & $17.70 \pm 0.70$ \\
19.84 & $16.13 \pm 0.69$ \\
21.10 & $15.11 \pm 0.49$ \\
22.77 & $14.23 \pm 0.44$ \\
24.36 & $13.38 \pm 0.44$ \\
25.74 & $13.22 \pm 0.44$ \\
27.57 & $12.52 \pm 0.39$ \\
29.29 & $11.60 \pm 0.36$ \\
31.13 & $11.10 \pm 0.37$ \\
32.71 & $10.7 \pm 0.36$ \\
34.23 & $10.11 \pm 0.33$ \\
35.99 & $9.64 \pm 0.41$ \\
37.73 & $9.04 \pm 0.36$ \\
39.41 & $9.05 \pm 0.31$ \\
$A$ &
\end{tabular}

a A systematic error of $\pm 3 \%$ was added in quadrature to each data point. 


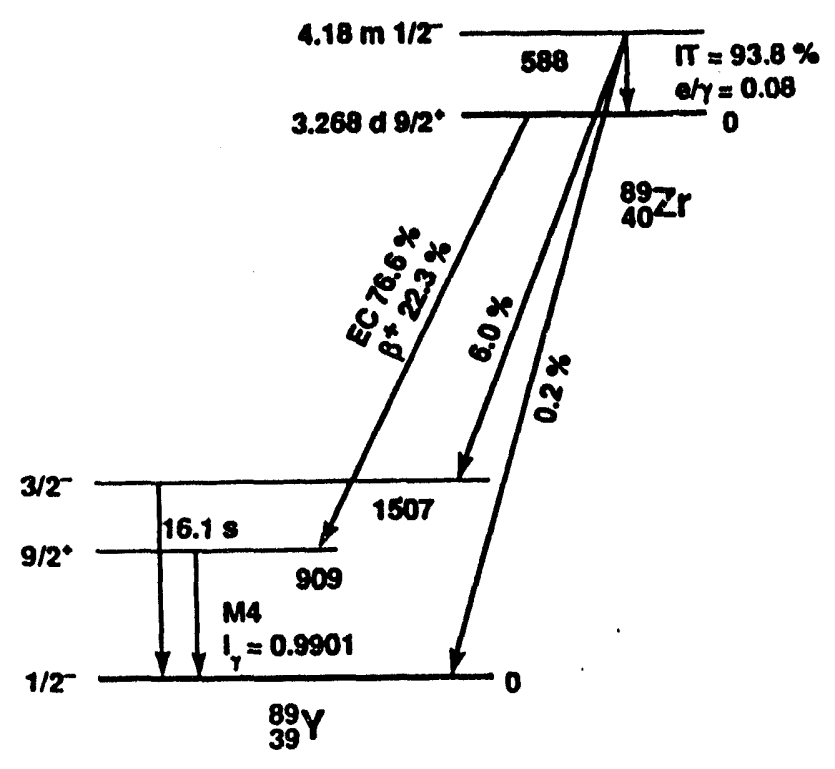

FIG. 1 The essentials of the ${ }^{89} \mathrm{Zr} \rightarrow{ }^{89} \mathrm{Y}$ decay scheme

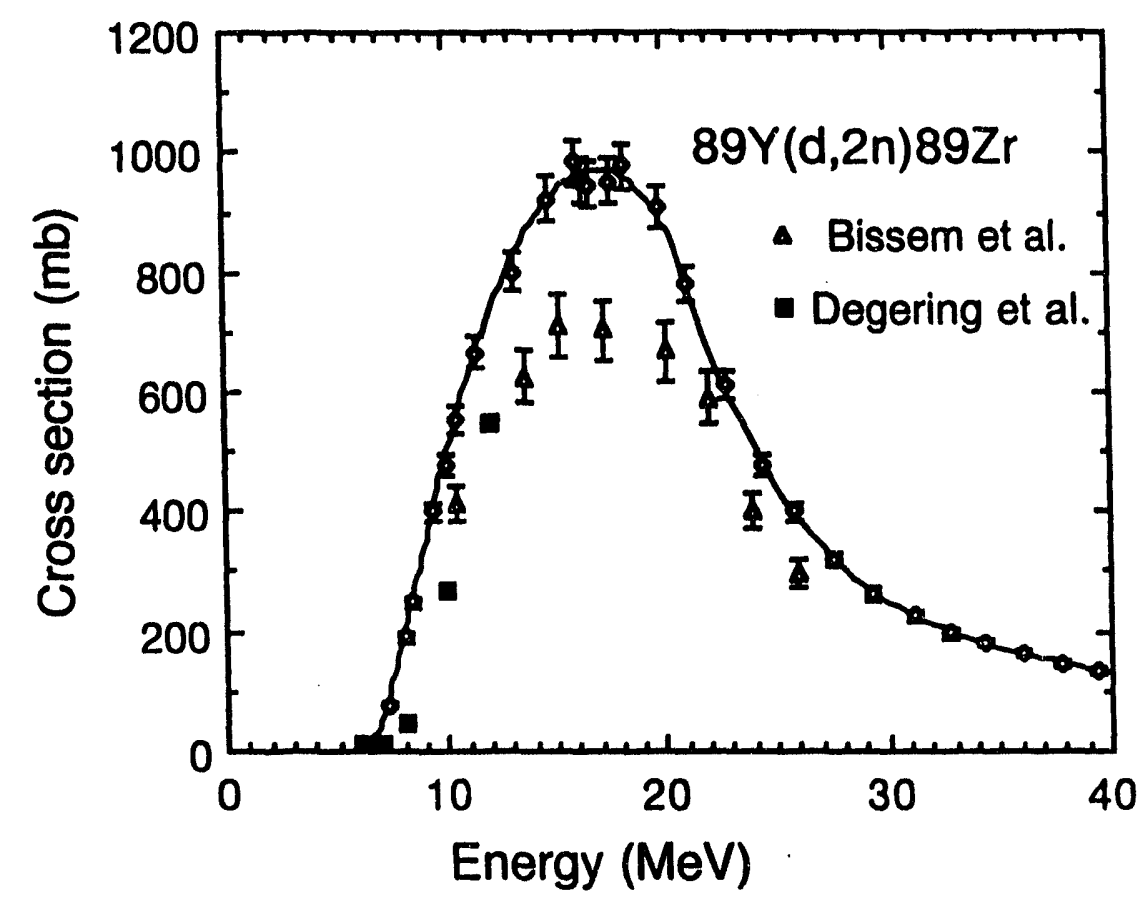

FIG. 2 The ${ }^{89} \mathrm{Y}(\mathrm{d}, 2 \mathrm{n})^{89 \mathrm{Zr}}$ excitation function The curve on this and the rest of the figures is the result of a MLR spline fit to the data points. 


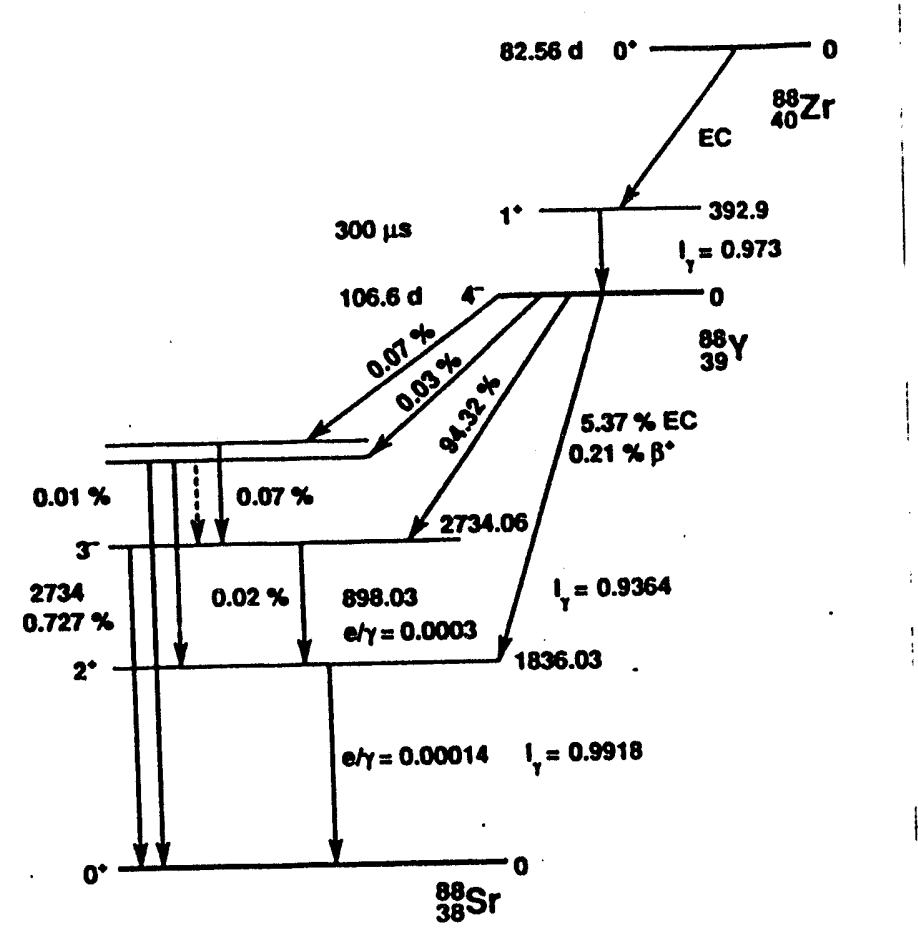

FIG. 3 The essentials of the ${ }^{88} \mathrm{Zr} \rightarrow{ }^{88} \mathrm{Y} \rightarrow^{88} \mathrm{Sr}$ decay scheme

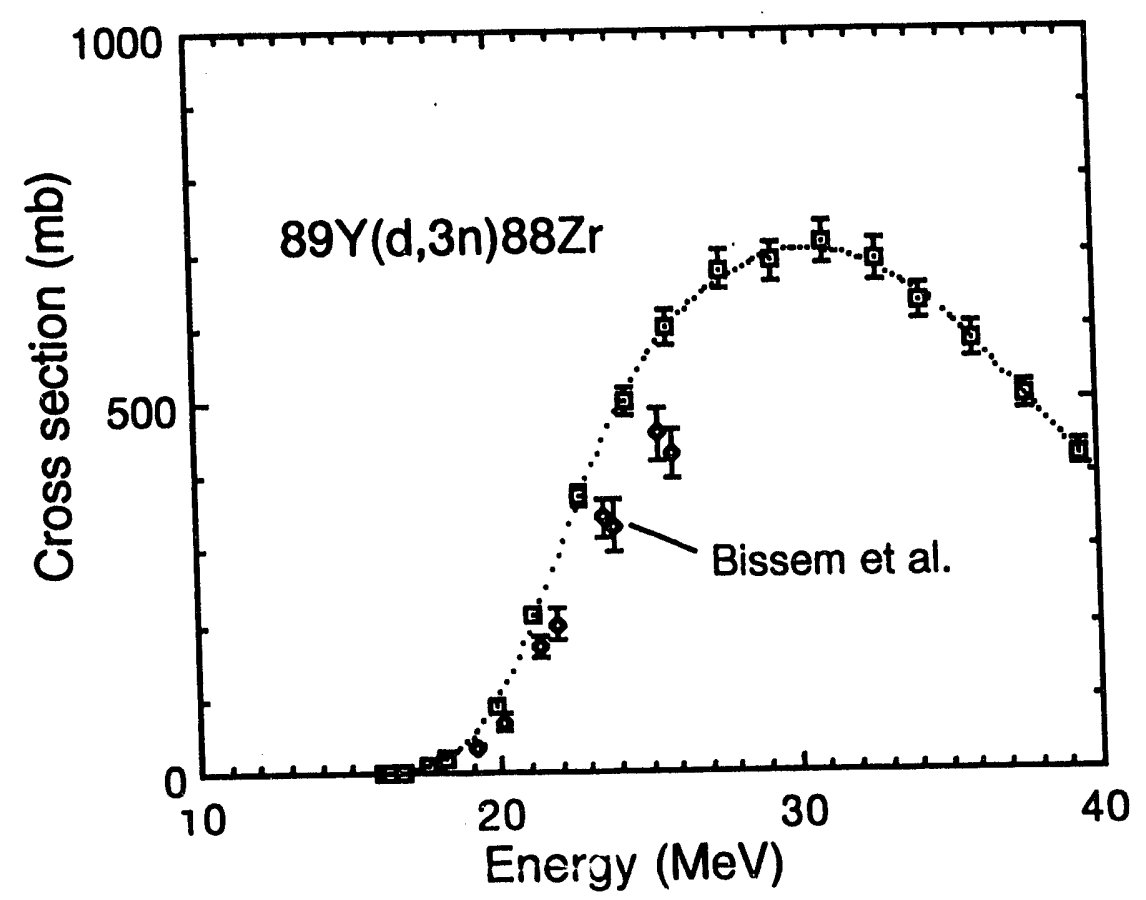

FIG. 4 The ${ }^{89} \mathrm{Y}(\mathrm{d}, 3 \mathrm{n})^{88} \mathrm{Zr}$ excitation function. 


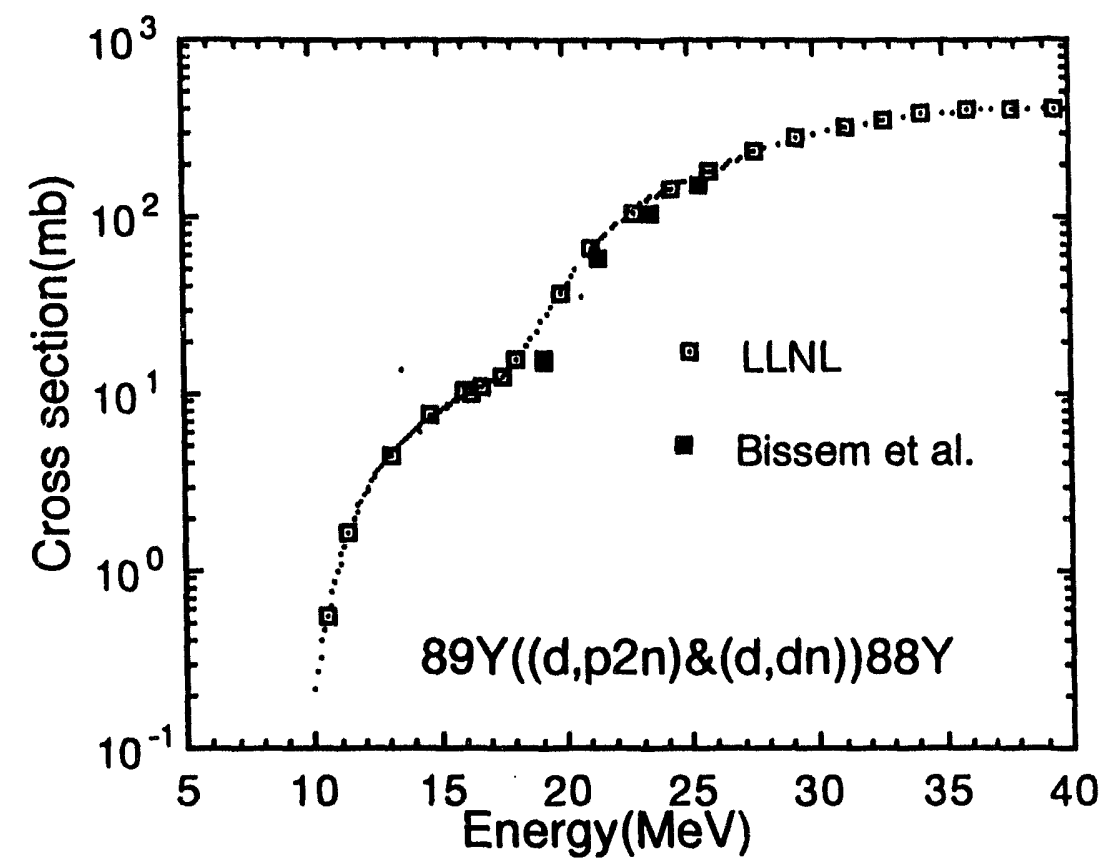

FIG. 5 The ${ }^{89} Y[(d, p 2 n) \&(d, d n)]{ }^{88} Y$ excitation function.

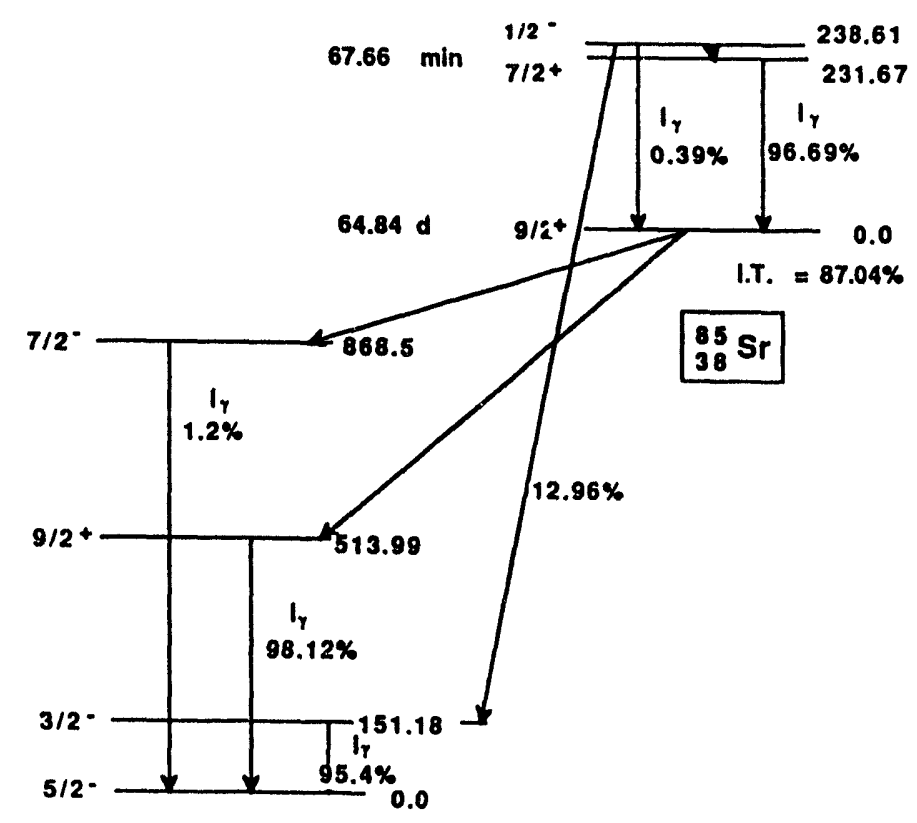

FIG. 6 The essentials of the ${ }^{85} \mathrm{Sr} \rightarrow{ }^{85} \mathrm{Rb}$ decay scheme 
FIG. 6 The essentials of the ${ }^{85} \mathrm{Sr} \rightarrow{ }^{85} \mathrm{Rb}$ decay scheme

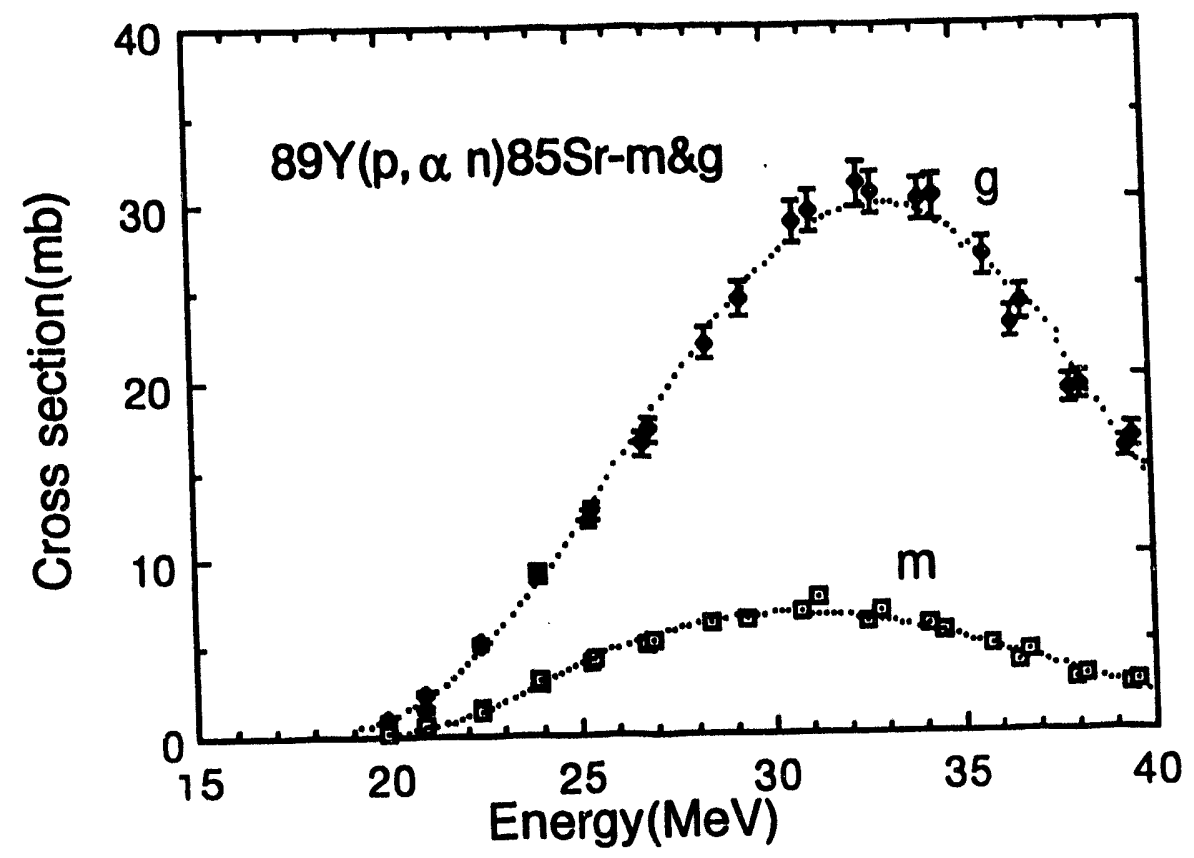

FIG. 7 The ${ }^{89} Y(p, \alpha n)^{85} \mathrm{~S} r^{m}, g$ excitation functions

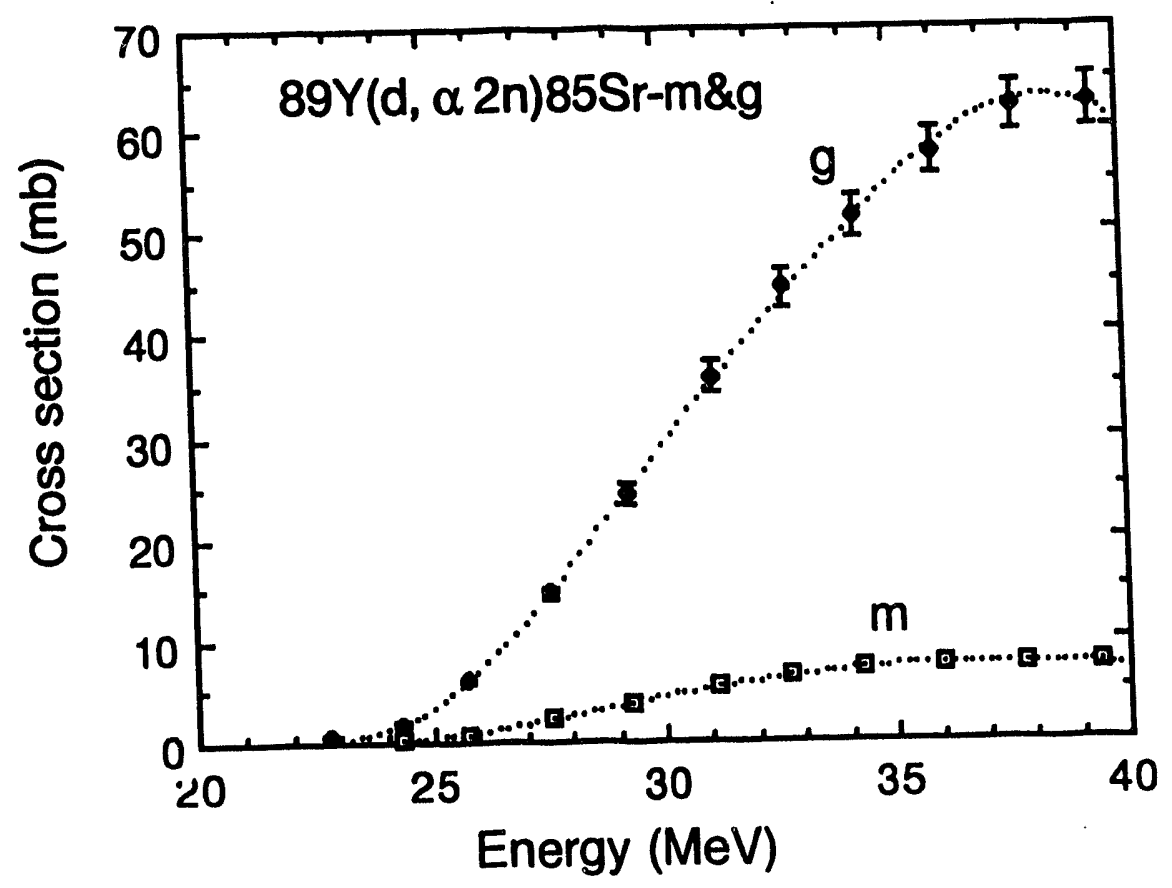

FIG. 8 The ${ }^{89} Y(d, \alpha 2 n)^{85} \mathrm{Sr}^{\mathrm{m}, g}$ excitation functions. 


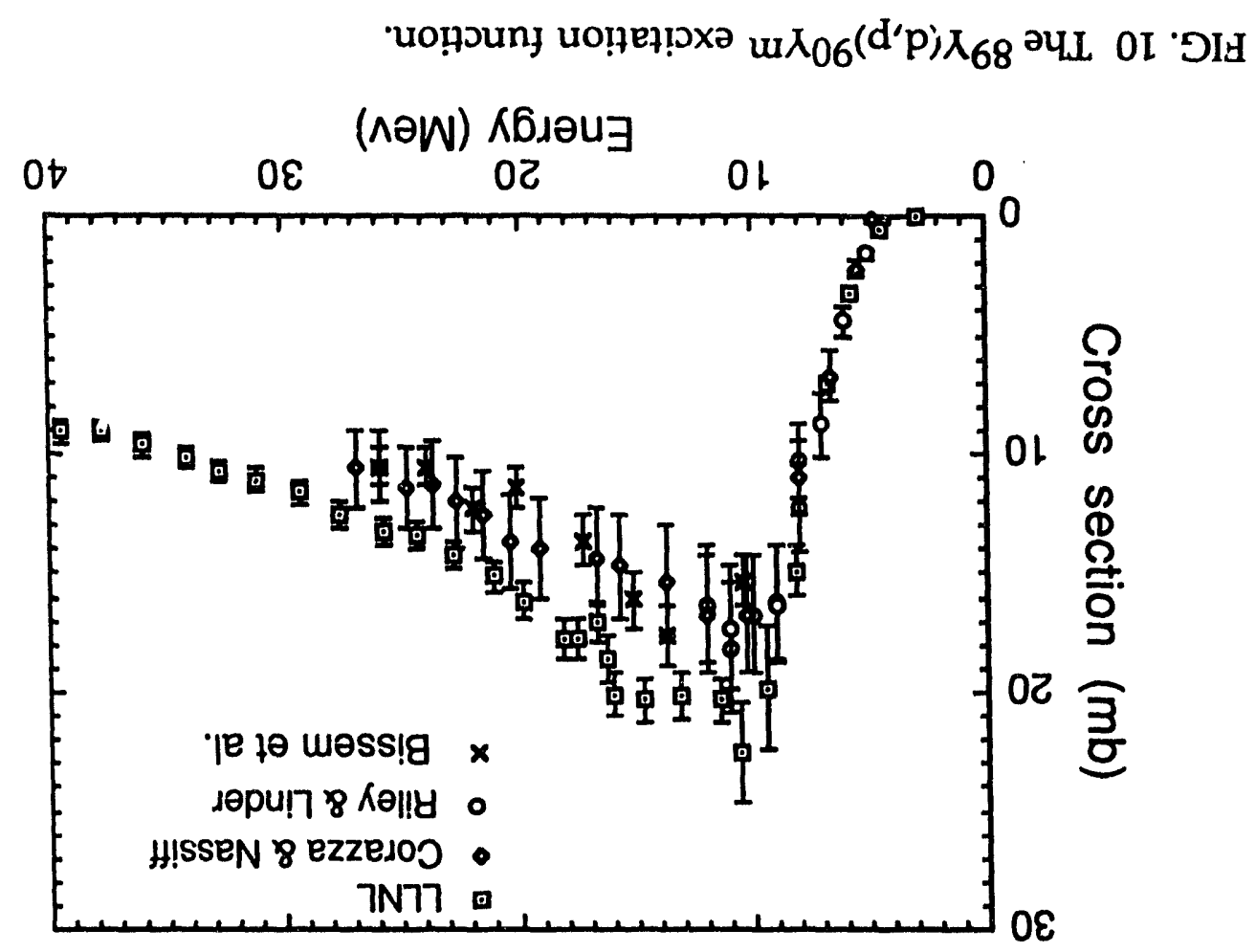

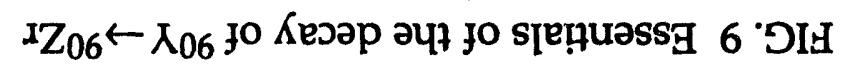

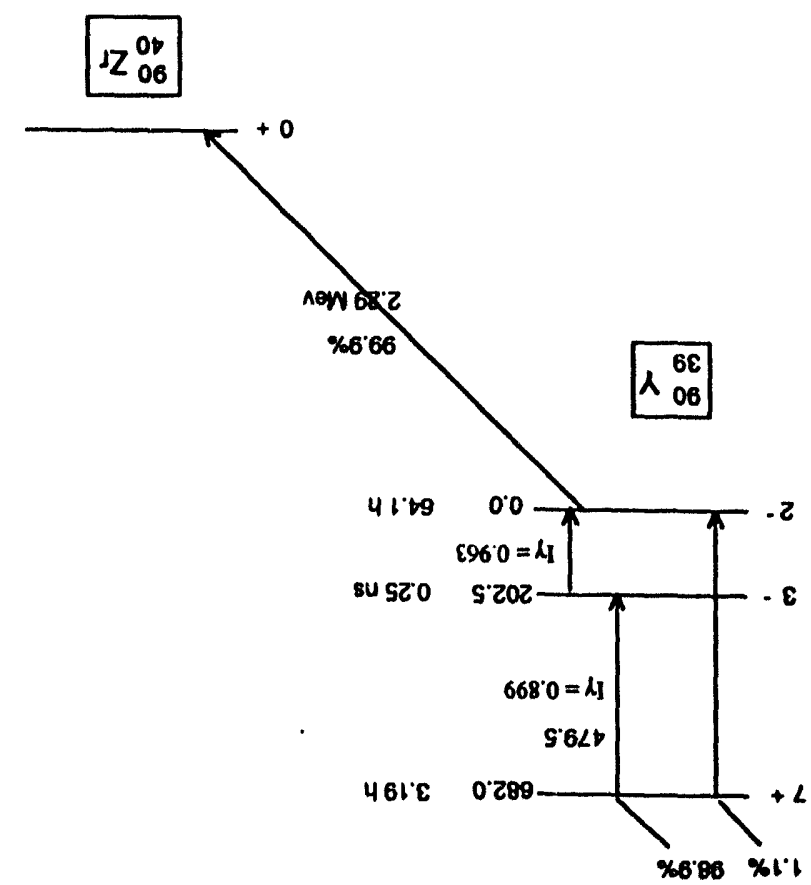




\title{
5. Measurements of the Excitation Functions of the Isobaric Chain $87 \mathrm{Y}, 87 \mathrm{Ym}, 87 \mathrm{Yg}$, and ${ }^{87} \mathrm{Srm}$
}

\author{
H. I. West, Jr., H. O'Brien, R. G. Lanier, R. J. Nagle, and M. G. Mustafa \\ Lawrence Livermore National Laboratory \\ Livermore, CA 94550 \\ INTRODUCTION
}

In the course of measuring the yttrium proton and deuteron excitation functions (for other work see [1]), we obtained the excitation functions of the isobaric decay chain ${ }^{87} \mathrm{Zr} \rightarrow{ }^{87} \mathrm{Ym}^{\mathrm{m}} \rightarrow{ }^{87} \mathrm{Yg} \rightarrow{ }^{87} \mathrm{Sr}^{\mathrm{m}} \rightarrow{ }^{87} \mathrm{Srg}$ up to projectile energies of $40 \mathrm{MeV}$. (For an earlier account see [2].) Not only do the results provide studies of higher order reactions but in studying the isobaric decay chain, commonalty in the modeling the reaction cross sections is present which will restrict the available model options.

\section{EXPERIMENTAL PROCEDURE}

We used the activated-foil method in measuring the excitation functions. Stacks of yttrium foils interspersed with aluminum ion-recoil catcher foils and energy-degrader foils were irradiated with carefully measured charges of protons and deuterons. The induced activities were counted using large-volume germanium $\gamma$-ray detectors and the spectra were analyzed using the code GAMANAL [3]. The beam charge was measured using an ORTEC 439 digital current integrator having an absolute accuracy of $\pm 0.2 \%$. The yttrium foils varied from 6 to $11 \mathrm{mg} / \mathrm{cm}^{2}$ and were uniform to at least $2 \%$. Gamma counting and analyzing are believed good to $2 \%$.

The irradiations were carried out using the Lawrence Livermore National Laboratory's Cyclograff for protons below $27 \mathrm{MeV}$ and for deuterons below $20 \mathrm{MeV}$. Energies of the projectiles entering a foil stack were known to $\pm 20 \mathrm{keV}$. However, uncertainties in determining the energy loss in the foils, etc. increased the energy uncertainties to \pm 50 to $\pm 100 \mathrm{keV}$. The measurements were extended (overlapped in energy with the earlier measurements) to $40 \mathrm{MeV}$ by irradiations at Crocker Nuclear Laboratory (CNL) at the University of Cilifornia, Davis, California. For these measurements, the limitations on the energy accuracy (measured by a time of flight method) ranged between \pm 100 to $\pm 250 \mathrm{keV}$. A detailed account of the experimental work was presented previously [2].

\section{The Decay Scheme and Data Reduction}

Figure 1 shows the essentials of the decay scheme used in analyzing the data. The goal of our analysis was to obtain the populations of the levels labeled 
$N_{1}, N_{22}, N_{21}$, and $N_{32}$ at zero time which then were used to determine cross sections. First, we discuss the essentials of the decay scheme.

The half-life of $87 \mathrm{Zr}$ was remeasured during the course of this work to obtain $1.676 \pm 0.005 \mathrm{~h}$, which compares favorably with $1.68 \mathrm{~h}$ obtained by Prestwood et al. [4]. For the half-lives of $87 \mathrm{Ym}^{\mathrm{m}}$ and $87 \mathrm{Yg}$, we used the values of $13.37 \mathrm{~h}$ and $3.317 \mathrm{~d}$, respectively, obtained by Prestwood et al. [4]. For the half-life of ${ }^{87} \mathrm{Sr}$, we used a weighted average $2.804 \pm 0.003 \mathrm{~h}$ using the values obtained by Goodier et al. [5] and Legrand et al. [6]. Theoretical conversion coefficients were used for the 381-MeV M4 transition in ${ }^{87} \mathrm{Y}$ and the $484-\mathrm{keV} \mathrm{M} 1$ and $388-\mathrm{keV}$ M4 transitions in $87 \mathrm{Sr}$. However, these M4's are well studied [7] and known to agree well with theory.

The branching to the first two excited states of ${ }^{87} \mathrm{Sr}$ was redetermined. At equilibrium in the ${ }^{87} \mathrm{Y} \rightarrow{ }^{87} \mathrm{~S} \mathrm{r}^{\mathrm{m}}$ decay we have

$$
f_{21 a}=f_{32} \frac{C r_{33}}{C r_{32}} \frac{I_{\gamma 32}}{I_{\gamma 33}} \frac{\lambda_{32}}{\lambda_{32}-\lambda_{21}}
$$

Here, $f_{21 a}$ and $f_{32}$ are the decay fractions, $\mathrm{Cr}_{32}$ and $\mathrm{Cr}_{33}$ the respective r-ray decay rates of the 388- and $484-\mathrm{keV} \gamma$ rays and $\lambda$ the decay constants. From 20 measurements of $\mathrm{Cr}_{33} / \mathrm{Cr}_{32}$ we obtained 1.098. Using $\mathrm{f}_{32}=0.997$ (Nuclear Data Sheets, quoting the work of Zoller et al. [8]) we obtain $f_{21 a}=0.9637$. Under the assumption of no transition to ${ }^{87} \mathrm{Srg}$ we obtain $f_{21 b}=0.0363$.

There is a small amount of $\beta^{+}$and EC decay from ${ }^{87} Y^{m}$ to ${ }^{87} \mathrm{Srg}$. Nuclear Data Sheets gives $0.75 \%$ for $\beta^{+}$(quoting the work of Zoller et al. [8]) and $0.82 \%$ for EC, yielding a total of $1.57 \%$. In our work we studied the decay of separated zirconium samples. Spectral data of the decay of the annihilation radiation were studied. A deconvoluted component of $13.317 \mathrm{~h}$ gave $\beta^{+}=0.79 \%$ and $0.78 \%(\approx 5 \%$ accuracy) from two different studies in good agreement with that in NDS.

In our studies, we measured the $381-\mathrm{keV} \gamma$ ray to determine the decay of ${ }^{87} \mathrm{Ym}^{\mathrm{m}}$, the $484-\mathrm{keV} \gamma$ ray for the decay of ${ }^{87} \mathrm{Yg}$, and the $388-\mathrm{keV} \gamma$ ray for the decay of ${ }^{87} \mathrm{Sr}$. For ${ }^{87} \mathrm{Zr}$ we measured the most intense $\gamma$ ray in the prompt decay, the 1227$\mathrm{keV} \gamma$ ray populating the metastable state. Lederer et al. [9] gives the intensity for the decay as $4 \%$ of the total whereas Nuclear Data Sheets [10] gives $3.03 \%$. Clearly, we needed an accurate reliable value for the decay. In the course of determining this intensity, we studied the decay scheme further to obtain the relative intensities of the $\gamma$ rays (other than the metastable decay) to that of the $1227-\mathrm{keV}$ transition (the details of this study are reported elsewhere in this document [11]). Then, from zirconium fractions, chemically separated from cyclotron targets, we observed the ingrowth of the metastable state and the other states down the decay chain. The data sets consisted of 31 countings for each of two samples covering the period from $10 \mathrm{~min}$ to 10 days after separation. 
The value obtained for the $1227-\mathrm{keV} \gamma$ ray is $3.36 \%$ per $87 \mathrm{Zr}$ decay. The procedure made use of a chi-squared analysis of the data fit as is brought out later. The data analysis was sensitive to variations in the decay branch to variations of $\pm 0.5 \%$ of this value. The absolute accuracy is believed good to better than $\pm 2 \%$. The population of the levels in ${ }^{87} Y$, indicated schematically along with that for ${ }^{87} \mathrm{Ym}^{\mathrm{m}}$ were established by the $1227-\mathrm{keV}$-ray intensity using our knowledge of the decay scheme. Any anticipated changes in the decay scheme will not change the results of the present analysis. The equations used in this evaluation and the general data analysis are now developed.

The differential equations describing the decays of $N_{1}, N_{22}, N_{21}$, and $N_{32}$ are:

$$
\begin{aligned}
& \frac{d N_{1}}{d t}=-\lambda_{1} N_{1} \\
& \frac{d N_{22}}{d t}=\left(f_{1 a}+f_{1 b}+f_{1 d}\right) \lambda_{1} N_{1}-\lambda_{22} N_{22} \\
& \frac{d N_{21}}{d t}=f_{1 c} \lambda N_{1}+f_{22} \lambda_{22} N_{22}-\lambda_{21} N_{21} \\
& \frac{d N_{32}}{d t}=\left(f_{21 a}+f_{21 b}\right) \lambda_{21} N_{21}-\lambda_{32} N_{32}
\end{aligned}
$$

The values at the end of bombardment are $N_{10}, N_{220}, N_{210}$, and $N_{320}$. In terms of these values, the solutions to the equations are:

where:

$$
\begin{aligned}
N_{1}= & N_{10} e^{-\lambda_{1} t} \\
N_{22}= & N_{10} C_{1} F_{1}^{22}(t)+N_{220} e^{-\lambda_{22} t} \\
N_{21}= & N_{10}\left[C_{2} F_{1}^{21}(t)-C_{1} C_{3} F_{22}^{21}(t)\right]+N_{220} C_{3} F_{22}^{21}(t)+N_{210} e^{-\lambda_{22} t} \\
N_{32}= & N_{10}\left[C_{2} C_{4} F_{2}^{32}(t)-C_{1} C_{3} C_{5} F_{22}^{32}(t)+C_{6}\left(C_{1} C_{3}-C_{2}\right) F_{21}^{22}(t)\right]+ \\
& N_{220}\left[C_{3} C_{5} F_{22}^{32}(t)-C_{3} C_{6} F_{21}^{32}(t)\right]+N_{210} C_{6} F_{21}^{32}(t)+N_{320} e^{-\lambda_{32} t}
\end{aligned}
$$

$$
F_{i}^{j}=e^{-\lambda_{1} t}-e^{-\lambda_{j} t}
$$

Here $i$ and $j$ take on the indicated values in the $F$ terms and 


$$
\begin{aligned}
& C_{1}=\left(f_{1 a}+f_{1 b}+f_{1 d}\right) \frac{\lambda_{1}}{\lambda_{22}-\lambda_{1}} \\
& C_{2}=\frac{\left(f_{1 c} \lambda_{1}+f_{23} \lambda_{23} C_{1}\right)}{\lambda_{21}-\lambda_{1}} \\
& C_{3}=f_{22} \frac{\lambda_{22}}{\lambda_{21}-\lambda_{22}} \\
& C_{4}=\left(f_{21 a}+f_{21 b}\right) \frac{\lambda_{21}}{\lambda_{32}-\lambda_{1}} \\
& C_{5}=\left(f_{21 a}+f_{21 b}\right) \frac{\lambda_{21}}{\lambda_{32}-\lambda_{22}} \\
& C_{6}=\left(f_{21 a}+f_{21 b}\right) \frac{\lambda_{21}}{\lambda_{32}-\lambda_{21}}
\end{aligned}
$$

Experimentally, the activity $A$ is given by

$$
A=\frac{C r}{f_{b} I_{r}}
$$

in which $f_{b}$ is the decay fraction of the parent nucleus and $I_{y}$ the fraction of the transition going by $\gamma$ rays i.e. $\gamma /(\gamma+e)$ (Note that $t_{\gamma}$ used in Lederer et al. [9] usually equals the $f_{b} I_{\gamma}$ used here. Often the counting periods were long, relative to some of the half-lives, hence the effective experimental activities are integrals over the counting period and analytically must be represented by integrals over the $N_{1}, N_{22}, N_{21}$, and $N_{32}$ equations, that is

$$
A_{i}=\left[\frac{1}{f_{b} I_{y}} \frac{1}{t_{2}-t_{1}} \int_{t_{1}}^{t_{2}} \operatorname{Cr}(t) d t\right]_{i}=\frac{\lambda_{i}}{t_{2}-t_{1}} \int_{t_{1}}^{t_{2}} N_{i} d t
$$

We have a new set of four equations which with a change in notation are written as 


$$
\begin{aligned}
& \frac{y_{i}^{a}}{\sigma_{i}^{d}}=\frac{1}{\sigma_{i}^{d}}\left(x_{i}^{a} N_{1}\right) \\
& \frac{y_{i}^{b}}{\sigma_{i}^{b}}=\frac{1}{\sigma_{i}^{b}}\left(x_{i 1}^{b} N_{1}+x_{i 2}^{b} N_{2}\right) \\
& \frac{y_{i}^{c}}{\sigma_{i}^{c}}=\frac{1}{\sigma_{i}^{c}}\left(x_{i 1}^{c} N_{1}+x_{i 2}^{c} N_{2}+x_{i 3}^{c} N_{3}\right) \\
& \frac{y_{i}^{d}}{\sigma_{i}^{d}}=\frac{1}{\sigma_{i}^{d}}\left(x_{i 1}^{d} N_{1}+x_{i 2}^{d} N_{2}+x_{i 3}^{d} N_{3}+x_{i}^{d} N_{4}\right)
\end{aligned}
$$

Here, yi replaces the experimental $A_{i}$, and the $x_{i}$ are the integrals over the time dependent terms. $N_{1}$ through $N_{1}$ are the respective values of the numbers of nuclei at the end of bombardment, and the $\sigma_{i}$ are the variances of the counting rates. The gamma ray analysis code GAMANA* [3] gives the percentage weights which were essential to the success of the data analysis. Note that for each counting period (i) we have a set of four equations $a, b, c$, and $d$. In principle, a set can be solved immediately. However, we found it easier to keep track of the errors by using the method of least squares. We can define a term $S$, which we wish to minimize as

$$
S=\sum_{i=1}^{i \approx m} w_{i}^{a}\left(x_{i}^{a} N_{1}-y_{i}^{a}\right)^{2}+w_{i}^{b}\left(x_{i 1}^{b} N_{1}+x_{i 2}^{b} N_{2}-y_{i}^{b}\right)^{2}+e t c .
$$

in which the weight $w_{i}=\frac{1}{\sigma_{1}}$. One proceeds by obtaining

$$
\frac{\partial S}{\partial N_{1}}, \frac{\partial S}{\partial N_{2}}, \frac{\partial S}{\partial N_{3}}, \text { and } \frac{\partial S}{\partial N_{4}}
$$

and setting each equal to zero. This gives the normal equations. However, our set of weighted equations can be solved by the usual methods of least squares. The computer routine we used returns $\left(X^{t} X\right)_{k t}^{-1}$, in which $X$ is the matrix of the $x_{i} / \sigma_{l}$ terms and $X^{t}$ the transpose. The goodness of fit for: $N$ can be calculated from

$$
\sigma_{N K}=\sqrt{\frac{\left(X^{i} X\right)_{k K}^{-1}}{m-k} \sum_{i=1}^{i=m}\left(y_{i}-y\right)^{2}}
$$

in which $k$ refers to $a, b, c$, and $d$.

For parameter studies we calculated 


$$
\overline{\mathbf{X}}_{k}^{2}=\sum \frac{1}{\sigma_{i k}} \frac{\left(y_{i k}-\bar{y}_{k}\right)^{2}}{m-k}
$$

which is close to 1.0 for a well-behaved set of data. For checking individual data entries, we obtained

$$
\mathrm{X}_{k}^{2}=\frac{1}{\sigma_{i k}}\left(y_{i k}-\bar{y}_{k}\right)^{2}
$$

The chi-squared analysis was quite useful in weeding out bad data. We used data from several different detector systems. Thus, even though most of the counting data had a statistical accuracy of a fraction of one percent, calibration inaccuracies were present which affected the chi-squared analysis. The calibrations were supposed to be good to about $2 \%$. However, we usually found that adding $1 \%$ in quadrature was ample to yield a good chi-squared value.

The coding was set up so that any contiguous set of equations could be used in the analysis. Of course, constants had to be imputed in place of the earlier equations in the sequence if the corresponding equations were not used in the analysis. The equations gave the number of nuclei at the end of bombardment. In some cases there was considerable ingrowth during the period of bombardment $(\sim 20 \mathrm{~min})$. To correct for this, the exact differential equations were solved and implemented into the coding.

\section{RESULTS}

The proton cross sections are given in Table 1 and the deuteron data given in Table 2. The respective proton and deutron data are plotted in Fig. 2 and Fig. 3. The errors given in the tables are a combination of effects. First we have the errors returned by the code which are basically statistical. To allow for calibration uncertainties between gamma-ray counters, we added $1.0 \%$ in quadrature to the primary statistical errors and in that sense a systematic error was made to look like a statistical error. Errors due to foil nonuniformities appeared in the data and effects greater than $2 \%$ were corrected by intercomparing the foils by means of $x$-ray fluorescent analysis. In addition, a $2 \%$ uncertainity was allowed for the absolute calibration and another $2 \%$ was allowed for decay-scheme uncertainities. All of these errors were added in quadrature.

Certain features are immediately apparent in the data. (Refer to Table 3 for $Q$ values calculated from masses listed in [12].) The ${ }^{87} \mathrm{Yg}^{\mathrm{g}}$ and ${ }^{87} \mathrm{Ym}$ proton data in Fig. 2 clearly show deuteron exit channels at low energies as shown by the shape of the excitation function in comparison to the threshold energies. It would also appear that for at least $87 \mathrm{Yg}$, a small triton channel had opened up. There is no evidence in the ${ }^{87} \mathrm{Sr}^{\mathrm{m}}$ data for a deuteron exit channel. The deuteron data ${ }^{87} \mathrm{Yg}$ and ${ }^{87} \mathrm{Ym}^{\mathrm{m}}$ in Fig. 3 also show marked evidence of the deuteron exit channel. For the ${ }^{87} \mathrm{Sr}^{\mathrm{m}}$ data, the 
deuteron exit channels probably play an important role; however, the low-energy cross section is dominated by alpha emission.

\section{ACKNOWLEDGMENTS}

This work was performed under the auspices of the U.S. Department of Energy by Lawrence Livermore National Laboratory under contract W-7405-Eng-48.

\section{REFERENCES}

[1] M. G. Mustafa, H. I. West, Jr., H. O'Brien, R. G. Lanier, M. Benhamou, and T. Tamura, Phys. Rev. C 38, 1624 (1988).

[2] H. I. West, Jr., R. G. Lanier, M. G. Mustafa, H. A. O’Brien, and R. J. Nagle, Nuclear Chemistry Division FY87 Annual Report, Lawrence Livermore National Laboratory, UCAR 10062/87, 2-34 (1987).

[3] R. Gunnink and J. B. Niday, Lawrence Livermore National Laboratory, Livermore, CA, UCRL 51061 (1972).

[4] R. J. Prestwood, K. W. Thomas, D. R. Nethaway, and N. Smith, Phys. Rev. C 29, 805 (1984).

[5] I. W. Goodier, F. H. Hughes, and M. J. Woods, Int. J. Appl. Rad and Isotope. 19, 795 (1968).

[6] J. Legrand, F. Lagoutine, and J. P. Bretone, Int. J. Appl. Rad and Isotopes 21, 139 (1970).

[7] L. G. Mann and P. Axel, Phys. Rev. 84, 221 (1951).

[8] W. H. Zoller, W. B. Walters, and C. D. Coryell, Phys. Rev. 185, 1537 (1969).

[9] Table of Isotopes, John Wiley and Sons, Inc., New York, ed. C. M. Lederer and V. S. Shirley (1978).

[10] P. Luksch and J. W. Tepel, Nucl. Data Sheets 27, No. 3, draw. 9 (1979).

[11] H. I. West, Jr., and R. J. Nagle, Paper 6 of this report.

[12] J. K. Tuli, Nuclear Wallet Cards, published by National Nuclear Data Center, Brookhaven National Laboratory (1985). 
TABLE 1. Proton excitation functions

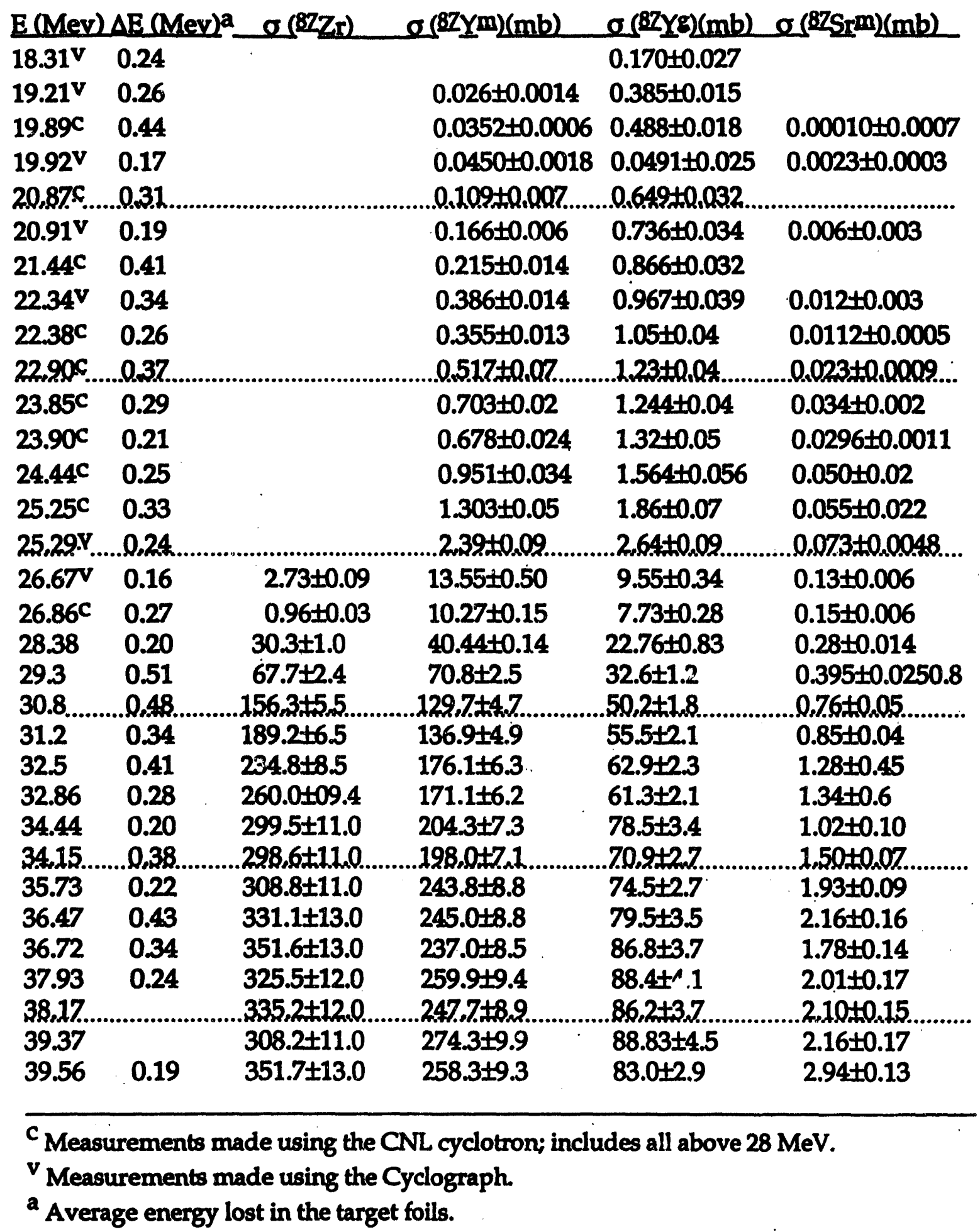


TABLE 2. Deuteron excitation functions

\begin{tabular}{|c|c|c|c|c|c|}
\hline $\mathrm{E}(\mathrm{Me}$ & $\triangle \mathrm{E}(\mathrm{Me}$ & $\sigma(8 \mathrm{z} \mathrm{Zr})(\mathrm{mb})$ & $\sigma(87 \underline{Y m})(m b)$ & $\sigma(87 \underline{Y g})(\mathrm{mb})$ & $\sigma(87 \mathrm{Sr} m)(\mathrm{mb})$ \\
\hline 2.90 & & & & & $0.00026 \pm 0.00011$ \\
\hline 4.44 & 0.70 & & & & $0.0284 \pm 0.0013$ \\
\hline 5.69 & 0.61 & & & & $0.215 \pm .008$ \\
\hline 6.67 & 0.26 & & & & $0.585 \pm 0.027$ \\
\hline 7.27. & .0 .27$. & & & & $0.820 \pm 0.045$ \\
\hline 8.40 & 0.21 & & & & $1.51 \pm 0.074$ \\
\hline 9.89 & 0.23 & & & & $1.95 \pm 0.12$ \\
\hline 11.37 & 0.47 & & & & $2.83 \pm 0.11$ \\
\hline 13.08 & 0.45 & & & & $3.00 \pm 0.12$ \\
\hline 14.63. & .0 .34 & & & & $3,00 \pm 0.11$ \\
\hline 16.26 & 0.43 & & & & $2.63 \pm 0.11$ \\
\hline 18.14 & 0.30 & & & & $2.49 \pm 0.16$ \\
\hline 19.84 & 0.32 & & & & $2.37 \pm 0.12$ \\
\hline 21.10 & 0.334 & & & $0.310 \pm 0.22$ & $2.08 \pm 0.07$ \\
\hline 22,77. & $.0,31 \ldots$ & & $.0,359 \pm 0.038$ & $0.062+0.061$ & $1.98 \pm 0.07$ \\
\hline 24.36 & 0.29 & & $0.740 \pm 0.066$ & $0.43 \pm 0.20$ & $1.80 \pm 0.06$ \\
\hline 25.74 & 0.33 & & $1.29 \pm 0.06$ & $0.70 \pm 0.08$ & $1.67 \pm 0.06$ \\
\hline 27.57 & 0.28 & & $2.21 \pm 0.09$ & $1.11 \pm 0.12$ & $1.59 \pm 0.06$ \\
\hline 29.29 & 0.22 & & $3.95 \pm 0.14$ & $1.84 \pm 0.09$ & $1.47 \pm 0.05$ \\
\hline 31.13. & 0.31 & ...3.9.5t0.28 & $12.36 \pm 0.50$ & $.5 .17 . \pm 0.29$. & $.1 .40 \pm 0.05 \ldots$ \\
\hline 32.71 & 0.25 & $16.24 \pm 0.57$ & $30.91 \pm 1.1$ & $9.90 \pm 0.58$ & $1.40 \pm 0.05$ \\
\hline 34.23 & 0.20 & $42.02 \pm 01.5$ & $56.80 \pm 2.0$ & $14.79 \pm .61$ & $1.46 \pm 0.05$ \\
\hline 35.99 & 0.33 & $81.8 \pm 2.9$ & $95.2 \pm 3.4$ & $24.0 \pm 1.2$ & $1.53 \pm 0.06$ \\
\hline 37.73 & 0.28 & $128.1 \pm 4.5$ & $140.6 \pm 5.3$ & $35.3 \pm 2.2$ & $1.47 \pm 0.09$ \\
\hline 39.41 & 0.21 & $182.5 \pm 6.4$ & $178.0 \pm 6.3$ & $34.7 \pm 1.8$ & $1.97 \pm 0.08$ \\
\hline
\end{tabular}

TABLE 3. $Q$ values and thresholds of possible reactions [12]

\begin{tabular}{|c|c|c|}
\hline Reaction & O value $(\mathrm{MeV})$ & Threshold (MeV) \\
\hline${ }^{89} Y(p, 3 n)^{87} \mathrm{Zr}$ & -25.278 & 25.56 \\
\hline,$p 2 n)^{87 Y}$ & -20.830 & 21.06 \\
\hline ,dn $)^{87} Y$ & -18.606 & 18.82 \\
\hline , t) $87 Y$ & -12.349 & 12.50 \\
\hline , $2 n)^{87} Y^{m}$ & -21.211 & 21.45 \\
\hline ,dn) $)^{87} \mathbf{Y}^{\mathrm{m}}$ & -18.987 & 19.20 \\
\hline,$t)^{87} Y^{m}$ & -12.730 & 12.87 \\
\hline,$d p)^{87} \mathrm{Sr}^{\mathrm{m}}$ & -16.351 & 16.54 \\
\hline${ }^{89} \mathrm{Y}(\mathrm{d}, 4 \mathrm{n})^{87} \mathrm{Zr}$ & -27.502 & 28.12 \\
\hline,$p 3 n)^{87} Y$ & -23.054 & 23.57 \\
\hline
\end{tabular}


TABLE 3. (Continued)

\begin{tabular}{|c|c|c|}
\hline Reaction & O value (MeV) & Threshold (MeV) \\
\hline,$d 2 n)^{87 Y}$ & -20.830 & 21.30 \\
\hline th $)^{87} Y$ & -1.437 & 1.47 \\
\hline ,p3n) ${ }^{87} Y^{m}$ & -23.435 & 23.96 \\
\hline, $\mathrm{d} 2 \mathrm{n})^{87} \mathrm{Y}^{\mathrm{m}}$ & -21.211 & 21.69 \\
\hline , th $)^{87} Y^{m}$ & -1.818 & 1.86 \\
\hline ,2p2n)E7S $\mathrm{r}^{\mathrm{m}}$ & -20.799 & 21.27 \\
\hline dpn $)^{87} \mathrm{Sr}^{m}$ & -18.575 & 18.99 \\
\hline $2 \mathrm{~d})^{87} \mathrm{Sr}^{\mathrm{m}}$ & -16.351 & 16.72 \\
\hline,$\alpha)^{87} \mathrm{Srm}^{m}$ & 7.496 & \\
\hline
\end{tabular}

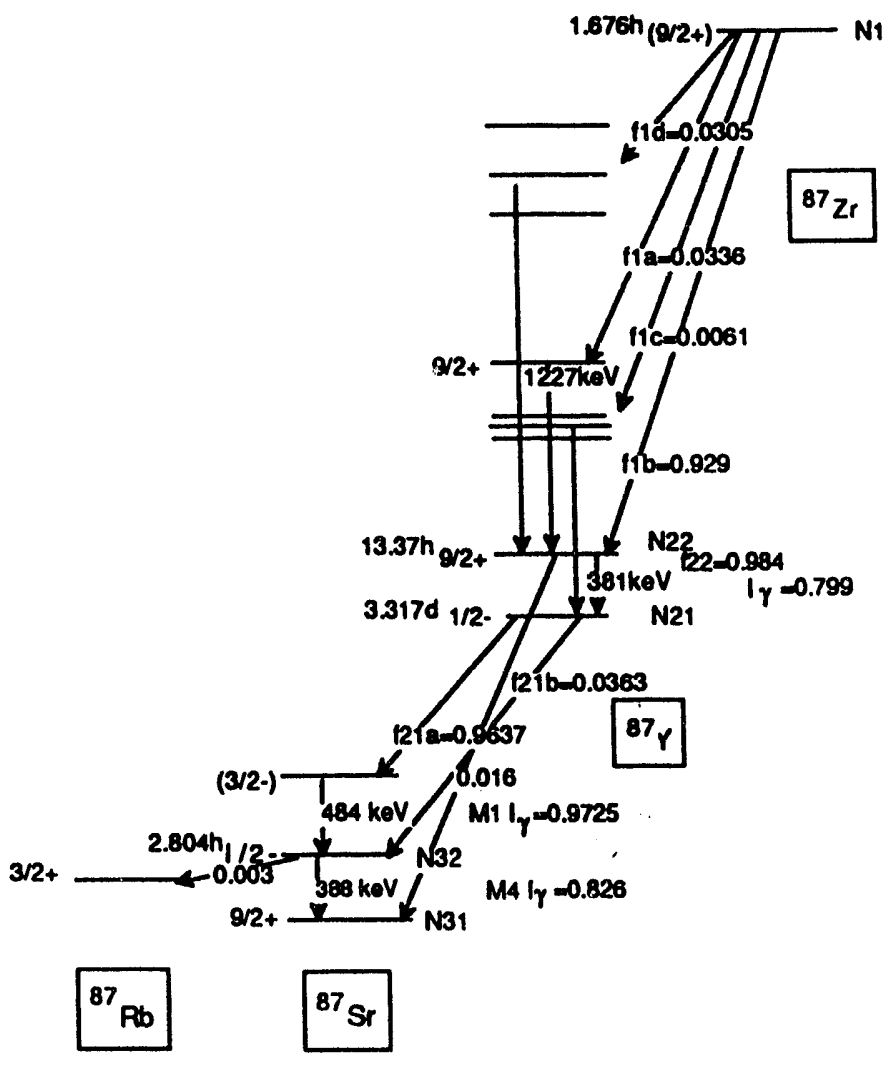

Fig. 1. The ${ }^{87} \mathrm{Zr} \rightarrow{ }^{87} \mathrm{Y} \rightarrow{ }^{87} \mathrm{Sr}$ decay scheme. 


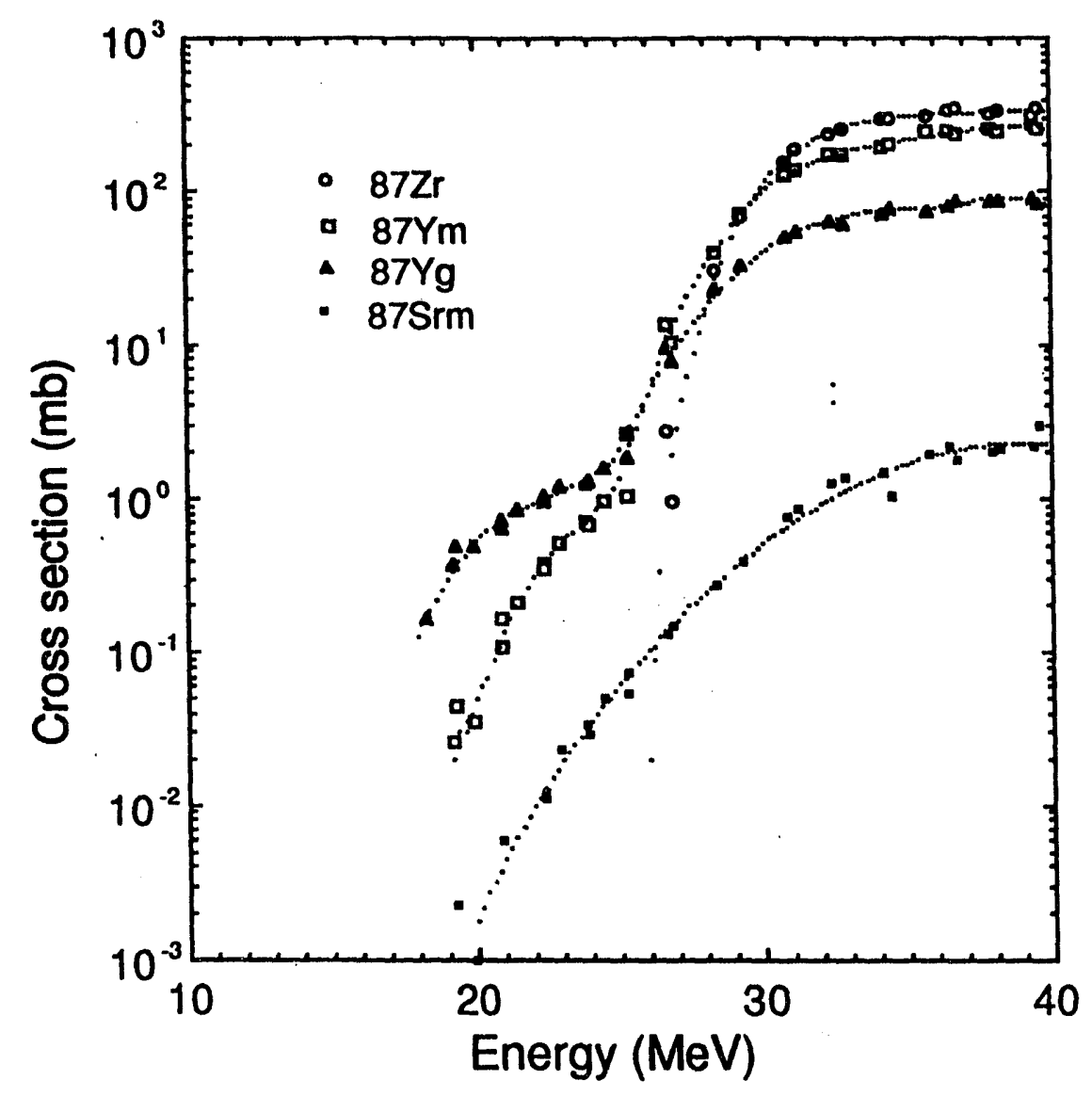

Fig. 2. Results for ${ }^{87} \mathrm{Zr} \rightarrow{ }^{87} \mathrm{Y} \rightarrow{ }^{87} \mathrm{Sr}$ population and decay after proton irradiation 


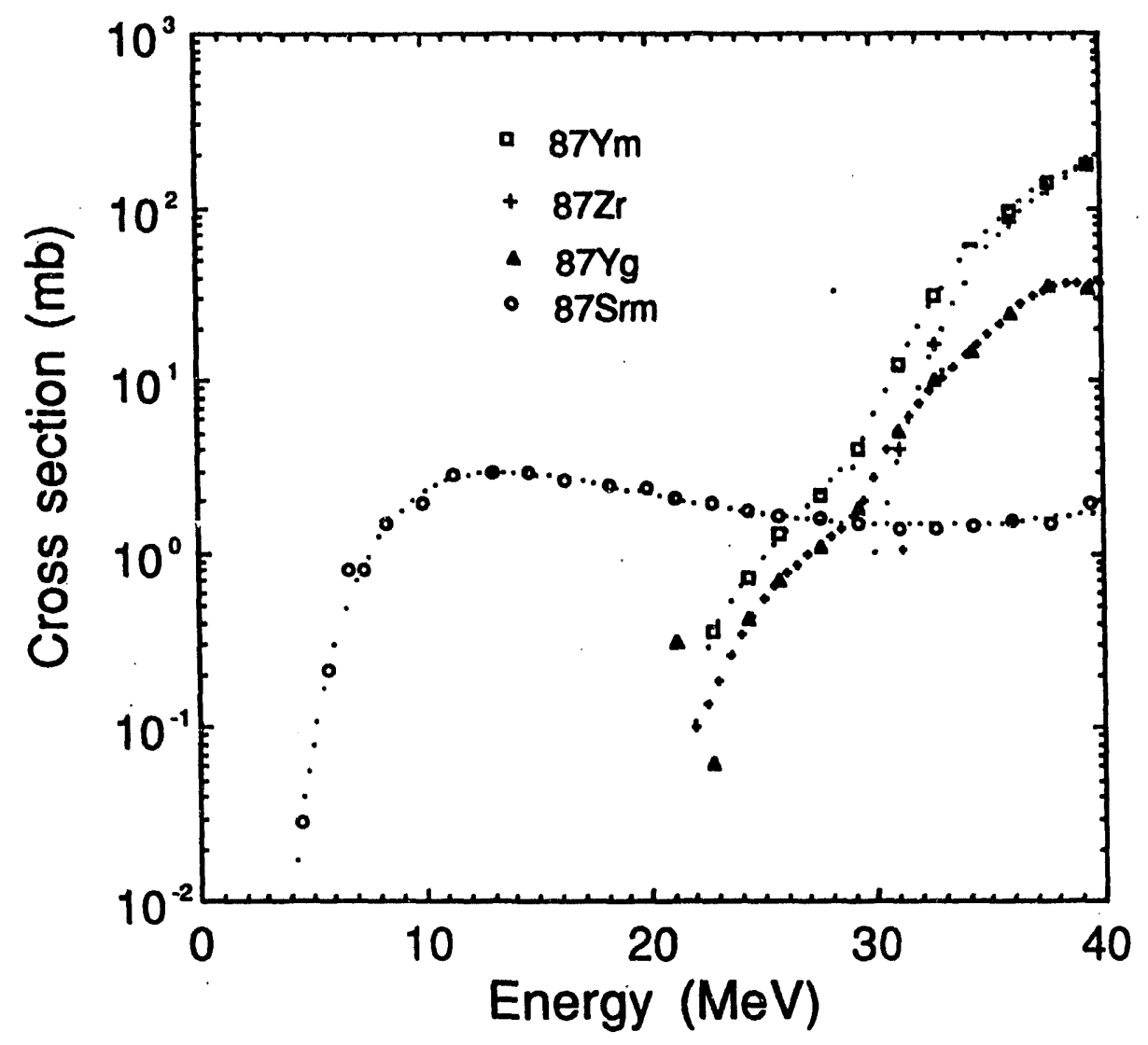

Fig. 3. Results for ${ }^{87} \mathrm{Zr} \rightarrow{ }^{87} \mathrm{Y} \rightarrow{ }^{87} \mathrm{Sr}$ population and decay after deuteron irradiation 
6. Levels in $87 \mathrm{Y}$ Observed in the Decay of $87 \mathrm{Zr}$

\author{
H. I. West, Jr. and R. J. Nagle \\ Lawrence Livermore National Laboratory, \\ Livermore, California 94550
}

\title{
INTRODUCTION
}

During the study of the excitation functions of the reactions produced by protons and deuterons of energies up to $40 \mathrm{MeV}$ on ${ }^{89} \mathrm{Y}$, we studied the $\mathrm{A}=87$ decay chain ${ }^{87} \mathrm{Zr} \rightarrow{ }^{87} \mathrm{Zrm} \rightarrow{ }^{87} \mathrm{Yg}^{\mathrm{g}} \rightarrow{ }^{87} \mathrm{Sr}^{\mathrm{m}}$. Those results are presented elsewhere [1]. Here we discuss level data we obtained for ${ }^{87} \mathrm{Y}$ as an outgrowth of this work. This study was necessary to establish means of determining the absolute decay of $87 \mathrm{Zr}$ through measuring the intensity of the $1226.94-\mathrm{keV} \gamma$-ray. Nuclear Data Sheets (NDS1) [2] gives $I \gamma=3.03 \%$, a number we would expect to be good to about $10 \%$. As a result of the present work, including the study of the decay of the metastable $380.88-\mathrm{keV}$ state, we have obtained $\mathrm{I} \gamma=3.36 \%$ to $\pm 2 \%$.[1]

We have also measured the half-life of the $87 \mathrm{Zr}$ decay to be $1.676 \pm 0.005 \mathrm{~h}$, which compares favorably with the $1.68 \mathrm{~h}$ measured by Prestwood et al. [3]. The ground state of $87 \mathrm{Y}$ is $\mathrm{J}^{\pi}=1 / 2^{-}$and the ground state for $87 \mathrm{Zr}$ is taken as $\mathrm{J}^{\pi}=9 / 2^{+}$. $87 Y$ is well-known for its $9 / 2^{+}$metastable state at $380.88-\mathrm{keV}$. Prestwood et al. report a half-life for the beta decay of ${ }^{87} \mathrm{Y}$ as $3.317 \mathrm{~d}$, and for the M4 decay of the $380.88-\mathrm{keV}$ metastable state, $13.37 \mathrm{~h}$. We take the decay energy of ${ }^{87} \mathrm{Zr}$ as 3666 $\mathrm{keV}$, determined from Nuclear Wallet Cards [4].

\section{EXPERIMENTAL LEVEL DATA}

Here we report on the energy levels in ${ }^{87} Y$ populated through the beta decay of $87 \mathrm{Zr}$. We performed studies of the $\gamma$-spectra preliminary to the work described here. Our experiment began with the irradiation of a set of three ${ }^{89} \mathrm{Y}$ foils with protons of input energies of $40 \mathrm{MeV}$ for $24 \mathrm{~min}$. with an accumulated charge of $1500 \mathrm{mC}$. Target foil densities were 10,10 , and $5 \mathrm{mg} / \mathrm{cm}^{2}$ respectively. The irradiation was performed using the Crocker Nuclear Laboratory Cyclotron at the University of California, Davis. The targets were transported to LLNL within a half life. Chemistry was performed to separate out only the zirconium fraction.

Gamma spectra were obtained using a germanium spectrometer detector having a volume of $24 \mathrm{~cm}^{3}$ and moderately good resolution $(\sim 1.6 \mathrm{keV}$ at $1 \mathrm{MeV})$. The spectrometer was calibrated before the run using a ${ }^{56} \mathrm{Co}$ source and the linearity established by a five-term polynomial fit to the data. In order to enhance the high-energy $\gamma$-rays in the presence of moderately intense low-energy $\gamma$-rays, an absorber, $29.22 \mathrm{gm} / \mathrm{cm}^{2}$ of lead, was used. Spectra were obtained in 13 
runs varying from $10 \mathrm{~min}$ to $800 \mathrm{~min}$. counts. Four spectra covering the period 4.8 to 10.7 hours after irradiation were summed for the final data analysis, the other data being used to help establish and eliminate background $\gamma$-rays. Internal energy calibrations were provided using the $909.088-\mathrm{keV} \gamma$ of ${ }^{89} \mathrm{Zr}$ and the $1920.634-\mathrm{keV} \gamma$ of ${ }^{86} \mathrm{Y}$ ( $\left.16.5 \mathrm{~h}\right)$ decay, since these lines showed in even the earliest data analyzed. These energies were established from late data after $88 \mathrm{Y}$ had grown in sufficiently, using as reference the 898.045 (6) and 1836.042 (4)-keV $\gamma$ rays. In addition, annihilation radiation $(511.00 \mathrm{keV})$ was used. The average energy correction applied to the data was $-0.04 \mathrm{keV}$.

The data were analyzed by means of the code GAMANAL [5]. $\gamma$-ray energy uncertainties are reported as given by the code, in some cases increased to a minimum of $0.03 \mathrm{keV}$ to allow for the calibration and measurement uncertainties. The $1226.94 \gamma$-ray (3.36\% of the ${ }^{87} \mathrm{Zr}$ decay) was used as the relative decay reference standard and assigned a value of 1000 . We used the Ritz principle in establishing the level scheme. Because of this, sometimes the very weakest, and thus uncertain peaks in the spectra, can provide the needed information to establish a level, and thus we have tried to extract all pertinent $\gamma$ 's. Of course, for such weak $\gamma$-rays we have very poor decay information, and the possibility exists that one or two weak $\gamma$ 's were improperly assigned. In view of this, we note a number of low-intensity $\gamma$-rays with an intensity of 1.0 or less. However, those at $>2.5 \mathrm{MeV}$ are the most certain, since there, the Compton background was minimal.

\section{PRIOR INVESTIGATIONS}

Nuclear Data Sheets (NDS1) [2] cover the available data to early 1979. The decay scheme presented there is based on work of Arlt et al. [6], and Y. Away et al. [7] The work of the evaluator was valuable in the present work, but all too often, our new $\gamma$ s, with more accurate energies, do not all fit as presented.

NDS1 presents $(p, \gamma)$ work of Nottrodt et al. [8], and of Piotrowski et al. [9]., that were of particular value. The level energies were close enough to our measurements to be quite useful. The ( $\left.{ }^{3} \mathrm{He}, \mathrm{d}\right)$ data of Maher et al. [10], and the $(p, t)$ work of Oelrich et al. [11], although covered in NDS1, are at times singled out.

More recent $(p, n \gamma)$ work of Takagi [12] have been of particular value. He made use of $\boldsymbol{\gamma}$ spectra, excitation functions, angular distributions, and internal conversion coefficients. His procedure was to collect $\gamma$ spectra for each $50-\mathrm{keV}$ step in beam energy, thus clearly associating levels with their $\gamma$-decay energies. He did not study levels greater than $2400 \mathrm{keV}$, however. Fields et al. [14], have studied selected levels through angular distributions using the ( $p, 2 n \gamma)$ and $(\alpha$, $2 \mathrm{n} \gamma)$ reactions. 


\section{DATA ANALYSIS}

Our data assignments relied upon (1) the Ritz principle, (2) the fact that the $\gamma$-decay intensity out of a level must be greater than or equal to the sum of the intensities of the $\gamma s$ feeding the level, and (3) that when multiple choices are possible, the choice be based upon known-or-possible spins and multipolarities.

A small code was written for checking the possible assignment of the various measured $\boldsymbol{\gamma}$-rays into energy differences between proposed levels. For trial levels, we first used the levels given in the decay scheme in NDS1 and the level diagram for $(p, \gamma)$ work given in NDS1. We also used the work of Takagi extensively. Corrections to the earlier level energies were made as needed. We also made use of a level-finding code developed by D. White called RITZ Iprivate communication, 1988]. A number of $\gamma$ 's were still not assigned. We then constructed possible levels using the unassigned $\gamma \mathrm{s}$ as transitions to the lowest lying levels. Finally a number of $\gamma$ 's were assigned to levels on the basis of a single $\gamma$-ray using data obtained from in-beam particle work. In the latter case, in almost all cases indicated, the transition would not fit elsewhere. (For almost all

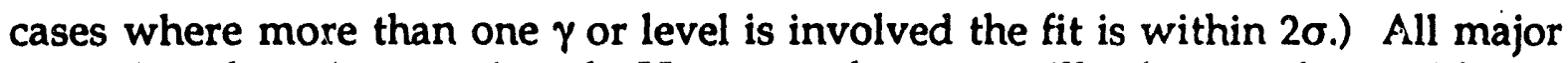
transitions have been assigned. However, there are still a few weak transitions not assigned which must go either to the ground state (g.s.) or the metastable $9 / 2+$ level at $380.88 \mathrm{keV}$.

The data are listed in two tables: Table 1, the $\gamma$-transitions, and Table 2, the assigned levels. For the $\gamma$-transitions, the level assignments are given. In some cases more than one possible set of levels is indicated. In such cases, the one listed (1) is used in subsequent work. A short discussion is given for each listed level. The systematics of Raman and Gove [13] were used extensively in assigning $\mathrm{J}^{\pi}$.

\section{A Conflict Involving the 1404.85 and $2037.37 \mathrm{keV}$ Levels}

Fields et al. [14], on the basis of $(\mathrm{d}, 2 \mathrm{n} \gamma)$ work, which included angular distributions, assigned $\mathrm{j}^{\pi}$ of $13 / 2^{+}$and $15 / 2^{+}$, respectively, to the $1404.85-$ and 2037.37-keV levels. Takagi using $(p, n \gamma)$ work, finds that the $1404.85-\mathrm{keV}$ level could be $11 / 2^{+}$or $13 / 2^{+}$. On the basis of beta decay data and possible log $\mathrm{ft}$ values he ruled out $13 / 2+$ for the $1404.85-\mathrm{keV}$ level. He also observed the $2037.37-\mathrm{keV}$ level, assigning 11/2, 13/2. Takagi measured $\alpha_{\mathrm{k}}$ for the $633.20-\mathrm{keV}$ transition depopulating the $2037.37-\mathrm{keV}$ level and the $1023.95-\mathrm{keV}$ transition depopulating the 1404.85-keV levels. Unfortunately in both cases, theoretical M1's and E2's are about equal. Our data supports $11 / 2^{+}$for the 1404.85 level. We expect that the angular distributions measured by Field et al. is consistent with $13 / 2^{+}$for the 2037.37-keV level, and thus there can be no beta decay to this level.

Fig. 1 shows the features regarding the population of the two levels. We note that the intensity feeding the $1404.85-\mathrm{keV}$ level is $176.3 \pm 3.8$, and that 
depleting the level $270.90 \pm 2.7$ resulting in beta decay feeding of $94.6 \pm 4.7, \log \mathrm{ft}$ $=6.8$ for an allowed or first forbidden transition, consistent with a $\mathrm{J}^{\pi}=11 / 2^{+}$.

An effort was made to assign unassigned $\gamma$ 's as possibly feeding the $1404.85-\mathrm{keV}$ level in an attempt to reduce the beta decay to this level as presently required by the unknown $\gamma$ transitions. The only transition added was the $1158.79-\mathrm{keV} \gamma$ from a proposed level at 2563.64-keV. This transition was proposed earlier in the decay scheme reported in NDS1 and apparently is based upon coincidence studies.

If the $13 / 2^{+}$assignment for the $2037.80-\mathrm{keV}$ level is to hold up, there can be no beta decay to this level. In looking for $\gamma$ 's to balance the input to the output we found that the 1147.13-keV $\gamma$ that fit poorly elsewhere (on the basis of energy fits well here in terms of intensity. Thus the intensity input becomes $27.1 \pm 1.6$ and output $27.1 \pm 2.2$. We thus have a proposed level at $3184.93 \mathrm{keV}$. The work of Oelrich et al. [11] shows a level at $3181 \pm 5 \mathrm{keV}$ that may fit. Their observed lvalue from partical work is uncertain for the determination of $\mathrm{j} \pi$.

\section{The Energy Level Scheme of $87 Y$}

The energy level results in Table. 2 are presented in Figs. $2 a$ and $2 b$

\section{New Nuclear Data Sheet Evaluation}

The work reported here was finished sometime before the new NDS evaluation by Sievers in 1991 [15] herein called NDS2. Thus we feel it appropriate to do no more than make a comparison with the newer results. In the following the new results are given in italics. We first examine Draw. 9, covering the results for $\beta+$ decay. We agree with most of the assignments in Draw. 9. However there are a few problems. The $2241.8 \mathrm{keV}$ level is not possible as shown by using our more accurately measured $\gamma$ rays. Thus the 1862,836 , and $633 \mathrm{keV} \gamma$ 's must go elsewhere. The $1410 \gamma$ for the $2202.3 \mathrm{keV}$ level does not fit. The 3263.2 level is defined by the two transitions; the $1857 \gamma$ goes to the 1405.5, level on the basis of coincidence data, and the $2883 \gamma$ goes to the 381.2 level, ostensibly on the basis of the energy fit (cannot be in coincidence as shown in Draw. 9 because of the long halflife). When we look at our $\gamma$ s, the energies do not add up. Thus we argue for only one level, using the coincidence results. Using our results, we have $1856.77 \gamma+1405.85$ level $=3261.62 \mathrm{keV}$ level.

For the level results in Table 2, we have added the new results from NDS2. The results are shown in italics. Interestingly, there are some energy differences between the levels in Draw. 9 and the level listings. Our values are in much better agreement with the level listings than with those in Draw. 9

\section{ACKNOWLEDGMENTS}

This work was performed under the auspices of the U.S. Department of Energy by Lawrence Livermore National Laboratory under contract W-7405-Eng-48.

$$
6-4
$$




\section{REFERENCES}

[1] H. I. West, Jr., H. O'Brien, R. G. Lanier, R. J. Nagle, and M. G. Mustafa, Paper 5 in this report.

[2] NDS1: P. Luksch and J. W. Tepel, Nuclear Data Sheets 27, No. 3 (1979).

[3] R. J. Prestwood, K. W. Thomas, D. R. Nagle, and N. Smith, Phys. Rev. C 29, 805 (1984)

[4] J. K. Tuli, Nuclear Wallet Cards, National Nuclear Data Center, Brookhaven (1985).

[5] R. Gunnink and J. B. Niday, Lawrence Livermore, National Laboratory, Report No. UCRL-51061, re the code GAMANAL.

[6] A. Arlt, N. G. Zaitreva, B. Kracik, M. G. Laschilov, G. Musiol, C. T. Mink and H. Strusny, Bull. Acad. USSR (SER PHYS.) 35, 52 (1971).

[7] Y. Away, T. Katow, A. Hashizumi, and T. Hamada, IPCR Cyclotron Progress Report 5, 57 (1971)

[8] H. P. Nottrodt, F. Rauch, and P. N. Trehan, Proc. Inter. Sym. Neutron Capture Gammay Ray Spectroscopy and Related Topics, 2nd Petten, The Netherlands.

[9] J. Piotrowski, G. Szeflinska, Z. Szeflinski, Z. Wilhelmi, Proc. Int. Conf. Selected Topics in Nuclear Structure, Dubna, 1, 55 (1976): JINR-D-9682 (1976)

[10] J. V. Maher, J. R. Cornfert and G. C. Morrison, Phys. Rev. C3, 1162 (1971).

[11] J. C. Oelrich, K. Krien, R. M. DelVecchio and R. A. Naumann, Phys. Rev. C14, 563 (1976).

[12] N. Takagi, Nucl. Phys. A346, 93 (1980).

[13] S. Raman and N. B. Gove, Phys. Rev. 7, 6 (1973).

[14] C. A. Fields, F. W. N. de Boer, J. J. Kraushaar, W. W. Pratt, R. A. Ristinen and L. E. Samuelson, Nucl. Phys. A340, 365 (1980)

[15] NDS2: H. Sievers, Nuclear Data Sheets 62, p. 406,Draw. 9 \& 11 (1991) 
TABLE 1. $\boldsymbol{\gamma}$-Ray Transitions

\begin{tabular}{|c|c|c|c|}
\hline Ex(keV) & Iq & \multicolumn{2}{|c|}{ Level Assignment } \\
\hline $611.03 \pm 0.05$ & $33.7 \pm 2.6$ & 2201.72-1590.17 & Takagi, NDS1 (coinc.) \\
\hline $633.2 \pm 0.13$ & $12.2 \pm 2.1$ & $2037.80-1404.85$ & $\begin{array}{l}\text { Fields et al., (coinc.), } \\
\text { Takagi }\end{array}$ \\
\hline $771.49 \pm 0.04$ & $59.0 \pm 2.0$ & 1152.38- 380.88 & NDS1 $(\mathrm{p}, \gamma)$, Takagi \\
\hline $793.55 \pm 0.03$ & $127.6 \pm 1.7$ & $793.55-\quad 0.0$ & $\begin{array}{l}\text { NDS1 }(p, \gamma) \text { Fields et al. } \\
\text { (coinc.) }\end{array}$ \\
\hline $796.72 \pm 0.04$ & $74.0 \pm 1.6$ & 2201.72-1404.85 & $\begin{array}{l}\text { NDS1 decay scheme } \\
\text { (coinc.), Takagi }\end{array}$ \\
\hline $\begin{array}{l}835.75 \pm 0.06 \\
898.67 \pm 0.31\end{array}$ & $\begin{aligned} 21.8 & \pm 1.7 \\
2.5 & \pm 1.5\end{aligned}$ & $\begin{array}{l}1629.30-793.55 \\
2303.52-1404.85\end{array}$ & $\begin{array}{l}\text { NDS1 }(p, \gamma), \text { Takagi } \\
\text { Takagi }\end{array}$ \\
\hline $\begin{array}{l}920.18 \pm 0.08 \\
944.43 \pm 0.19 \\
951.27 \pm 0.45\end{array}$ & $\begin{array}{l}8.5 \pm 1.2 \\
2.9 \pm 1.4 \\
1.3 \pm 1.0\end{array}$ & $\begin{array}{l}2072.52-1152.38 \\
2552.21-1607.85 \\
2154.06-1202.63\end{array}$ & $\begin{array}{l}\text { NDS1 }(p, \gamma), \text { Takagi } \\
\text { Takagi }\end{array}$ \\
\hline $972.34 \pm 0.04$ & $37.6 \pm 1.5$ & (1) $2124.72^{a}-1152.38$ & The only evidence \\
\hline $986.72 \pm 0.49$ & $1.4 \pm 1.1$ & $\begin{array}{l}\text { (2) } 2377.19^{b}-1404.85 \\
\text { (1) } 2994.98-2008.34 \\
\text { (2) } 3059.37-2072.52 \\
\text { (1) } 2399.4-1404.85\end{array}$ & for (a) or (b) \\
\hline $\begin{array}{l}995.1 \pm 0.16 \\
1006.19 \pm 0.39\end{array}$ & $\begin{array}{l}5.3 \pm 1.3 \\
1.6 \pm 1.0\end{array}$ & $\begin{array}{c}\text { (1) } 2399.4 \text { - } 1404.85 \\
\text { (2) } 3372.30-2377.19 \\
3078.53-2072.52\end{array}$ & (c) proposed level \\
\hline $1023.95 \pm 0.03$ & $270.9 \pm 2.7$ & $\begin{array}{l}\text { 1404.85- } 380.88 \\
\text { al. coinc.), Takagi }\end{array}$ & NDS1 $(p, \gamma)$, Fields et \\
\hline $1040.87 \pm 0.15$ & $3.0 \pm 1.2$ & $\begin{array}{l}3078.53-2037.80 \\
2655.74-1607.85\end{array}$ & \\
\hline $\begin{array}{l}1047.88 \pm 0.03 \\
1074.32 \pm 0.11\end{array}$ & $\begin{aligned} 22.9 & \pm 1.0 \\
4.9 & \pm 1.2\end{aligned}$ & $\begin{array}{l}2655.74-1607.85 \\
2276.89-1202.63\end{array}$ & Takagi \\
\hline $1147.13 \pm 0.06$ & $22.9 \pm 1.0$ & $3184.93-2037.80$ & \\
\hline $1158.79 \pm 0.03$ & $72.1 \pm 1.0$ & $2563.64-1404.85$ & $\begin{array}{l}\text { NDS1 decay scheme } \\
\text { (coinc.) }\end{array}$ \\
\hline $\begin{array}{l}1181.32 \pm 0.22 \\
1185.12 \pm 0.45\end{array}$ & $\begin{array}{l}1.6 \pm 0.6 \\
0.74 \pm 0.57\end{array}$ & $\begin{array}{l}1180.9-0.0 \\
1978.67-793.55\end{array}$ & $\begin{array}{l}\text { NDS1 }(p, \gamma) \\
\text { Takagi }\end{array}$ \\
\hline $1202.63 \pm 0.03$ & $50.0 \pm 0.8$ & 1202.63- $\quad 0.0$ & $\begin{array}{l}\text { NDS1 (p, } \gamma) \text {, Fields } \\
\text { et.al. (coinc.), Takagi }\end{array}$ \\
\hline $1205.69 \pm 0.11$ & $4.2 \pm 0.7$ & 2813.59-1607.85 & $\begin{array}{l}\text { NDS1 decay scheme } \\
\text { (coinc.) }\end{array}$ \\
\hline $1209.87 \pm 0.03$ & $329.2 \pm 3.3$ & $1590.17-380.88$ & $\begin{array}{l}\text { 'JDS1 (p, } \gamma) \text {, decay } \\
\text { scheme (coinc.),Takagi }\end{array}$ \\
\hline $1214.79 \pm 0.04$ & $17.3 \pm 0.7$ & 2008.34- 793.55 & $\begin{array}{l}\text { Fields et al. (coinc.), } \\
\text { Takagi }\end{array}$ \\
\hline $1222.61 \pm 0.07$ & $6.2 \pm 0.7$ & 2374.98-1152.38 & \\
\hline
\end{tabular}

6-6 


\begin{tabular}{|c|c|c|c|}
\hline $1226.94 \pm 0.03$ & 1000. & $1607.85-380.88$ & $\begin{array}{l}\text { NDS1 (p,y) decay } \\
\text { scheme (coinc.), } \\
\text { Takagi }\end{array}$ \\
\hline $1243.12+0.50$ & $0.5 \pm .44$ & $\begin{array}{l}\text { (1) } 2872.20-1629.30 \\
\text { (2) } 3023.56-1780.19\end{array}$ & \\
\hline $1250.53 \pm 0.19$ & $2.9 \pm 1.1$ & 2655.74-1404.85 & \\
\hline $1290.65 \pm 0.25$ & $1.4 \pm 0.6$ & 2994.98-1704.42 & \\
\hline $1310.08 \pm 0.34$ & $0.89 \pm 0.45$ & $2939.45-1629.30$ & \\
\hline $1331.98 \pm 0.35$ & $0.7 \pm 0.5$ & 2939.56-1607.85 & \\
\hline $1349.40 \pm 0.09$ & $1.3 \pm 0.5$ & $\begin{array}{l}2552.17-1202.63 \\
\text { (1) } 2159.21-793.55\end{array}$ & \\
\hline $1365.40 \pm 0.23$ & $1.0 \pm 0.40$ & $\begin{array}{l}\text { (1) 2159.21-793.55 } \\
\text { (2) 2994.98-1629.30 }\end{array}$ & \\
\hline $1387.09 \pm 0.04$ & $23.6 \pm 0.7$ & $2994.98-1607.85$ & $\begin{array}{l}\text { NDS1 decay scheme } \\
\text { (coinc.) }\end{array}$ \\
\hline $\begin{array}{l}1399.29 \pm 0.05 \\
1404.04 \pm 0.20\end{array}$ & $\begin{array}{c}36.8 \pm 0.6 \\
2.3 \pm 0.6\end{array}$ & $\begin{array}{r}1780.19-380.88 \\
\text { (1) } 2994.98-1590.75 \\
\text { (2) } 3183.62-1780.19\end{array}$ & \\
\hline $1429.97 \pm 0.43$ & $1.0 \pm 0.5$ & 3059.37-1629.30 & \\
\hline $1449.18 \pm 0.07$ & $7.0 \pm 0.4$ & $\begin{array}{l}\text { (1) } 2601.55-1152.03 \\
\text { (2) } 3078.53-1629.30\end{array}$ & \\
\hline $1452.87 \pm 0.13$ & $2.4 \pm 0.4$ & $2655.74-1202.63$ & \\
\hline $1460.65 \pm 0.20$ & $1.2 \pm 0.4$ & $3498.68-2037.80$ & \\
\hline $1467.29 \pm 0.12$ & $2.6 \pm 0.4$ & 2872.20-1404.85 & \\
\hline $\begin{array}{l}1470.84 \pm 0.12 \\
1483.21 \pm 0.07\end{array}$ & $2.6 \pm 0.4$ & 3078.53-1607.85 & \\
\hline $\begin{array}{l}1483.21 \pm 0.07 \\
1487.91 \pm 0.08\end{array}$ & $\begin{array}{l}7.4 \pm 0.4 \\
5.3 \pm 0.6\end{array}$ & $\begin{array}{l}2276.89-793.55 \\
3117.29-1629.30\end{array}$ & Takagi \\
\hline $\begin{array}{l}1487.91 \pm 0.08 \\
1559.64 \pm 0.28\end{array}$ & $0.73 \pm 0.36$ & 2353.55- 793.55 & Takagi \\
\hline $1571.13 \pm 0.38$ & $0.7 \pm 0.5$ & $2975.96-1404.85$ & \\
\hline $1591.53 \pm 0.40$ & $2.1 \pm 1.1$ & $3372.30-1730.19$ & \\
\hline $\begin{array}{l}1654.37 \pm 0.09 \\
1656.93 \pm 0.05\end{array}$ & $\begin{array}{r}4.0 \pm 0.8 \\
14.9 \pm 0.8\end{array}$ & $3059.37-1404.85$ & Takagi \\
\hline $1691.61 \pm 0.04$ & $\begin{array}{l}14.9 \pm 0.8 \\
11.4 \pm 0.4\end{array}$ & $\begin{array}{l}2037.80-380.88 \\
2072.52-380.88\end{array}$ & $\begin{array}{l}\text { Takagi } \\
\text { NDS1 }(p, \gamma), \text { Takagi }\end{array}$ \\
\hline $1704.71 \pm 0.49$ & $\begin{array}{l}11.4 \pm 0.4 \\
0.31 \pm 0.29\end{array}$ & $\begin{array}{lc}2072.52- & 380.88 \\
1704.18- & 0.0\end{array}$ & NDS1 $(p, \gamma)$, Takagi \\
\hline $1758.98 \pm 0.17$ & $1.6 \pm 0.4$ & $\begin{array}{l}\text { (1) } 2939.56-1180.95 \\
\text { (2) } 2552.17-793.55\end{array}$ & \\
\hline $1773.18 \pm 0.05$ & $5.4 \pm 0.4$ & 2154.06- 380.88 & Takagi \\
\hline $1807.94 \pm 0.02$ & $40.2 \pm 1.0$ & $\begin{array}{l}\text { 2601.55- } 793.55 \\
\text { (coinc.) }\end{array}$ & NDS1 decay scheme \\
\hline $1820.93 \pm 0.03$ & $27.2 \pm 0.5$ & 2201.72- 380.88 & Takagi \\
\hline $\begin{array}{l}1856.77 \pm 0.05 \\
1862.22+0.04\end{array}$ & $11.8 \pm 0.4$ & 3059.37-12.02.63 & \\
\hline $\begin{array}{l}1862.22 \pm 0.04 \\
1896.12 \pm 0.07\end{array}$ & $9.3 \pm 0.5$ & 2655.75- 793.55 & \\
\hline $\begin{array}{l}1896.12 \pm 0.07 \\
1914.64 \pm 0.06\end{array}$ & $\begin{array}{l}3.5 \pm 0.4 \\
57+0.4\end{array}$ & $\begin{array}{l}2276.89-380.88 \\
3117.29-1202.63\end{array}$ & Takagi \\
\hline $\begin{array}{l}1914.64 \pm 0.06 \\
1963.59 \pm 0.25\end{array}$ & $\begin{array}{l}5.7 \pm 0.4 \\
1.0 \pm 0.3\end{array}$ & $2344.47-380.88$ & Takagi \\
\hline $2019.07 \pm 0.06$ & $5.1 \pm 0.3$ & $2399.97-380.88$ & Takagi \\
\hline
\end{tabular}




\begin{tabular}{|c|c|c|c|}
\hline $2062.51 \pm .30$ & $0.6 \pm .24$ & $3265.19-1202.63$ & \\
\hline $2112.6 \pm 0.57$ & $0.34 \pm 0.25$ & $\begin{array}{l}\text { (1) } 2112.64-\quad 0.0 \\
\text { (2) } 3265.19-1152.38\end{array}$ & \\
\hline $2149.27 \pm 0.22$ & $1.1 \pm 0.3$ & & \\
\hline $2159.34 \pm 0.16$ & $1.35 \pm 0.39$ & $2159.21-\quad 0.0$ & $\operatorname{NDS1}(p, \gamma)$ \\
\hline $2171.32 \pm 0.04$ & $18.4 \pm 0.5$ & $2552.17-380.88$ & \\
\hline $2182.38 \pm 0.04$ & $23.4 \pm 0.5$ & $2975.96-793.55$ & \\
\hline $2220.72 \pm 0.03$ & $70.0 \pm 0.7$ & $2601.55-380.88$ & \\
\hline $2274.82 \pm 0.32$ & $0.61 \pm 0.23$ & $2655.74-380.88$ & \\
\hline $2285.74 \pm 0.54$ & $0.26 \pm 0.19$ & $3488.24-1202.63$ & \\
\hline $2323.83 \pm 0.13$ & $1.33 \pm 0.21$ & $3117.29-793.55$ & \\
\hline $2353.67 \pm 0.18$ & $1.00 \pm 0.24$ & $2353.67-\quad 0.0$ & \\
\hline $2432.70 \pm 0.05$ & $7.1 \pm 0.3$ & $2813.59-380.88$ & \\
\hline $249134 \pm 0.17$ & $0.89 \pm 0.17$ & $2872.20-380.88$ & \\
\hline $2543.09 \pm 0.30$ & $0.40 \pm 0.19$ & $2543.09-\quad 0.0$ & \\
\hline $2578.76 \pm 0.20$ & $0.73 \pm 0.17$ & $3372.30-793.55$ & \\
\hline $2614.11 \pm 0.02$ & $29.1 \pm 0.5$ & $2994.98-380.88$ & \\
\hline $2661.46 \pm 0.14$ & $1.05 \pm 0.15$ & & \\
\hline $2678.53 \pm 0.11$ & $1.31 \pm 0.16$ & $3059.37-380.88$ & \\
\hline $2694.92 \pm 0.49$ & $0.1 \pm 0.05$ & $3488.24-793.55$ & \\
\hline $2719.12 \pm 0.22$ & $0.36 \pm 0.10$ & & \\
\hline $2736.41 \pm 0.05$ & $5.2 \pm 0.2$ & $3117.29-380.88$ & \\
\hline $2740.29 \pm 0.19$ & $0.51 \pm 0.10$ & $3121.40-380.88$ & \\
\hline $2802.74 \pm 0.17$ & $0.47 \pm 0.10$ & $3183.62-380.88$ & \\
\hline $2854.54 \pm 0.23$ & $0.40 \pm 0.09$ & & \\
\hline $2884.32 \pm 0.09$ & $9.0 \pm 0.9$ & $3265.19-380.88$ & \\
\hline $2991.46 \pm 0.53$ & $0.09 \pm 0.04$ & $3372.30-380.88$ & \\
\hline $3023.23 \pm 0.22$ & $0.19 \pm 0.05$ & $3023.56-\quad 0.0$ & \\
\hline $3056.24 \pm 0.33$ & $0.09 \pm 0.03$ & $3056.24-\quad 0.0$ & \\
\hline $3107.32 \pm 0.19$ & $0.28 \pm 0.05$ & $3488.24-380.88$ & \\
\hline $3117.95 \pm 0.06$ & $2.3 \pm 0.1$ & $3498.68-380.88$ & \\
\hline $3174.43 \pm 0.24$ & $0.21 \pm 0.05$ & & \\
\hline
\end{tabular}


TABLE 2 ENERGY LEVELS

$380.88 \pm 0.02 \mathrm{keV} \quad 9 / 2+$ level

Metastable level with 13.37 hours half life. Spin and parity well established. Find $26 \mathrm{~g}$ 's of intensity(int.) 1882.5 feeding the level. Fraction of $87 \mathrm{Zr}$ decay going to level $=93.07 \%$. $\log \mathrm{ft}=4.7$ [380.79 keV, 9/2+]

$793.55 \pm 0.03 \mathrm{keV} \quad 5 / 2^{-}$level

Spin and parity well established (see, e.g., Takagi) Find $12 \gamma \mathrm{s}$ of intensity $128.5 \pm 2.4$ feeding and one $\gamma$, the $793.55-\mathrm{keV}$ of intensity, 127.6 \pm 1.7 going to ground state (g.s.), depopulating (depop.) level. Possible log $\mathrm{ft}$ values support spin assignment. $\gamma$ 's feedings are from 3488.24-, 3372.30-, 3117.29-, 2975.96-, 2813.59- 2655.74- 2601.55-, 2276.89-, 2159.21-, 2008.34-, 1978.67-, and 1629.39-keV . [793.6 keV , 5/2-]

$1152.38 \pm 0.03 \mathrm{keV} \quad 5 / 2^{+}$level

( $\left.{ }^{3} \mathrm{He}, \mathrm{d}\right)$ work and $(\mathrm{p}, \mathrm{n} \gamma)$ work confirm $\mathrm{J}^{\pi}$. There should be no beta decay to level. Find four $\gamma$ 's from 2601.55-, 2374.98-. 2124.72-, and 2072.52-keV, int. 59.3 \pm 1.6 , feeding and one $\gamma$, int. $59.0 \pm 2.0$, to $380.88-\mathrm{keV}$ level, depop. level. To keep beta feeding to zero, had to assign the 972.34-keV $\gamma$ into $1152.38-\mathrm{keV}$ level from a $2124.72-\mathrm{keV}$ level. This may be the $2122 \pm 5-\mathrm{keV}$ level seen in $(p, t)$ work of Oelrich et al. [1153.2 $k e V,(5 / 2+)]$

\section{$1180.95 \pm 0.22 \mathrm{keV} \quad 3 / 2^{-}$level}

Takagi reports $1182.1 \mathrm{keV} 3 / 2^{-}$. Find one weak $\gamma$ of int. $1.6 \pm 0.4$ from the $2939.56-\mathrm{keV}$ level and one of int. $1.6 \pm 0.6$ to g.s. depop. level. We find no beta decay, which is consistent with $3 / 2$.

\section{$1202.63 \pm 0.03 \mathrm{keV} \quad\left(5 / 2^{-}\right)$level}

Takagi reports $1203.1 \mathrm{keV} \mathrm{5/2}$. Find seven $\gamma$ 's of int. $26.9 \pm 1.5$ feeding level and one of int. $50.0 \pm 0.8$ to g.s. depop. level. $\gamma$ 's feeding are from 3488.24-, 3265.19-, 3117.29-, 3059.37-, 2655.74-, 2552.17-, and 2276.89-keV . Have a conflict. Beta decay should be zero but have an int. 23.0 \pm 1.7 to account for. Do not find a likely $\gamma$ of the right intensity coming from a possible level based on particle work. Either the spin is wrong or there are several weak low-energy $\gamma$ /s feeding the level that we were unable to see. [1202.51 keV, (5/2)-] 
$1404.85 \pm 0.03 \mathrm{keV} \quad 11 / 2^{+}$level

No spin data in NDS1. Fields et al. $(d, 2 n \gamma)$ assign $13 / 2^{+}$, Takagi from $(p, n \gamma)$ and beta decay work prefers $11 / 2^{+}$. Our data excludes $13 / 2^{+}$.

Find nine $\gamma$ 's, int. 176.3 \pm 3.8 , feeding level and one $\gamma,(1023.95-\mathrm{keV})$, int. 270.9 \pm 2.7 , depop. level. $\log \mathrm{ft} .=6.8$. Discussed in more detail elsewhere. [1405.1 keV, $\left.\left(7 / 2^{+}, 9 / 2^{+}\right)\right]$or is it $\left[1404.4 \mathrm{keV},\left(13 / 2^{+}\right)\right]$?

$1590.15 \pm 0.03 \mathrm{keV} \quad 11 / 2^{+}$level

Takagi reports $1591.2 \mathrm{keV}, 11 / 2^{+}$, Fields et al., report $1590.6 \mathrm{keV}, 11 / 2^{+}$. Find two $\gamma / \mathrm{s}$ feeding level of total int. $36.0 \pm 2.3$ from $2994.98-\mathrm{keV}$ and 2201.75-keV and one $\gamma$ int. 329 \pm 3.0 to 380.88-keV level depop. level. $\log \mathrm{ft}=6.4$ consistent with an allowed assignment. [1590.7 keV, $\left.\left(11 / 2^{+}\right)\right]$

$1607.85 \pm 0.03 \mathrm{keV} \quad 9 / 2^{+}$level

Takagi reports $1608.4 \mathrm{keV}\left(9 / 2^{+}\right)$. Maher et al. report $1605 \mathrm{keV} \mathrm{9/2+}$. Find $7 \gamma$ 's of total int. 56.9 2.5 feeding level from 3078.53-, 2994.98-, 2939.56-, 2813.59-, 2655.74-, and 2552.17-keV . The 1226.94-keV transition, which forms our int. standard 1000.0, depop level to the 380.88-keV level. $\log \mathrm{ft}=5.75$. [1608.6 keV]

$1629.30 \pm 0.04 \mathrm{keV} \quad 7 / 2^{-}$level

Takagi reports $1630.1 \mathrm{keV}, 7 / 2^{-}$Find four $\gamma$ 's feeding level, total int. 7.7 \pm 1.0 from 3117.29-, 3059.37-, 2936.56-, and 2872.20-keV, and one $\gamma$ int. 21.8 1 1.7, to 793.55-keV level depop. level. $\log \mathrm{ft}=7.6$.

[1629.4 keV, $\left.\left(1 / 2^{-}, 3 / 2^{-}\right)\right]$

$1704.42 \pm 0.22 \mathrm{keV} \quad 3 / 2^{+}$level

Takagi reports $1704.8 \mathrm{keV}, 3 / 2^{+}$. There should be no beta decay. Find a weak $\gamma$ of int. 1.40 \pm 0.25 from the 2994.98-keV level feeding and one of int. 0.31 0.29 , depop. level to g.s. The lack of an exact match in int. is not significant. [1704.2 keV, (5/2-)]

$1780.19 \pm 0.04 \mathrm{keV}$ level ?

Find no evidence for level from prior work. Find one $\gamma$ feeding level int. 2.1 11.1 from 3372.30-keV level. Possibly one or two $\gamma$ 's assigned elsewhere feed this level. One $\gamma$, int. 36.0 \pm 0.6 , depop. level to 380.88$\mathrm{keV}$ level. $\log \mathrm{ft}=\mathbf{7 . 0}$. 
$1978.67 \pm 0.45 \mathrm{keV} \quad 7 / 2^{-}$level

Takagi reports a level at $1980.1-\mathrm{keV}, 7 / 2^{-}$. Our $\gamma$ transition $1185.12 \mathrm{keV}$ from a proposed level at $1978.67 \mathrm{keV}$ to $793.55 \mathrm{keV}$ is consistent with Takagi's observation. NDS1 lists a level at $1979.3 \mathrm{keV}\left(9 / 2^{-}\right)$. [1979.2 $\mathrm{keV},(7 / 2,9 / 2)-]$

2008.34 $\pm 0.04 \mathrm{keV} \quad 7 / 2^{-}$level

Takagi reports a level at $2009.2 \mathrm{keV}, 9 / 2^{-}, 11 / 2^{-}$. Fields et al., from $(\mathrm{p}, 2 \mathrm{n} \gamma)$ report $2007.9 \mathrm{keV}, 7 / 2^{-}$. Find one $\gamma$ feeding this level from the 2994.88-keV level and one $\gamma$ depop. The transition of the 1214.79-keV $\gamma$ from this level to the 793.55-keV level is the key to reducing beta decay to the 793.55-keV level to zero as needed by $]^{\pi}$. $\log \mathrm{ft}=7 / 2$. [2007.91 $\mathrm{keV},(7 / 2)]$

$2037.80 \pm 0.05 \mathrm{keV} \quad\left(13 / 2^{+}\right)$level

Takagi reports $2038.4 \mathrm{keV}\left(11 / 2^{+}, 13 / 2^{+}\right)$. Fields et al., report 2037.7-keV $\left(15 / 2^{+}\right)$. Our observed $\gamma$ transitions (three in, two out) make the $\mathrm{J}^{\pi}$ assignment of Fields et al. unlikely even though we balance the $\gamma$ int. into and out of this level. See discussion of the 1404.85- and 2037.80keV. [2037.7 keV, $\left.\left(15 / 2^{+}\right)\right]$

$2072.52 \pm 0.04 \mathrm{keV} \quad\left(7 / 2^{+}, 9 / 2^{+}\right)$level

Takagi reports $2073.1 \mathrm{keV}, 7 / 2^{+}, 9 / 2^{+}$. Find one $\gamma$ of int. $1.6 \pm 1.0$ feeding from the 3078.53-keV level (there may be a second $\gamma$ ) and two $\gamma$ 's depop. level, int. 19.9 \pm 1.3 , to the 1152.38-and 380.88-keV. Log $\mathrm{ft}=7.3$. [2072.7 keV]

\section{$2112.64 \pm 0.57 \mathrm{keV} \quad(5 / 2+)$ level}

NDS1 lists a level 2111.4 $\pm 0.9 \mathrm{keV}(3 / 2-)$ from $(p, \gamma)$ work. Takagi identifies a level at $2112.5 \mathrm{keV}$ assigning $\mathrm{J}^{\pi}=5 / 2^{+}$. We see the g.s. transition only. Int $=0.34 \pm 0.25$. $\log \mathrm{ft}=8.9-9.7$. Need $\log \mathrm{ft}>11$ for second forbidden non-unique. Probably have feeding from another level. [2111.1 keV]

$2124.72 \pm 0.04 \mathrm{keV}$ level

This may be the level at $2122 \pm 5 \mathrm{keV} 5 / 2^{+}, 7 / 2^{+}$reported from (p,t) work of Oelrich et al. Define level by the $972.34-\mathrm{keV} \gamma$, int. 37.6, to the 1152.38-keV level. This $\gamma$ is needed to reduce the beta decay to the 1152.38-keV level to zero as required by the $\mathrm{J}^{x}$ of that level. [2122 keV, $\left.5 / 2+, 7 / 2^{+}\right]$ 
2154.06 $\pm 0.07 \mathrm{keV} \quad 9 / 2^{-}$level

Level is reported by Takagi at 2154.6-keV, 9/2, $11 / 2^{-}$and Oelrich et al. at $2165 \pm 5 \mathrm{keV}, 7 / 2^{-}, 9 / 2^{-}$. Find a $\gamma, 1773.18 \mathrm{keV}$, int. 5.4 40.4 , depop. level to the $380.88-\mathrm{keV}$ level, and a second $\gamma, 951.27-\mathrm{keV}$, int. 1.3 \pm 1.0 , going to the $1202.63-\mathrm{keV}$ level. $\log \mathrm{ft}=7.8$.

$2159.21 \pm 0.20 \mathrm{keV}$ level

NDS1 lists a level at $2158.9 \mathrm{keV}, 7 / 2$. Find two $\gamma$ 's depop level, one of int. $1.0 \pm 0.4$ to the $793.55 \mathrm{keV}, 5 / 2^{-}$level and the second of int. $1.4 \pm 0.4$ to the g.s. $\gamma$-branching excludes $7 / 2^{-}$and $5 / 2^{-}$seems likely but $\log \mathrm{ft}=8.2$. We need $\mathrm{J}^{\pi}>8.5$ for first forbidden unique. For 5/2- or other possibilities it appears we need $\gamma$ feeding to the level, and that we have not observed. [2158.9 keV]

$2201.72 \pm 0.06 \mathrm{keV} \quad\left(9 / 2^{+}\right)$level

Takagi reports a level at $2202.3 \mathrm{keV}, 7 / 2,9 / 2$. Oelrich et al. report $2202 \pm 5 \mathrm{keV}, 7 / 2^{-}, 9 / 2^{-}$, and Maher et al. report $2203 \mathrm{keV}, 9 / 2^{+}$. Find three $\gamma$ s total int. 134.9 \pm 2.8 depop. level to 1590.75-, 1404.85-, and 380.88-keV. $\log \mathrm{ft}=6.4$. $\gamma$ data allow $\mathrm{J}^{\pi}=7 / 2^{+}, 9 / 2^{ \pm}$; preference $9 / 2^{+}$. [2201.7 keV, $\left.\left(7 / 2^{+}, 9 / 2^{+}\right)\right]$

$2276.89 \pm 0.05 \mathrm{keV} \quad\left(7 / 2^{+}\right)$level

Takagi reports $2277.5 \mathrm{keV},(7 / 2,9 / 2)$. Oelrich et al. report $2287 \pm 5 \mathrm{keV}$, $5 / 2^{+}, 7 / 2^{+}$. Maher et al. report $2278 \mathrm{keV}, 5 / 2^{-}$. Find three $\gamma / \mathrm{s}$ of comparable int. (total int. 15.811.3) depop. level to $1202.63,793.55$, and 380.88-keV. $\log \mathrm{ft}=7.3$. $\mathrm{J}^{\pi}$ from $\gamma$ work $\left(7 / 2^{ \pm}, 9 / 2^{-}\right), 5 / 2$ excluded; preference $\left(7 / 2^{+}\right)$. [2278 keV, $\left.(7 / 2)^{-}\right]$

$2303.52 \pm 0.31 \mathrm{keV}$ level ?

Takagi reports a level at $2302.5 \mathrm{keV}, \mathrm{j}^{\pi} \geq 7 / 2$. We find evidence for the level from one $\gamma$ from this level, int. $2.5 \pm 1.5$, to the $1404.85-\mathrm{keV}$ level. $\log \mathrm{ft}=8.0$ - 8.4.

$2344.47 \pm 0.25 \mathrm{keV}$ level

Takagi reports a level $2345.0 \mathrm{keV}, \mathrm{j}^{\pi} \geq 9 / 2$. We establish the level on the basis of the $1963.59-\mathrm{keV} \gamma$, int. 1.0 0.3 , to the $380.88-\mathrm{keV}$ level. Log $\mathrm{ft}=$ 8.4. $[2246 \mathrm{keV},(5 / 2)+]$ 
$2353.55 \pm 0.15 \mathrm{keV}$ level

Takagi reports a level $2353.6 \mathrm{keV}(7 / 2,9 / 2,11 / 2)$. NDS1 lists $2354.5 \pm 1.2$

$\mathrm{keV}$ from $(\mathrm{p}, \gamma)$ work. We find a $\gamma$ from this level of int. $0.73 \pm 0.36$

feeding the 793.55-keV level and a second $\gamma$ of int. 1.00 \pm 0.24 feeding the g.s.. $\log \mathrm{ft}=8.1$. [2354.5 keV]

$2374.98 \pm 0.07 \mathrm{keV}$ level ?

Oelrich et al. report a level $2374 \mathrm{keV}\left(15 / 2^{-}, 17 / 2^{-}\right)$. We see the level through the single $1222.6-\mathrm{keV} \gamma$, int. $6.2 \pm 0.7$, to the $1152.38-\mathrm{keV}$ level. $\log \mathrm{ft}=7.6$. Possible $\mathrm{J}^{\pi}=(7 / 2,9 / 2,11 / 2)^{ \pm}$.

$2399.97 \pm 0.03 \mathrm{keV} \quad\left(7 / 2^{+}\right)$level

Takagi reports a level at $2400.1 \mathrm{keV}, \mathrm{j} \pi \geq 7 / 2$. Maher et al., report 2407 $\mathrm{keV}, 5 / 2^{+}$. Oelrich et al., report $2413 \mathrm{keV}\left(5 / 2^{+}, 7 / 2^{+}\right)$. Find a $\gamma$ int. $5.1 \pm 0.3$, to the $380.88-\mathrm{keV}$ level and a $\gamma$ int. $5.3 \pm 1.3$, to the $1404.85-\mathrm{keV}$ level. $\log \mathrm{ft}=7.6 . \gamma$ data supports $]^{\pi}=\left(7 / 2^{+}, 9 / 2^{ \pm} .11 / 2^{ \pm}\right)$; assign $7 / 2^{+}$.

$2543.09 \pm 0.04 \mathrm{keV}$ level ?

Oelrich et al. report level at $2544 \pm 5 \mathrm{keV}, \mathrm{J}^{\pi}=9 / 2^{+}, 11 / 2^{+}$. Find a single $\gamma$, int. 0.4 \pm 0.2 , depop. level to g.s. $\log \mathrm{ft}=8.6$.

$2552.17 \pm 0.05 \mathrm{keV}$ level

Level not reported in prior work. Find three $\gamma$ 's depop. level to $1607.85-, 1202.63-$, and 380.88-keV. Total int. 22.9 \pm 1.5 . Log $\mathrm{ft}=6.7$. $\mathrm{J}^{\pi}$ $=(7 / 2,9 / 2,11 / 2)^{+}\left[2553.1 \mathrm{keV},\left(9 / 2^{+}\right)\right]$

$2563.64 \pm 0.04 \mathrm{keV}$ level

NDS1 lists $2564.6 \pm 1.1 \mathrm{keV},\left(9 / 2^{+}, 11 / 2^{+}\right)$probably based on Oelrich et al. We need to assign the 1158.79-keV $\gamma$, int. 72.1. NDS1 (coinc.) decay scheme shows transition as such. However, find two other $\gamma$ 's assigned by NDS1 to depop. this level do not fit energy basis. In particular this included the 972.3 . [2563.9 $\mathrm{keV},(9 / 2+)]$

$2601.55 \pm 0.04 \mathrm{keV} \quad 7 / 2^{+}$level

Oelrich et al., report level at $2601 \pm 5 \mathrm{keV}, 5 / 2^{+}, 7 / 2^{+}$. Find three $\gamma$ 's depop. level to the 380.88- 793.55-, and 1152.38-keV. Depop. int. 117.0 $01.5 \log \mathrm{ft}=6.1$. $\mathrm{J}^{\pi}$ preference from $\gamma$ data, $7 / 2^{+}$. Assign $7 / 2^{+}$. [2602.1 keV, $\left.\left(7 / 2^{+}\right)\right]$ 
$2655.74 \pm \mathrm{C} .03 \mathrm{keV}$ level

No prior evidence exists for this level. Find $5 \gamma$ 's depop. level to $1607.85-, 1404.85-, 1202.63-, 793.55-$, and $380.88-\mathrm{keV}$; total int. 38.1 11.6 . Log $\mathrm{ft} .=6.5 . J^{\pi}$ preference $\left(7 / 2^{+}, 9 / 2^{-}\right)$

$2813.59 \pm 0.05 \mathrm{keV}$ level

Oelrich et al. report level at $2808 \pm 5 \mathrm{keV}\left(9 / 2^{+}, 11 / 2^{+)}\right.$. Also is listed in decay scheme in NDS1. Find two $\gamma$ 's depop. level to the 1607.85-, and 380.88-keV. Depop. int. 11.3 \pm 0.8 . $\log \mathrm{ft}=7.0 . \gamma$ in NDS1 decay scheme to the $1404.85-\mathrm{keV}$ level, list as coinc., not observed.

$[2812.2 \mathrm{keV}, 9 / 2+, 11 / 2+]$

$2872.20 \pm 0.10 \mathrm{keV} \quad 11 / 2^{-}$level

Oelrich et al., report $2871 \pm 5 \mathrm{keV}\left(11 / 2^{-}, 13 / 2^{-}\right)$. Find three $\gamma / \mathrm{s}$, int. 4.0 \pm 0.6 , depop. level going to the 1629.30, 1404.85-, and 380.88-keV. Log $\mathrm{ft}=7.3$. $\gamma$ decay permits $\mathrm{f}^{\pi}\left(11 / 2^{-}, 9 / 2^{+} .7 / 2^{+}\right)$. We assigned $\mathrm{J}^{\pi}=11 / 2^{-}$ [2871 keV, $\left.\left(11 / 2^{-}, 13 / 2^{-}\right)\right]$

$2939.90 \pm 0.20 \mathrm{keV}$ level

No evidence for level from prior work. Find three $\gamma$ 's of total int. 3.2 +0.8 depop. level going to $1629.30-, 1607.85-$, and $1180.95-\mathrm{keV}$. Log ft $=7.4$. $\mathrm{J}^{\pi}$ preference $\left(7 / 2^{+}, 9 / 2^{-}\right)$.

$2975.96 \pm 0.04 \mathrm{keV}$ level

No prior evidence for level. Find two $\gamma$ 's depop. level, one int. 23.4t 0.5 to 793.55 - and second, int. $0.7 \pm 0.5$, to the $1404.85-\mathrm{keV}$. $\log \mathrm{ft}=6.3$. $\mathrm{J}^{\pi}$ preference $7 / 2^{+}$.

$2994.98 \pm 0.03 \mathrm{keV} \quad\left(7 / 2^{+}\right)$level

Maher et al., report a level at $2995 \mathrm{keV}, 5 / 2^{+}$. Oelrich et al., report $2997 \pm 5 \mathrm{keV}, 5 / 2^{+} 7 / 2^{+}$. Arlt et al. report $2997 \mathrm{keV}$ from beta decay. Find five $\gamma$ 's depop. level to 2008.39-, 1704.42-, 1607.85-, 1590.75, and 380.88-keV. Depop. int. $=57.8 \pm 1.6 . \log \mathrm{ft}=6.0 . \mathrm{J}^{\pi}$ preference $7 / 2^{+}$. [2995 keV, (5/2)+]

$3056.24 \pm 0.33 \mathrm{keV}$ level

Oelrich et al., report a level $3057 \pm 5 \mathrm{keV}, 5 / 2^{+}, 7 / 2^{+}$. Find one $\gamma$ to g.s., int. $0.09 \pm 0.03 . \log \mathrm{ft}=8.6 . \quad[3057 \mathrm{keV},(5 /+, 7 / 2+)]$ 
$3059.37 \pm 0.04 \mathrm{keV}$ level

Could be the level reported by Oelrich et al. mentioned in regard to the 3056.24-keV level; otherwise, not previously reported. Find four $\gamma$ 's depop. level going to 1629.30-, 1404.85-, 1202.63-, and 380.88-keV.

Depop. int. 18.1 $\pm 1.0 . \log \mathrm{ft}=6.4 . \mathrm{J}^{\pi}$ preference $\left(7 / 2^{+}, 9 / 2^{-}\right) \quad[3057 \mathrm{keV}$, $(5 / 2+, 7 / 2+)]$

$3078.53 \pm 0.15 \mathrm{keV}$ level

No prior evidence for level. Find three $\gamma$ 's depop. level, int. 7.2 \pm 1.1 , to 2072.52-, 2037.8-, and 1607.85-keV. $\log \mathrm{ft}=6.1$. $\mathrm{J}^{\pi}$ preference $\left(7 / 2^{+}, 9.2^{+}\right.$, $11 / 2^{+}$).

$3117.29 \pm 0.03 \mathrm{keV}$ level

No prior clear evidence for level. Find four $\gamma / s$ total int. $17.5 \pm 0.8$, to at 1629.30-, 1202.63-, 793.55-, and 380.88-keV. $\log \mathrm{ft}=6.4$. $\mathrm{J}^{\pi}$ preference $\left(7 / 2^{ \pm}, 9 / 2^{-}\right)$.

$3121.40 \pm 0.19 \mathrm{keV}$ level

Oelrich et al. report level at $3121 \pm 5 \mathrm{keV}, 5 / 2^{+}, 7 / 2^{+}$. Find one transition, a $2740.49-\mathrm{keV} \gamma$, int. 0.5 \pm 0.1 , depop. the level feeding the 380.88-keV level. [3120 keV, 9/2+,11/2+]

$3184.93 \pm 0.07 \mathrm{keV}$ level

Possibly the level reported by Oelrich et al. at $3181 \pm 5 \mathrm{keV}(13 / 2+$, $15 / 2+$ ). The transition depop. this proposed level is a 1147.13-keV $\gamma$, int. 22.9, and is needed to reduce the beta decay to the $2037.80-\mathrm{keV}$ level to zero. $\log i t=6.1 . \quad\left[3181 \mathrm{keV} \mathrm{keV},\left(13 / 2^{+}, 15 / 2^{+}\right)\right]$

$3265.19 \pm 0.09 \mathrm{keV}$ level

NDS1 lists a level $3264.0 \pm 1.4 \mathrm{keV},(7 / 2,9 / 2,11 / 2)$. Find two $\gamma$ s int. 9.6 \pm 0.9 , depop. level to the $1202.63-$ and $380.88-\mathrm{keV}$. There is possibly a third $\gamma . \log \mathrm{ft}=6.1$. NDS1 lists a coinc. $\gamma$ transition to the $1607.85-\mathrm{keV}$ level. We do not find a good energy fit and following Takagi have assigned the $1659.93-\mathrm{keV} \gamma$ elsewhere.

$\left[3262.8 \mathrm{keV},\left(9 / 2^{+}, 11 / 2^{+}\right)\right]$[See discussion of NDS2 results. The only possible value would be $3261.62 \mathrm{keV}$ using our energies and this would have to be another level than the one we observe.] 
$3372.30 \pm 0.05 \mathrm{keV}$ level

No prior evidence exists for level. Find three $\gamma^{\prime}$ s, int. 2.9 \pm 1.1 , to

1780.19-, 793.55- and 380.88-keV. Log $\mathrm{ft}=6.6 . \mathrm{J}^{\pi}$ preference $\left(7 / 2^{+}, 9 / 2^{-}\right)$.

$3488.24 \pm 0.17 \mathrm{keV}$ level

This plus the 3498.68-keV level may be the level at $3485 \pm 20 \mathrm{keV}$,

NDS1 lists for $(p, \gamma)$ work. Find three weak $\gamma$ 's of total int. 0.6 0.2

depop. level going to 1202.63-, 793.55-and 380.88-keV. Log $\mathrm{ft}=6.7 . \mathrm{J}^{\pi}$ preference $\left(7 / 2^{ \pm}, 9.2^{-}\right)$.

$3498.68 \pm 0.07 \mathrm{keV}$ level

This level plus possibly our $3488.24-\mathrm{keV}$ level may be the level at

$3485 \pm 20 \mathrm{keV}$, NDS1 lists for $(p, \gamma)$ work. Find two $\gamma$ 's depop. level, int.

$3.5 \pm 0.4$, going to 2037.80 - and $380.88-\mathrm{keV}$. Note that the last $\gamma$ is 3117.80 $\mathrm{keV}$ and is close in energy to the $3117.29-\mathrm{keV}$ level but not close enough for assignment as the g.s. transition. $\log \mathrm{ft}=6.1$. $\mathrm{J}^{\pi}$ preference $\left(9 / 2^{+}, 11 / 2^{ \pm}\right)$. 


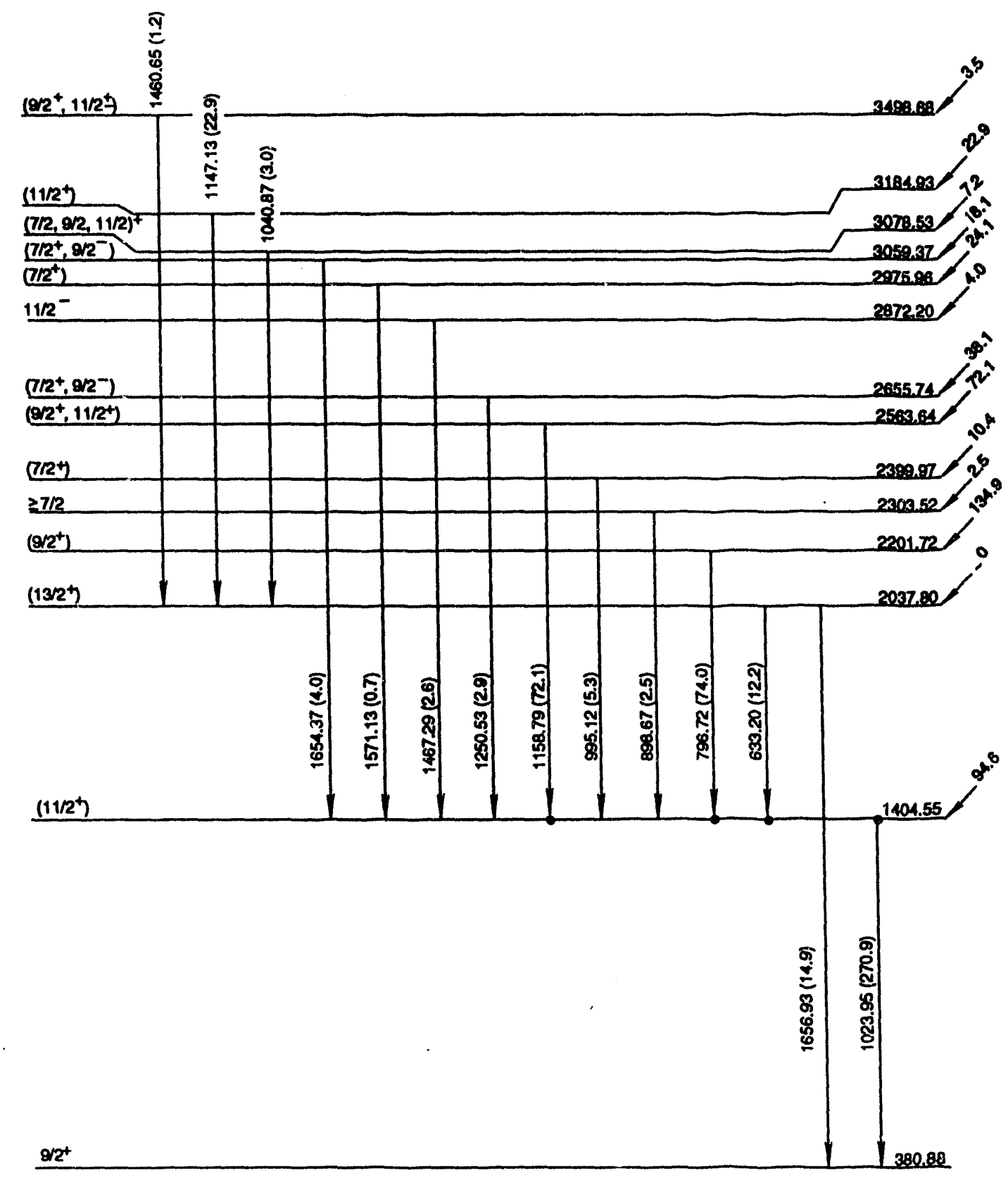

FIG. 1. Population of the $1404.55-$ and the $2037.80-\mathrm{keV}$ levels. 


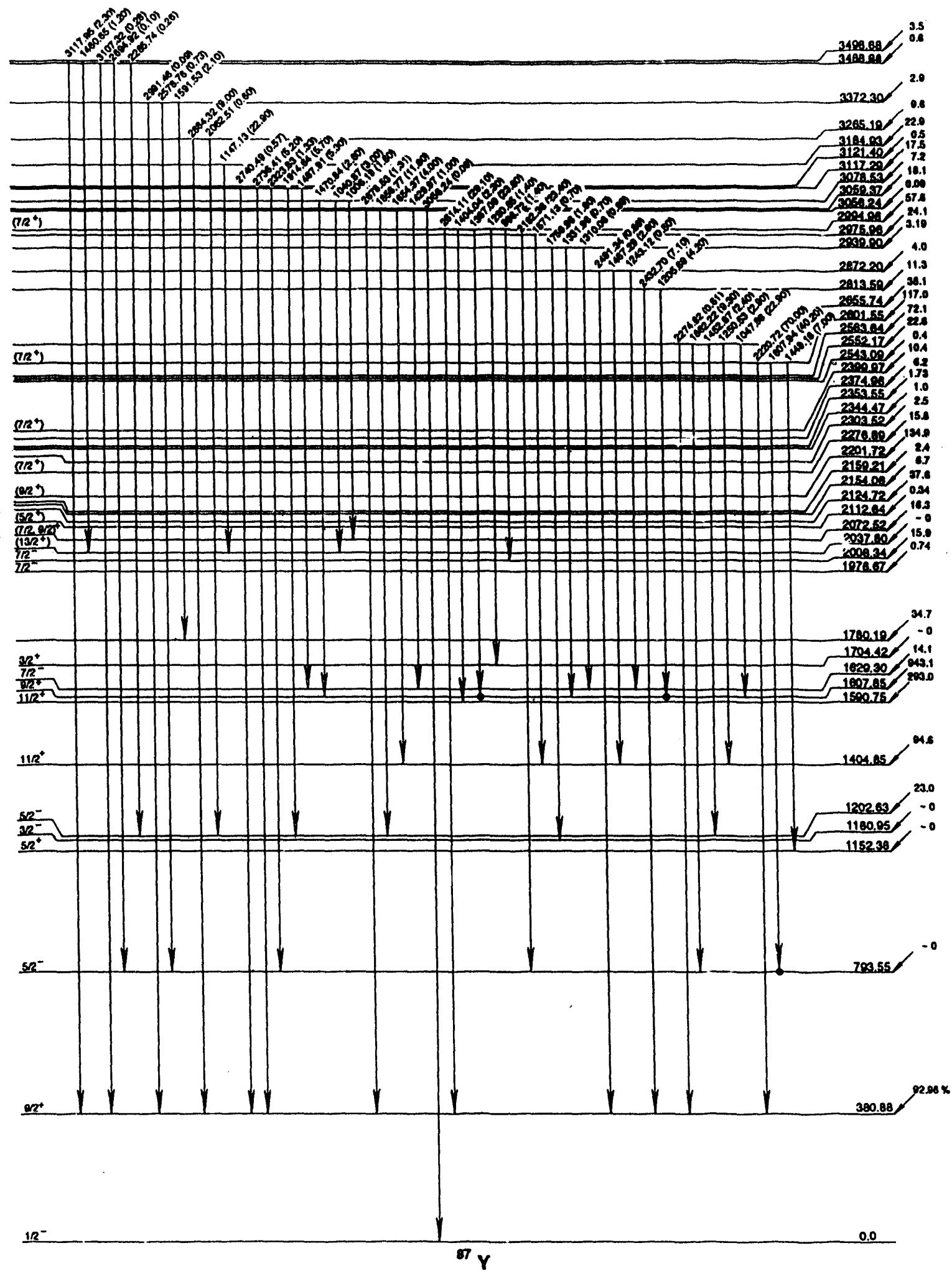

FIG. 2a Proposed energy level scheme of ${ }^{87} Y$ 


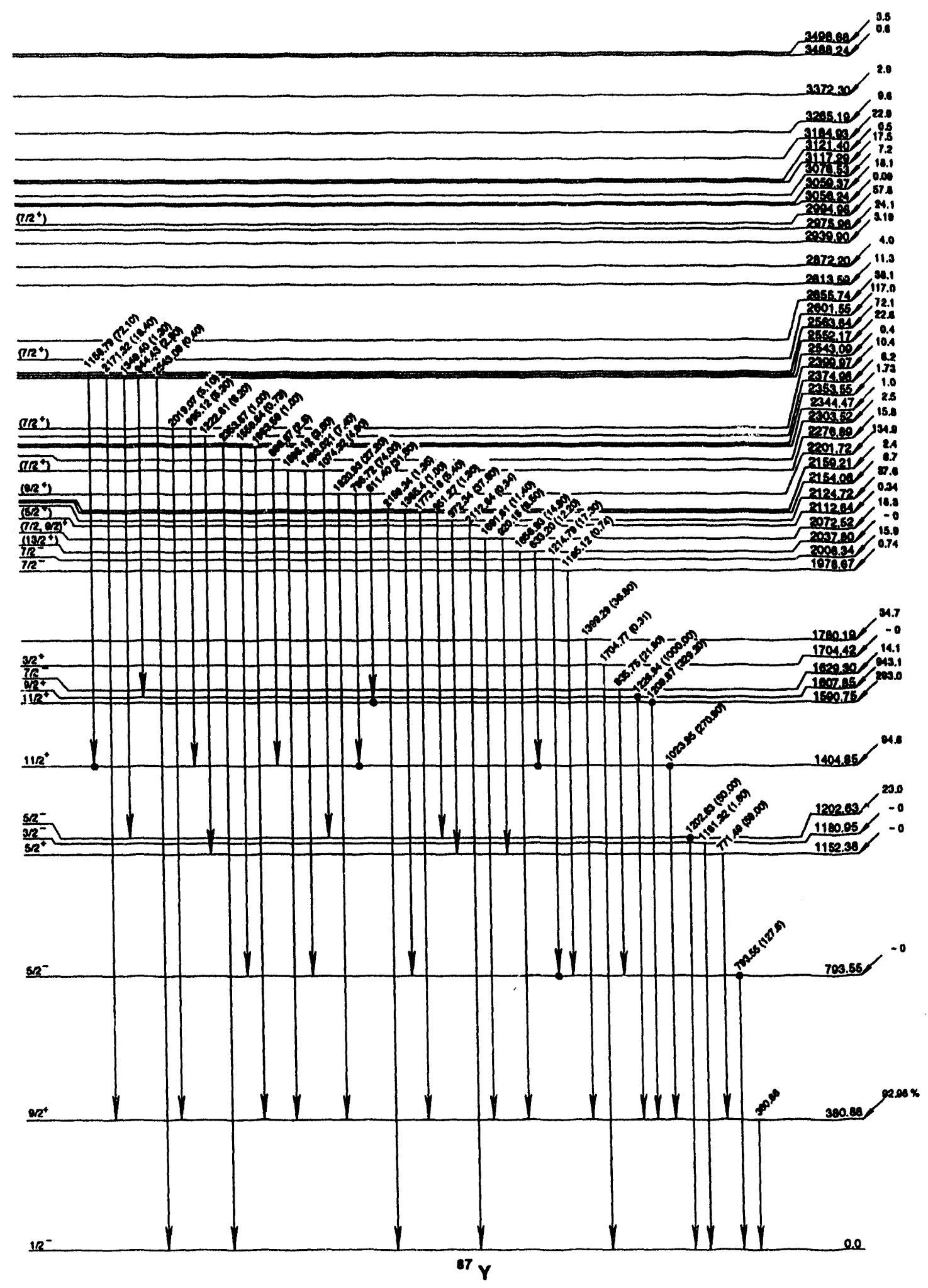

FIG. $2 b$ Proposed energy level scheme of ${ }^{87} Y$ 


\title{
7. Nuclear Reaction Excitation Functions from the Irradiation of
} ${ }^{151,153} \mathrm{Eu}$ with Protons and Deuterons up to $35 \mathrm{MeV}$

\author{
H. I. West, Jr., R. G. Lanier, M. G. Mustafa, and R. M. Nuckolls \\ Lawrence Livermore National Laboratory \\ Livermore, California 94550 \\ a]. Frehaut, A. Adam, and C. Philis \\ Service de Physique et Techniques Nucleaires \\ Boîte Postale No. 12 \\ Centre d'Etudes Bruyeres-le-Chatel \\ 91680 Bruyeres-le-Chatel, France
}

\section{INTRODUCTION}

We have measured the nuclear excitation functions for the reactions produced by protons and deuterons up to $35 \mathrm{MeV}$ on ${ }^{151} \mathrm{Eu}$ and ${ }^{153} \mathrm{Eu}$. The reactions studied along with their respective reaction $Q$ values are listed in Table 1. This work is the result of work begun at Centre $d^{\prime}$ Etudes, Bruyeres-le-Chatel, France (CEB) using the Van de Graaff accelerator to make measurements up to 12 $\mathrm{MeV}$. These measurements were followed up by irradiations, $15-35 \mathrm{MeV}$, at the University of California Crocker Nuclear Laboratory (CNL) at Davis, and with work done later using the newly installed Van de Graaff accelerator at Lawrence Livermore National Laboratory (LLNL).

Earlier measurements of $\mathrm{Eu}$ are not extensive. Komura et al. [1] studied the reactions of protons on Eu up to 52- $\mathrm{MeV}$ proton energy. They used targets of $\mathrm{Eu}_{2} \mathrm{O}_{3}\left(0.9\right.$ to $\left.2.5 \mathrm{mg} / \mathrm{cm}^{2}\right)$ deposited on thin aluminum foils. The proton energy uncertainties at $52-15 \mathrm{MeV}$ were $0.2 \mathrm{MeV}$ at $52 \mathrm{MeV}$ to $1 \mathrm{MeV}$ at $15 \mathrm{MeV}$. At 15 to $6 \mathrm{MeV}$ the uncertainties were $0.2 \mathrm{MeV}$ at $15 \mathrm{MeV}$ to $0.5 \mathrm{MeV}$ at $6 \mathrm{MeV}$. Konyakhin et al. [2] have measured the $(d, 2 n)$ excitation functions up to $21 \mathrm{~A} \therefore \mathrm{V}$. They used thick $\left(38 \mathrm{mg} / \mathrm{cm}^{2}\right)$ encapsulated metallic targets and made no attempt to correct for the target thickness. Cross-section errors were $\pm 20 \%$ and energy errors $\sim 0.2 \mathrm{MeV}$. (Later when we compare our data with these data we update the earlier data as needed for $I \gamma$, isotopic abundances, etc. )

Our 151,153Eu(p,n) 151,153Gd data up to $12 \mathrm{MeV}$ were reported, in part, earlier [3]. The interest there was the appearance of nuclear-shape effects between the near spherical $(\beta=0.13)$ nucleus ${ }^{151} \mathrm{Eu}$ and the prolate $(\beta=0.28)$ nucleus ${ }^{153} \mathrm{Eu}$. The prolate shape enhances the cross-section, relative to the spherical case, by $\sim 35 \%$ at low energies. These data were analyzed by means of a coupled-channel (C.C.) calculation. For the spherical case a Hauser Feshbach calculation, using e.g., the STAPRE code [4] is adequate. 
In the following we first present the details of the target preparation and calibration. This is followed by a discussion of the irradiations and counting of induced activities. We emphasize the fact that the energy ranges covered in the foil stacks overlapped in energy. Since considerable energy could be lost in a target foil, corrections were necessary in the rising portions of some of the excitation functions and the method is discussed. The data are presented and are then compared with theory as explained above.

TABLE 1. Reactions studied.

\begin{tabular}{|c|c|}
\hline Reaction & ${ }^{a} \mathrm{Q}(\mathrm{MeV})$ \\
\hline${ }^{151} \mathrm{Eu}(p, n)^{151} \mathrm{Gd}$ & -1.246 \\
\hline${ }^{153} \mathrm{Eu}(\mathrm{p}, \mathrm{n})^{153} \mathrm{Gd}$ & -1.267 \\
\hline${ }^{151} \mathrm{Eu}(\mathrm{p}, 3 \mathrm{n})^{149} \mathrm{Gd}$ & -16.453 \\
\hline${ }^{153} \mathrm{Eu}(p, 3 n)^{151} \mathrm{Gd}$ & -16.103 \\
\hline${ }^{151} \mathrm{Eu}(p, p 2 n)^{149} \mathrm{Eu}$ & -14.350 \\
\hline$(p, d n)$ & -12.126 \\
\hline$(p, t)$ & -5.869 \\
\hline${ }^{151} \mathrm{Eu}(\mathrm{d}, 2 \mathrm{n}){ }^{151} \mathrm{Gd}$ & -3.470 \\
\hline${ }^{153} \mathrm{Eu}(\mathrm{d}, 2 \mathrm{n})^{153} \mathrm{Gd}$ & -3.491 \\
\hline${ }^{151} \mathrm{Eu}(\mathrm{d}, 4 \mathrm{n})^{149} \mathrm{Gd}$ & -18.676 \\
\hline${ }^{151} \mathrm{Eu}(\mathrm{d}, \mathrm{p} 3 \mathrm{n}){ }^{149} \mathrm{Eu}$ & -16.574 \\
\hline$(d, d 2 n)$ & -14.350 \\
\hline$(d, t n)$ & -8.093 \\
\hline${ }^{153} \mathrm{Eu}(\mathrm{d}, 4 \mathrm{n}){ }^{151} \mathrm{Gd}$ & -18.327 \\
\hline
\end{tabular}

a Masses were taken from Nuclear Wallet Cards, Nat. Nucl. Data Center (1990) by J. K. Tuli. The results are basically from Wapstra and Audi [14]. See text regarding questionable accuracy of mass of ${ }^{153} \mathrm{Gd}$ and derived masses.

\section{THE EXPERIMENT}

\section{Targets}

We used the stacked-foil method for our cross-section measurements. Here one uses a number of target foils in a stack interspersed with aluminum energy degraders and recoil ion collectors. The foil stacks were contained in Faraday cups during irradiation and the accumulated charge measured by means of ORTEC 439 digital current integrators ( $\pm 0.2 \%$ accuracy). Activities were produced in the target foils which were counted off line after the irradiations.

Target preparation was a problem. Europium metal oxidizes rapidly in air; indeed, it ignites at $150-180^{\circ} \mathrm{C}$. Thus, we had to either encapsulate the europium or use a compound. The method we used was to contain the oxide $\mathrm{Eu}_{2} \mathrm{O}_{3}$ in a 
plastic matrix. To prepare the targets, the oxide was mixed with the polyimide resin, DuPont RC5057, which when polymerized is the equivalent of Kapton (a DuPont trade name). The mixture was spread out uniformly on glass and cured at temperatures up to $260^{\circ} \mathrm{C}$. The procedure was thoroughly tested using loadings of TiO2; and cross sections measured with the loadings were compared with results obtained from metallic foils. The method is described further in Paper 1. of this report.

For targets we punched out discs $25.4 \mathrm{~mm}$ in diameter from the Kapton sheets. The aerial densities of $\mathrm{Eu}$ in the target foils were intercompared by means of $x$-ray fluorescent spectrometry. The excitor source was ${ }^{241} \mathrm{Am}$, which decays with a $60-\mathrm{keV} \gamma$. The foils were thick enough that we had to correct for the absorption of both the excitor source $\gamma$-rays and the resultant $x$-rays. To calculate the self-absorption correction, we used literature values for the absorption coefficients. In the case of Kapton (here and for calculation of projectile energy loss), we need to know its elemental composition. Three HCNO assays yielded concentrations by weight as follows: $\mathrm{H}(3.5 \%), \mathrm{C}(64.94 \%), \mathrm{N}(8.00 \%)$ and $\mathrm{O}$ $(23.47 \%)$. X-ray fluorescent spectrometry gave only the relative areal density of the foils. For an absolute calibration, ten foils were burned to ash (individually) and the ash weighed as $\mathrm{Eu}_{2} \mathrm{O}_{3}$. All of the calibration measurements agreed to better than $1 \%$.

The areal density of the foils varied between 10 and $20 \mathrm{mg} / \mathrm{cm} 2$. One third of the density was elemental europium. As part of the foil analysis procedure, the foils were checked for uniformity by a four-point scan of each foil with the excitor g-rays using a $15 \mathrm{~mm}$ diameter mask defining the area being examined. Only foils uniform to better than $2 \%$ were accepted.

\section{The Irradiations}

When the work began, LLNL was in the process of installing a tandem Van de Graaff accelerator, thus the initial work up to $12 \mathrm{MeV}$ was carried out at the CEB in France. Later work was carried out at 15 to $35 \mathrm{MeV}$ using the cyclotron at the Crocker Nuclear Laboratory (CNL) at the University of California, Davis, followed up by complementary measurements up to $17 \mathrm{MeV}$ using the LLNL Tandem. For the cyclotron work, the foil stacks covered the range of about 5 $\mathrm{MeV}$ down from the incident projectile energy, thus runs at 15, 20,25, 30, and 35 $\mathrm{MeV}$ provided measurements down to about $10 \mathrm{MeV}$.

Foil stacks consisted of one to six target foils interspersed with thin aluminum used to degrade the beam energy and to catch ions that had recoiled out of the target foils. The catcher foils were counted to provide part of the target activity. In the rising portion of the excitation function, it was often necessary to use only one foil because of the large changes in energy of the projectiles in passing through target foils. Careful corrections for energy loss were made, as discussed later. At higher energies when working with the cyclotron, especially where we wanted considerable energy overlap in the measurements, we used up to six foils. 
There was concern about heat loss in the foils. To circumvent, this we rastered the beam over the target, i.e., over an area about one centimeter square. Besides reducing heat loading, this procedure helped average out any small non-uniformities in the foils. As a result of this, we were able to use currents up to 1.0 ramp with a heat loading up to one watt per foil.

\section{Data Reduction}

The foils from the first set of experiments were counted both at CEB and on our automated germanium $\gamma$-ray spectrometer system at LLNL and the $\gamma$ ray activities extracted. All later measurements were made at LLNL. Details of the counting of each nuclide will be discussed later. Here we discuss the analysis of the data to obtain the true cross-section and energy once the apparent crosssections have been measured. The apparent cross-sections is obtained by associating the measured activity in a foil with the average energy of the projectile in the foil. Because, often, there is the need to compare two or more cross-sections extracted from a single foil, we used the average energy of the projectile in the foil and then corrected the cross-sections accordingly. To obtain the average energy, we had to calculate the energy loss in each foil in the stack. Our calculations made use of the proton energy-loss calculations of Janni [5], which for deuterons were scaled properly to take care of the mass change. For Kapton, we used the elemental composition given earlier. Here, one must be careful since Kapton can pick up moisture, as much as $1 \%$ in weight. To insure ourselves that our energy-loss $r$ measurements on single foils a deuteron energies. We found $t h$. ions were accurate, we made tacks at the CEB using various proton and was less than $3 \%$ . even a 3-MeV energy loss our uncertainty

For the Van de Graaff work, the uncertainty in the bombarding energies was less than $50 \mathrm{keV}$, and in most cases below $14 \mathrm{MeV}$ the accumulated error in average energy in a foil was less than $100 \mathrm{keV}$. For the cyclotron work we had to rely upon a time of flight method, the so-called "Gamma Flash," to determine the energies. Here, the errors were larger. After needed corrections were applied, we found that for above $17 \mathrm{MeV}$ the errors varied from $\pm 100 \mathrm{keV}$ at $17 \mathrm{MeV}$ to $\pm 250 \mathrm{keV}$ at $35 \mathrm{MeV}$.

In the rising portion of the excitation functions, for the first order data, the energy loss in a foil could be as much as $1 \mathrm{MeV}$, which resulted in an apparent cross-section larger than the true cross-section. To obtain the true cross-section, we had to solve an integral equation by methods we have described previously in [6] and in Paper Two of this report. To do the deconvolution, we express the apparent cross-sections in a power series: $\ln \sigma(E)=A+B \ln E+C(\ln E)^{2}+\ldots \ldots .$. We note that the correction that must be applied to the data is dependent strongly on the slope of the data curve $d \ln \sigma(E) / d E$ and is insensitive to the magnitude of $\sigma(E)$. Thus, simply by integrating $\sigma(E)$ over the foil thickness, including straggling and comparing the value to $\sigma\left(E_{a v}\right)$ from the polynomial, we obtain a good correction, even for the first iteration. One repeats the process for each foil 
as needed. Note that this procedure does not average the data unless, of course, one reports $\sigma(E)$ from the data fit, and we do not. This procedure was applied primarily to the low-energy data up to $\sim 12 \mathrm{MeV}$. For the higher energies with reduced energy loss in the foil and greater uncertainty in the projectile energies, the correction usually was not warranted.

\section{Production of ${ }^{151,153} \mathrm{Gd}$}

\section{RESULTS}

The measurements of ${ }^{151,153} \mathrm{Eu}(\mathrm{p}, \mathrm{n}){ }^{151,153} \mathrm{Gd}$ and ${ }^{151,153} \mathrm{Eu}(\mathrm{d}, 2 \mathrm{n}){ }^{151,153} \mathrm{Gd}$ covering the energy range up to $12 \mathrm{MeV}$ were begun at $\mathrm{CEB}$ and finished at LLNL. The targets were initially counted at CEB and then sent to LLNL for cross calibration. In most cases, the two sets of measurements agreed within experimental error. The $\gamma$-ray energies and $I \gamma / s$ used for ${ }^{151} \mathrm{Gd}$ and ${ }^{153} \mathrm{Gd}$ are given in Table 2. The half lives are due to Nethaway of our laborato:y Iprivate communication, LLNL]. The I $\gamma$ for the $153.6-\mathrm{keV}$ gamma of ${ }^{151} \mathrm{Gd}$ is the average of $6.1(5 \%)$ of Gregorich, et al. [7] and the 6.3(4\%) of Voth, et al. [8]. The I $\gamma(5 \%)$ for the $97.43-\mathrm{keV}$ gamma of ${ }^{153} \mathrm{Gd}$ is from the Table of Radioactive Isotopes. [9] The other $\gamma$-ray intensities were adjusted slightly from that in the literature to fit the relative intensities measured at $\mathrm{CEB}$. The isotopic abundances used for natural europium are $47.8 \%$ for ${ }^{151} \mathrm{Eu}$ and $52.2 \%$ for ${ }^{153} \mathrm{Eu}$. $K_{\alpha}$ and $K_{\beta} x$-rays produced in the decay of $\mathrm{Gd}$ are 41 to $48 \mathrm{keV}$. Because of the germanium detector dead layers and the geometry used, we did not use additional absorbers and do not believe that there was significant loss $(>1 \%)$ due to $x-\gamma$ and/or $\gamma-\gamma$ coincidence summing.

TABLE 2. Decay scheme data for ${ }^{151} \mathrm{Gd}$ and ${ }^{153} \mathrm{Gd}$

\begin{tabular}{llr}
\hline & $\mathrm{E}(\mathrm{keV})$ & $\mathrm{I} \gamma(\%)$ \\
${ }^{151} \mathrm{Gd}\left(\mathrm{t}_{1 / 2}=125.6 \mathrm{~d}\right)$ & 153.6 & $6.20^{\mathrm{a}}$ \\
Isotopic abundance $47.8 \%$ & 174.7 & $2.98^{\mathrm{a}}$ \\
& 243.2 & $5.58^{\mathrm{a}}$ \\
& & \\
& & \\
& & \\
& & \\
& & \\
Is3 Gd $\left(\mathrm{t}_{1 / 2}=237.9 \mathrm{~d}\right)$ & 97.43 & $27.60^{\mathrm{b}}$ \\
a Error takic abundance $52.2 \%$ & 103.18 & $20.45^{\mathrm{b}}$ \\
b Error $\pm 5 \%$. & & \\
\end{tabular}

First order results acquired as a result of ${ }^{151} \mathrm{Gd}$ and ${ }^{153} \mathrm{Gd}$ counting are given in Table 4 for protons and in Table 6 for deuterons. For ${ }^{153} \mathrm{Eu}(\mathrm{p}, \mathrm{n})^{153} \mathrm{Gd}$ and ${ }^{153} \mathrm{Ev}(\mathrm{d}, 2 \mathrm{n}){ }^{153} \mathrm{Gd}$ there are no competing reactions producing ${ }^{153} \mathrm{Gd}$ so that these reactions are easily measured up to 35 and $33 \mathrm{MeV}$ respectively. For ${ }^{151} \mathrm{Gd}$ we obtained both ${ }^{151} \mathrm{Eu}[(p, n) \&(d, 2 n)]^{151} \mathrm{Gd}$ and the higher or 'er reactions 
${ }^{153} \mathrm{Eu}[(p, 3 n) \&(d, 4 n)]^{151 G d}$. These sets of data were analyzed assuming the ${ }^{151} \mathrm{Eu}$ isotopic abundance. The high-energy tails of the corresponding ${ }^{153} \mathrm{Gd}$ first order reactions were fit with a polynomial, the results normalized to the tails of the ${ }^{151} \mathrm{Gd}$ distribution at intermediate energies and subtracted to yield the higher order $(p, 3 n)$ and $(d, 4 n)$ data after correcting for different isotopic abundances (see footnote $b$ in Table 4). These normalized tails are shown as changes in symbols in Fig. 1 and Fig. 6. The resultant data for ${ }^{153} \mathrm{Eu}(p, 3 n){ }^{151} \mathrm{Eu}$ and ${ }^{153} \mathrm{Eu}(\mathrm{d}, 4 n){ }^{151} \mathrm{Gd}$ after the tail subtractions are given in Tables 5 and 7.

Results for ${ }^{149} \mathrm{Gd}$ and ${ }^{149} \mathrm{Eu}$

At energies from $\sim 14$ to $35 \mathrm{MeV}$ we observed the higher order reactions ${ }^{151} \mathrm{Eu}(\mathrm{p}, 3 n){ }^{149} \mathrm{Gd},{ }^{151} \mathrm{Eu}(\mathrm{d}, 4 n){ }^{149} \mathrm{Gd},{ }^{151} \mathrm{Eu}\left[\mathrm{p},(\mathrm{p} 2 \mathrm{n}+\mathrm{dn}){ }^{149} \mathrm{Eu}\right.$, and ${ }^{151} \mathrm{Eu}[\mathrm{d},(\mathrm{p} 3 \mathrm{n}+\mathrm{d} 2 \mathrm{n})]^{149} \mathrm{Eu}$. The measurements of the ${ }^{149} \mathrm{Eu}$ cross-sections are complicated except at the lowest energies because of the feeding from the ${ }^{149} \mathrm{Gd}$ decay and because of the low values of $I \gamma$ for the ${ }^{149} \mathrm{Eu}$ decay.

The most intense gamma rays in the decay of ${ }^{149} \mathrm{Gd}$ are as listed in Table 3. The relative values were determined from 21 sets of counting on four different counters. Sen et al. [10] obtained somewhat different values. For the $149.7-\mathrm{keV}$ gamma, one obtains $49.4 \%$ from their data. Nuclear Data Sheets [Sziics et al. Ref 11] gives $49.0 \%$, which we used. Our data consistency would be inferior for values much different than this.

TABLE 3. ${ }^{149} \mathrm{Gd}$ and ${ }^{149} \mathrm{Eu}$ decay scheme data

\begin{tabular}{lcc}
\hline & $\mathrm{E}(\mathrm{keV})$ & $\frac{\operatorname{Rel} I \gamma(\%)}{100^{\mathrm{a}}}$ \\
${ }^{149} \mathrm{Gd}(9.282 \pm 0.008 \mathrm{~d})$ & 149.7 & $57.28^{\mathrm{a}}$ \\
& 298.6 & $48.37^{\mathrm{a}}$ \\
& 346.7 & $\frac{I \gamma(\%)}{}$ \\
${ }^{149} \mathrm{Eu}(93.1 \mathrm{~d})$ & 277.09 & $3.55 \pm 0.11$ \\
& 327.53 & $4.03 \pm 0.12$ \\
&
\end{tabular}

The half-life of ${ }^{149} \mathrm{Gd}$ was not well known. To improve on it we counted two samples for $115 \mathrm{~d}$, obtaining 15-17 countings for the two most intense gammas in the decay. Analysis of the data yielded a half-life of $9.282 \pm 0.008 \mathrm{~d}$.

The ${ }^{149} \mathrm{Eu}$ data listed in Table 3 are accepted in Nuclear Data Sheets [12]. These are measurements by Meyer et al. [13] of our laboratory.

In order to obtain the ${ }^{149} \mathrm{Eu}$ cross-sections, we must solve the equation

$$
N_{02}=N_{2} e^{\lambda_{2} t}-\frac{\lambda_{1}}{\lambda_{2}-\lambda_{1}} e^{\lambda_{2} t}\left(e^{-\lambda_{1} t}-e^{-\lambda_{2} t}\right) N_{01}
$$


Here $N_{02}$ is the number of ${ }^{149} \mathrm{Eu}$ atoms at zero time, $N_{01}$ the number of ${ }^{149} \mathrm{Gd}$ atoms at zero time, and $N_{2}$ the number of ${ }^{149} \mathrm{Eu}$ atoms at time $t$. (Here, zero time is the end of bombardment, assuming a short bombardment time.) Our procedure was to determine $N_{01}$ from the total ${ }^{149} \mathrm{Gd}$ counting for the foil. We note that $N_{2}=A_{2} / \lambda_{2}$ contains $I \gamma$ in the denominator in its evaluation and since $I \gamma$ is small, the corresponding counting rates were small also and subject to error. Thus, in the region of low ${ }^{149} \mathrm{Eu}$ cross-sections and relatively high ${ }^{149} \mathrm{Gd}$ cross-sections, there was considerable error in the analysis. Fortunately, at the extremes in energy, good data were obtained.

The results for these higher-order reactions are given in Tables 5 and 7 and in Figures 3, 5, 8 and, 10.

\section{MODELING}

Our efforts at modeling have centered around the use of the HauserFeshbach statistical-model code STAPRE [4]. For a good example of past work using the ideas we have tried here see our paper on the bromine and iodine excitation functions [15]. We have used only the back-shifted (BS) prescription [16] as a means of introducing level-densities to the code. We have had success for the ${ }^{151} \mathrm{Eu}(\mathrm{p}, \mathrm{n})$ and $(\mathrm{p}, 3 \mathrm{n})$ reactions using $K=700$ to 900.

For ${ }^{153} \mathrm{Eu}$ we encountered serious problems, not only because or the nuclear shape problem, but because the mass of ${ }^{153} \mathrm{Gd}$ as given in the latest compilation of Wapstra and Audi [14] appears to be incorrect. They ignore the ${ }^{153} \mathrm{Gd}$ electron capture data of Boyer et al. [17] and Cretzu et al. [18] which determine the decay energy $Q_{\varepsilon}$ to be $240 \pm 3 \mathrm{keV}$. For allowed transitions, the measured $Q_{\varepsilon}$ should be very good. Wapstra and Audi adopt $484 \mathrm{keV}$ based on an unavailable report on charged particle data. All data derived from this value is suspect. We find that the old 1977 mass table [19] gives more reasonable results, with possibly some updating from the work of Voth et al. [20].

Even with this change, we have the problem of nuclear shape which can be allowed for partially by increasing the equivalent spherical radius by $1 \%$. This is not enough. We have also attempted to use the level density values Dilg et al. [21] and of Von Egidy et al. [22, 23]. Also, Ignatyuk has kindly attempted to provide a set of level densities [24]. At this point we have not exhausted this approach but it may be necessary to carry out a coupled-channel calculation before the problem is solved.

It is expected that the deuteron data for ${ }^{151} \mathrm{Eu}$ will require the same kind of treatment that we used for the halides [15]. For the ${ }^{153} \mathrm{Eu}$ data, however, we anticipate further problems. 


\section{ACKNOWLEDGMENTS}

We thank Plastics Shop and Material Fabrication Division for their help in making the targets. We thank the Van de Graaff crew at Bruyeres-le-Chatel for their help in making the irradiations. We thank the crews at LLNL and Crocker Laboratory, The University of California, Davis for their help in making irradiations. This work was performed under the auspices of the U.S. Department of Energy by Lawrence Livermore National Laboratory, Contract No. W-7405-ENG-48 and under the auspices of the Commissariat a l'Energie Atomique of France.

\section{REFERENCES}

[1] K. Komura, S. Tanaka, M. Uesugi, and M. Sakanoue, J. Inorg. Nucl. Chem. 38, 2157 (1976).

[2] N. A. Konyakhin, I. O. Konstantinov, P. O. Dmitriev, N. N. Krasnov, and V. M. Tuev, Sov. Atom. Energy 27, 944 (1969).

[3] R. G. Lanier, H. I. West, Jr., M. G. Mustafa, J. Frehaut, A. Adam, and C. A. Philis, Phys. Rev C 42, R479 (1990).

[4] M. Uhl and B. Strohmaier, Institut für Radiumforschung und Kernphysik (Vienna), Report No. IRK 76/01 with Addenda (1976).

[5] J. F. Janni, Atomic Data and Nuclear Data Tables 27, 147 \& 341 (1982).

[6] M. G. Mustafa, H. I. West, Jr., H. O'Brien, R. G. Lanier, M. Benhamou, and T. Tamura, Phys. Rev. C 38, 1624 (1988).

[7] . K. E. Gregorich, J. J. Moody, and G. T. Seaborg, Radio. Chem. Acta 35, 1 (1984).

[8] E. Voth, W.-D. Schmidt-Ott, and H. Behrens, Zeit. Phys. A313, 167 (1983).

[9] Table of Radioactive Isotopes, E. Browne, R.B. Firestone, edited by V.S. Shirley, John Wiley \& Sons (1986).

[10] P. Sen, H. Bakhru, N. Cue, R. Wiedeman, and J. Sprindele, Z. Phys. A275, 381 (1975).

[11] J. A. Sziics, M. W. Johns, and B. Singh, Nucl. Data Sheets 46, 147 (1985).

[12] J.A. Sziics, M. W. Johns, and B. Singh, Nucl. Data Sheets 46, 131 (1985). 
[13] R. A. Meyer, J. W. Meadows, and E. S. Marceas, J. Phys (London) G8, 1413 (1982).

[14] Atomic Mass Table, A. H. Wapstra, and G. Audi, Nuclear Phys. A432, 1 (1985).

[15] H. I. West, Jr., R. M. Nuckolls, B. Hudson, B. Ruiz, R.G. Lanier, and M.G. Mustafa, Phys. Rev. C 47, 248 (1993).

[16] W. Dilg, W. Schantil, H. Vonach, and M. Uhl, Nucl. Phys. A217, 269 (1973).

[17] P. Boyer, P. Chedin and J. Oms, Nucl. Phys. A99, 213 (1967).

[18] T. Cretzu, K. Hohmuth and G. Winter, Nucl. Phys. 56, 415 (1964).

[19] A. H. Wapstra and K. Bos, Atomic Data Tables 19, 177 (1977).

[20] E. Voth, W.-D. Schmidt-Ott, and H. Behrens, Z. Phys. A Atom. Nucl. 313, 167 (1983).

[21] W. Dilg, W. Schantil, H. Vonach, and M. Uhl, Nucl. Phys. A217, 269 (1973).

[22] T. Von Egidy, A. N. Behkami, and H. H. Schmidt, Nucl. Phys. A454, 109 (1986).

[23] T. Von Egidy, H. H. Schmidt, and A. N. Behkami, Nucl. Phys. A481, 189 (1988).

[24] A. V. Ignatyuk, The Univ. of Kentucky, private communication (1992). 
TABLE 4. Europium proton data: First order reaction Cross-sections (mb)

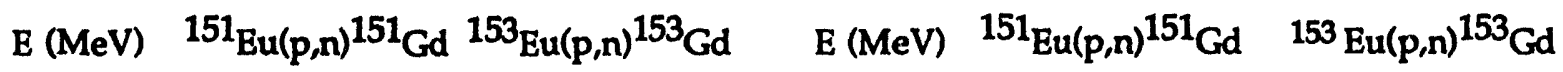

\begin{tabular}{|c|c|c|c|c|c|}
\hline $\begin{array}{l}4.72^{\mathrm{a}} \\
5.50 \\
5.71 \\
5.91 \\
6.03\end{array}$ & $\begin{array}{c}1.62 \pm 0.03^{a} \\
6.44 \pm 0.06 \\
7.40 \pm 0.05 \\
11.54 \pm 0.10 \\
11.98 \pm 0.10\end{array}$ & $\begin{array}{r}2.35 \pm 0.02^{a} \\
8.92 \pm 0.05 \\
10.20 \pm 0.04 \\
16.30 \pm 0.04 \\
16.56 \pm 0.05\end{array}$ & $\begin{array}{l}18.15 \\
18.77 \\
19.30 \\
19.70 \\
19.93\end{array}$ & $\begin{array}{l}(33.1) \\
(31.3) \\
(30.2) \\
(29.4) \\
(29.1)\end{array}$ & $\begin{array}{l}35.3 \pm 0.5 \\
35.2 \pm 0.2 \\
34.8 \pm 0.4 \\
33.9 \pm 0.4 \\
32.2 \pm 0.5\end{array}$ \\
\hline $\begin{array}{l}6.12 \\
6.38 \\
6.42 \\
6.63 \\
6.93\end{array}$ & $\begin{array}{l}15.5 \pm 0.1 \\
20.3 \pm 0.2 \\
24.9 \pm 0.5 \\
30.5 \pm 0.5 \\
42.7 \pm 0.7\end{array}$ & $\begin{array}{l}21.1 \pm 0.07 \\
27.9 \pm 0.20 \\
34.5 \pm 0.4 \\
41.8 \pm 0.3 \\
58.2 \pm 0.3\end{array}$ & $\begin{array}{l}20.42 \\
21.05 \\
21.50 \\
22.23 \\
22.63\end{array}$ & $\begin{array}{l}(28.3) \\
(27.8) \\
(26.8) \\
(26.0) \\
(25.2)\end{array}$ & $\begin{array}{l}32.3 \pm 0.5 \\
31.3 \pm 1.4 \\
30.4 \pm 0.6 \\
30.0 \pm 1.1 \\
28.4 \pm 0.6\end{array}$ \\
\hline $\begin{array}{l}7.17 \\
7.44 \\
7.85 \\
8.20 \\
8.48\end{array}$ & $\begin{array}{r}54.8 \pm 0.8 \\
66.4 \pm 0.6 \\
98.9 \pm 0.4 \\
128.2 \pm 1.0 \\
151.0 \pm 1.5\end{array}$ & $\begin{array}{r}74.3 \pm 0.4 \\
92.6 \pm 0.5 \\
129.7 \pm 0.5 \\
160.1 \pm 0.6 \\
185.1 \pm 0.4\end{array}$ & $\begin{array}{l}23.40 \\
23.91 \\
24.65 \\
25.04 \\
25.93\end{array}$ & $\begin{array}{l}(24.9) \\
(24.5) \\
(23.9) \\
(23.6) \\
(22.8)\end{array}$ & $\begin{array}{l}27.8 \pm 1.1 \\
26.9 \pm 0.3 \\
28.0 \pm 1.2 \\
25.6 \pm 0.3 \\
25.2 \pm 0.6\end{array}$ \\
\hline $\begin{array}{r}8.82 \\
9.29 \\
10.10 \\
10.30 \\
10.48\end{array}$ & $\begin{array}{l}168.4 \pm 2.0 \\
190.9 \pm 2.0 \\
195.9 \pm 1.5 \\
192.5 \pm 1.5 \\
186.2 \pm 1.4\end{array}$ & $\begin{array}{l}202.0 \pm 3.3 \\
215.4 \pm 1.0 \\
212.0 \pm 0.4 \\
208.1 \pm 0.7 \\
191.1 \pm 0.7\end{array}$ & $\begin{array}{l}26.60 \\
27.15 \\
28.16 \\
28.36 \\
30.11\end{array}$ & $\begin{array}{l}(22.3) \\
(21.9) \\
(21.2) \\
(21.0) \\
(19.6)\end{array}$ & $\begin{array}{l}26.3 \pm 0.6 \\
25.8 \pm 1.0 \\
23.2 \pm 0.5 \\
23.2 \pm 1.0 \\
21.8 \pm 0.4\end{array}$ \\
\hline $\begin{array}{l}10.65 \\
10.95 \\
11.58 \\
12.03 \\
13.28\end{array}$ & $\begin{array}{r}185.4 \pm 1.3 \\
169.1 \pm 2.0 \\
152.8 \pm 2.0 \\
131.0 \pm 0.4 \\
93.5 \pm 1.4\end{array}$ & $\begin{array}{l}200.2 \pm 0.6 \\
187.1 \pm 1.5 \\
170.3 \pm 1.5 \\
148.4 \pm 0.6 \\
101.0 \pm 0.7\end{array}$ & $\begin{array}{l}31.16 \\
31.94 \\
32.65 \\
33.19 \\
34.09 \\
35.49\end{array}$ & $\begin{array}{l}(18.8) \\
(18.2) \\
(17.7) \\
(17.4) \\
(16.6) \\
(15.6)\end{array}$ & $\begin{array}{l}21.2 \pm 0.7 \\
20.6 \pm 0.5 \\
19.3 \pm 0.5 \\
19.4 \pm 0.5 \\
19.0 \pm 0.7 \\
17.7 \pm 0.5\end{array}$ \\
\hline $\begin{array}{l}13.61 \\
13.66 \\
14.44 \\
14.62\end{array}$ & $\begin{array}{l}81.8 \pm 0.4 \\
84.9 \pm 0.1 \\
64.4 \pm 0.3 \\
61.9 \pm 0.5\end{array}$ & $\begin{array}{l}90.6 \pm 0.6 \\
90.9 \pm 0.3 \\
71.5 \pm 0.4 \\
68.3 \pm 0.2\end{array}$ & \multirow{2}{*}{\multicolumn{3}{|c|}{$\begin{array}{l}\text { a Resolution corrections were applied in the } \\
\text { rising portions of the excitation functions. } \\
\text { b Tail of the distribution given in column } 2 \\
\text { was determined from a fit to the }{ }^{153} \mathrm{Gd} \text { data } \\
\text { followed by a normalization at } \sim 14-16 \mathrm{MeV} \\
\text { to the }{ }^{151} \mathrm{Gd} \text { data and reducing by } 1.125 \text {. } \\
\text { Subtracting the tail from the }{ }^{151} \mathrm{Gd} \text { data } \\
\text { and correcting for isotopic abundances then } \\
\text { yielded the }{ }^{153} \mathrm{Eu}(\mathrm{p}, 3 \mathrm{n}){ }^{151} \mathrm{Gd} \text { cross sections } \\
\text { in Table } 5 \text {. }\end{array}$}} \\
\hline $\begin{array}{l}15.05 \\
15.71 \\
15.91 \\
16.38 \\
16.78\end{array}$ & $\begin{array}{l}56.7 \pm 0.3 \\
52.2 \pm 0.4 \\
45.05 \pm 0.3 \\
42.2 \pm 0.2 \\
38.0 \pm 0.3 \\
37.6 \pm 0.3\end{array}$ & $\begin{array}{r}58.6 \pm 0.2 \\
51.1 \pm 0.2 \\
47.7 \pm 0.2 \\
45.1 \pm 0.2 \\
-42.9 \pm 0.2\end{array}$ & & & \\
\hline $\begin{array}{l}16.89 \\
17.79 \\
17.93\end{array}$ & $\begin{array}{l}35.6 \pm 0.3 \\
(34.0)^{\mathrm{b}} \\
(33.7)\end{array}$ & $\begin{array}{l}40.2 \pm 0.2 \\
38.7 \pm 0.5 \\
36.3 \pm 0.4\end{array}$ & \multicolumn{3}{|c|}{$\begin{array}{l}\text { Errors given are stat. A systematic error of } \\
\pm 3 \% \text { should be added in quadrature plus the } \\
\text { errors in I . The errors are given this way to } \\
\text { facilitate taking ratios of data. }\end{array}$} \\
\hline
\end{tabular}


TABLE 5. Europium proton data: Higher order reactions.

Cross-sections (mb)

\begin{tabular}{|c|c|c|c|}
\hline $\mathbf{E}(\mathrm{MeV})$ & ${ }^{153} \mathrm{Eu}(p, 3 n)^{151_{G d^{a}}}$ & 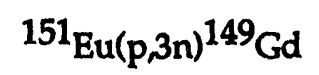 & ${ }^{151} \mathrm{Eu}[\mathrm{p},(\mathrm{p} 2 \mathrm{n}+\mathrm{dn})]^{149} \mathrm{Eu}$ \\
\hline 14.44 & & & $0.93 \pm 0.10$ \\
\hline 14.62 & & & $1.28 \pm 0.12$ \\
\hline 14.81 & & & $1.93 \pm 0.23$ \\
\hline 15.05 & & & $1.85 \pm 0.23$ \\
\hline 15.71 & & & $2.5 \pm 0.1$ \\
\hline 15.91 & & & $3.0 \pm 0.2$ \\
\hline 16.38 & & & $2.7 \pm 0.3$ \\
\hline 16.78 & & $0.13 \pm 0.01$ & $3.7 \pm 0.2$ \\
\hline 16.89 & & $0.16 \pm 0.01$ & $3.8 \pm 0.5$ \\
\hline 17.79 & $34.2 \pm 0.5$ & $29.0^{ \pm 0.1}$ & $4.2 \pm 0.5$ \\
\hline 17.93 & $45.3 \pm 0.7$ & $41.3 \pm 0.1$ & $4.8 \pm 0.8$ \\
\hline 18.15 & $73.6 \pm 1.0$ & $69.2 \pm 0.2$ & $7.5 \pm 1.2$ \\
\hline 18.77 & $141.3 \pm 0.8$ & $141.1 \pm 0.4$ & $7.7 \pm 1.5$ \\
\hline 19.30 & $249.3 \pm 1.6$ & $261.3 \pm 0.6$ & $9.7 \pm 1.7$ \\
\hline 19.70 & $296.5 \pm 2.7$ & $315.1 \pm 1.3$ & $12.2 \pm 2.3$ \\
\hline 19.93 & $318.6 \pm 2.2$ & $342.0 \pm 1.6$ & $13.8 \pm 3.3$ \\
\hline 20.42 & $452.6 \pm 2.2$ & $487.8 \pm 1.2$ & \\
\hline 21.05 & $552.1 \pm 2.1$ & $601.1 \pm 4.8$ & $24.6 \pm 7.1$ \\
\hline 21.50 & $619.5 \pm 2.3$ & $678.7 \pm 1.3$ & $11.1 \pm 5.0$ \\
\hline 22.23 & $736.0 \pm 3.1$ & $805.1 \pm 3.4$ & $29.2 \pm 7.9$ \\
\hline 22.63 & $765.9 \pm 3.3$ & $840.0 \pm 2.0$ & $11.3 \pm 4.7$ \\
\hline 23.40 & $843.6 \pm 4.5$ & $925.8 \pm 2.3$ & $27.1 \pm 6.0$ \\
\hline 23.91 & $927.4 \pm 6.7$ & $973.0 \pm 3.7$ & $28.7 \pm 5.6$ \\
\hline 24.65 & $922.2 \pm 8.3$ & $1016.3 \pm 2.3$ & $49.2 \pm 11.6$ \\
\hline 25.04 & $945.8 \pm 8.0$ & $1039.7 \pm 2.7$ & $38.8 \pm 4.3$ \\
\hline 25.93 & $969.1 \pm 2.3$ & $1088.5 \pm 2.4$ & $67.8 \pm 8.7$ \\
\hline 26.60 & $948.8 \pm 12$ & $1080.5 \pm 2.8$ & $43.9 \pm 4.6$ \\
\hline 27.15 & $929.6 \pm 6.3$ & $1073.7 \pm 2.8$ & $91.9 \pm 9.3$ \\
\hline 28.16 & $872.6 \pm 5.2$ & $1032.6 \pm 2.4$ & $65.9 \pm 4.1$ \\
\hline 28.36 & $858.1 \pm 5.3$ & $1022 \pm 3$ & $103 \pm 11$ \\
\hline 30.11 & $725 \pm 5$ & $878 \pm 5$ & $123 \pm 7$ \\
\hline 31.16 & $607 \pm 4$ & $765 \pm 3$ & $117 \pm 7$ \\
\hline 31.94 & $545 \pm 4$ & $680 \pm 2$ & $122 \pm 3$ \\
\hline 32.65 & $466 \pm 4$ & $587 \pm 3$ & $132 \pm 5$ \\
\hline 33.19 & $426 \pm 3$ & $529 \pm 1$ & $134 \pm 4$ \\
\hline 34.09 & $310 \pm 2$ & $452 \pm 2$ & $15 x \pm 4$ \\
\hline 35.49 & $269 \pm 2$ & $351 \pm 2$ & $156 \pm 4$ \\
\hline
\end{tabular}

a See footnote (b) of Table 4.

b Errors given are primarily stat. To this add in quadrature $\pm 3 \%$ systematic error and errors in $I \gamma / s$. 
TABLE 6. Europium deuteron data: first order reactions.

Cross-sections (mb) ${ }^{c}$

\begin{tabular}{|c|c|c|}
\hline $\mathrm{E}(\mathrm{MeV})$ & ${ }^{151} \mathrm{Eu}(\mathrm{d}, 2 \mathrm{n})^{151} \mathrm{Gd}$ & ${ }^{153} \mathrm{Eu}(\mathrm{d}, 2 n)^{153} \mathrm{Gd}$ \\
\hline $\begin{array}{l}4.86 \\
5.90 \\
5.92 \\
6.39 \\
6.75\end{array}$ & $\begin{array}{c}0.26 \pm 0.03^{a} \\
5.46 \pm 0.07 \\
5.10 \pm 0.10 \\
14.19 \pm 0.18 \\
26.04 \pm 0.16\end{array}$ & $\begin{array}{r}0.39 \pm 0.02^{\mathrm{a}} \\
8.01 \pm 0.05 \\
7.38 \pm 0.05 \\
20.35 \pm 0.15 \\
36.64 \pm 0.13\end{array}$ \\
\hline $\begin{array}{l}7.26 \\
7.61 \\
8.03 \\
8.28 \\
8.91\end{array}$ & $\begin{array}{c}68.75 \pm 0.40 \\
81.1 \pm 0.4 \\
135.3 \pm 0.6 \\
154.9 \pm 0.8 \\
241.7 \pm 0.9\end{array}$ & $\begin{array}{c}93.58 \pm 0.40 \\
111.6 \pm 0.4 \\
180.8 \pm 0.6 \\
205.7 \pm 0.6 \\
317.9 \pm 0.6\end{array}$ \\
\hline $\begin{array}{r}9.38 \\
9.81 \\
10.22 \\
10.35 \\
11.18\end{array}$ & $\begin{array}{l}293.0 \pm 0.6 \\
359.8 \pm 1.3 \\
391.5 \pm 2.0 \\
419.4 \pm 2.1 \\
521.6 \pm 1.7\end{array}$ & $\begin{array}{l}379.6 \pm 0.6 \\
470.2 \pm 1.2 \\
510.8 \pm 2.0 \\
544.7 \pm 2.2 \\
668.9 \pm 1.4\end{array}$ \\
\hline $\begin{array}{l}11.35 \\
12.32 \\
12.72 \\
13.06 \\
14.14\end{array}$ & $\begin{array}{l}517.6 \pm 7.0 \\
589.0 \pm 1.5 \\
623.7 \pm 1.7 \\
622 \pm 2.2 \\
624.4 \pm 1.7\end{array}$ & $\begin{array}{l}693.7 \pm 4.9 \\
753.8 \pm 2.2 \\
766.4 \pm 1.7 \\
812 \pm 3 \\
727.9 \pm 2.6\end{array}$ \\
\hline $\begin{array}{l}14.19 \\
14.40 \\
15.46 \\
15.64 \\
16.69\end{array}$ & $\begin{array}{l}621.4 \pm 2.3 \\
588 \pm 2.4 \\
548.7 \pm 2.1 \\
531 \pm 2.4 \\
459.1 \pm 5\end{array}$ & $\begin{array}{l}749.0 \pm 3.4 \\
694 \pm 3.7 \\
618.5 \pm 2.9 \\
609 \pm 2.9 \\
495.8 \pm 1.0\end{array}$ \\
\hline $\begin{array}{l}16.80 \\
17.94 \\
19.06 \\
19.34 \\
20.87\end{array}$ & $\begin{array}{l}437 \pm 1.7 \\
361 \pm 5 \\
298 \pm 1.4 \\
284 \pm 3.0 \\
231 \pm 1.5\end{array}$ & $\begin{array}{l}485 \pm 2.4 \\
398 \pm 3.5 \\
327 \pm 3 \\
307 \pm 1 \\
248 \pm 0.6\end{array}$ \\
\hline $\begin{array}{l}22.30 \\
23.64 \\
25.09 \\
26.38 \\
27.54\end{array}$ & $\begin{array}{l}(187)^{b} \\
(163) \\
(142) \\
(128) \\
(119)\end{array}$ & $\begin{array}{l}200 \pm 0.8 \\
175 \pm 0.8 \\
144 \pm 2.7 \\
134.2 \pm 1.7 \\
128.6 \pm 1.0\end{array}$ \\
\hline $\begin{array}{l}28.70 \\
29.73 \\
30.95 \\
32.11 \\
33.26\end{array}$ & $\begin{array}{r}(111) \\
(104) \\
(97) \\
(91) \\
(85)\end{array}$ & $\begin{array}{r}118.0 \pm 1.2 \\
104.7 \pm 1.2 \\
98.2 \pm 1.6 \\
90.1 \pm 1.8 \\
87.8 \pm 1.1\end{array}$ \\
\hline
\end{tabular}


a Resolution corrections were applied in the rising portion of the excitation functions.

b ${ }^{153} \mathrm{Gd}$ data used to estimate tail With tail subtracted from the ${ }^{151} \mathrm{Gd}$ we obtain the ${ }^{153} \mathrm{Gd}(\mathrm{d}, 4 \mathrm{n}){ }^{151} \mathrm{Gd}$ results in Table 7. Also see footnote (b) in

Table 4.

c Errors given are primarily stat. To this add in quadrature $\pm 3 \%$ systematic error and the uncertainty in $I \gamma / \mathrm{s}$.

TABLE 7. Europium deuteron data: higher order reactions.

\section{Cross-sections (mb) ${ }^{b}$}

\begin{tabular}{|c|c|c|c|}
\hline $\mathrm{E}(\mathrm{MeV})$ & ${ }^{153} \mathrm{Eu}(\mathrm{d}, 4 \mathrm{n}){ }^{151} \mathrm{Gd}$ & ${ }^{151} \mathrm{Eu}(\mathrm{d}, 4 n)^{149} \mathrm{Gd}$ & ${ }^{151} \mathrm{Eu}[d,(p 3 n+d 2 n)]^{149} \mathrm{Ev}$ \\
\hline $\begin{array}{l}19.34 \\
20.87\end{array}$ & & $\begin{array}{l}0.129 \pm 0.004 \\
4.17 \pm 0.03\end{array}$ & $\begin{array}{l}1.19 \pm 0.10 \\
2.8 \pm 0.4\end{array}$ \\
\hline 22.30 & $35 \pm 3^{a}$ & $39.4 \pm 0.2$ & $5.8 \pm 0.9$ \\
\hline $\begin{array}{l}23.64 \\
25.09 \\
26.38\end{array}$ & $\begin{array}{l}129 \pm 6 \\
299 \pm 10 \\
457 \pm 10\end{array}$ & $\begin{array}{l}131.8 \pm 0.7 \\
318.0 \pm 1.2 \\
477.6 \pm 1.9\end{array}$ & $\begin{array}{r}7.8 \pm 1.1 \\
14.0 \pm 2.8 \\
21.5 \pm 4.0\end{array}$ \\
\hline $\begin{array}{l}27.54 \\
28.70 \\
29.73\end{array}$ & $\begin{array}{l}609 \pm 10 \\
715 \pm 11 \\
780 \pm 13\end{array}$ & $\begin{array}{l}640.5 \pm 1.6 \\
758.8 \pm 2.3 \\
857.8 \pm 5.0\end{array}$ & $\begin{array}{l}28.7 \pm 5.5 \\
42.7 \pm 7.6 \\
64.1 \pm 7.8\end{array}$ \\
\hline $\begin{array}{l}30.95 \\
32.11 \\
33.26\end{array}$ & $\begin{array}{l}840 \pm 12 \\
829 \pm 10 \\
839 \pm 8\end{array}$ & $\begin{array}{l}932.4 \pm 6.3 \\
940.5 \pm 3.6 \\
954.2 \pm 5.7\end{array}$ & $\begin{array}{c}78.7 \pm 7.9 \\
92.5 \pm 7.3 \\
100.3 \pm 11.9\end{array}$ \\
\hline
\end{tabular}




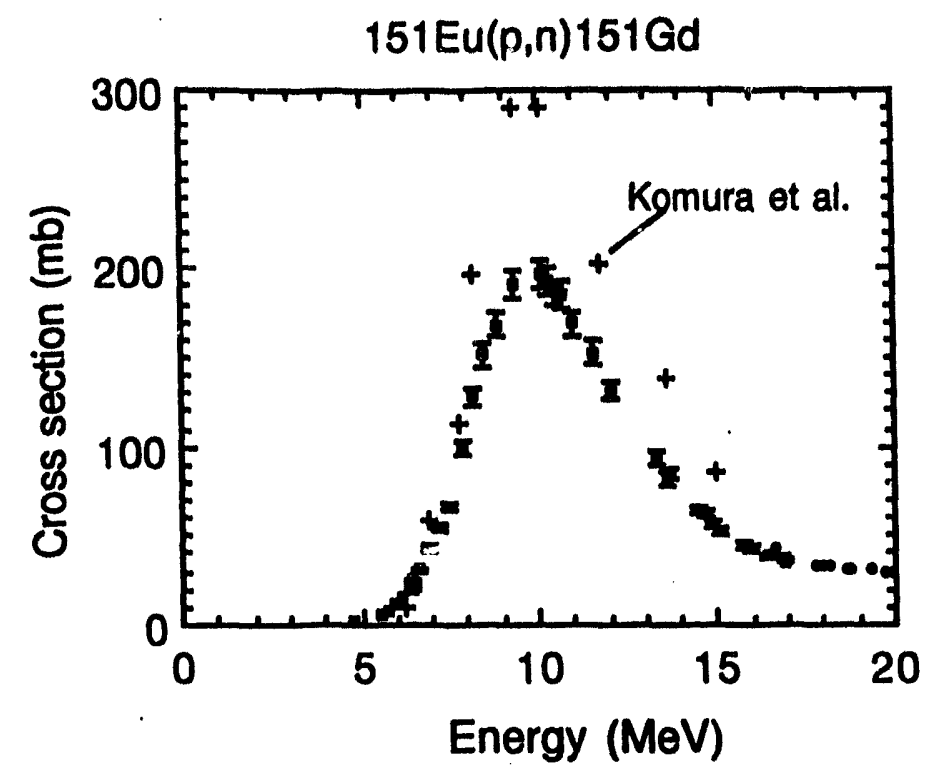

Fig. 1. Excitation function for $151 \mathrm{Eu}(\mathrm{p}, \mathrm{n}) 151 \mathrm{Gd}$. The tail at $>17 \mathrm{MeV}$ was determined using high energy data from the ${ }^{153} \mathrm{Eu}(p, n){ }^{153} \mathrm{Gd}$ excitation function. See text and Table 4 for details.

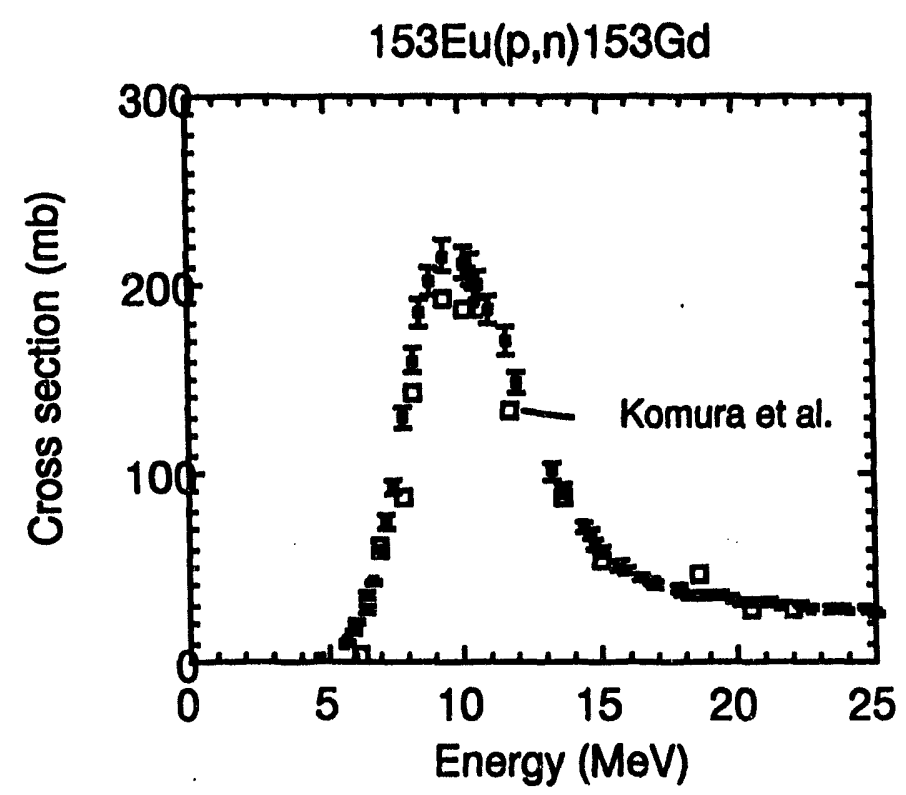

FIG. 2 Excitation function for ${ }^{153} \mathrm{Eu}(\mathrm{p}, \mathrm{n})^{153} \mathrm{Gd}$. See Table 4. 


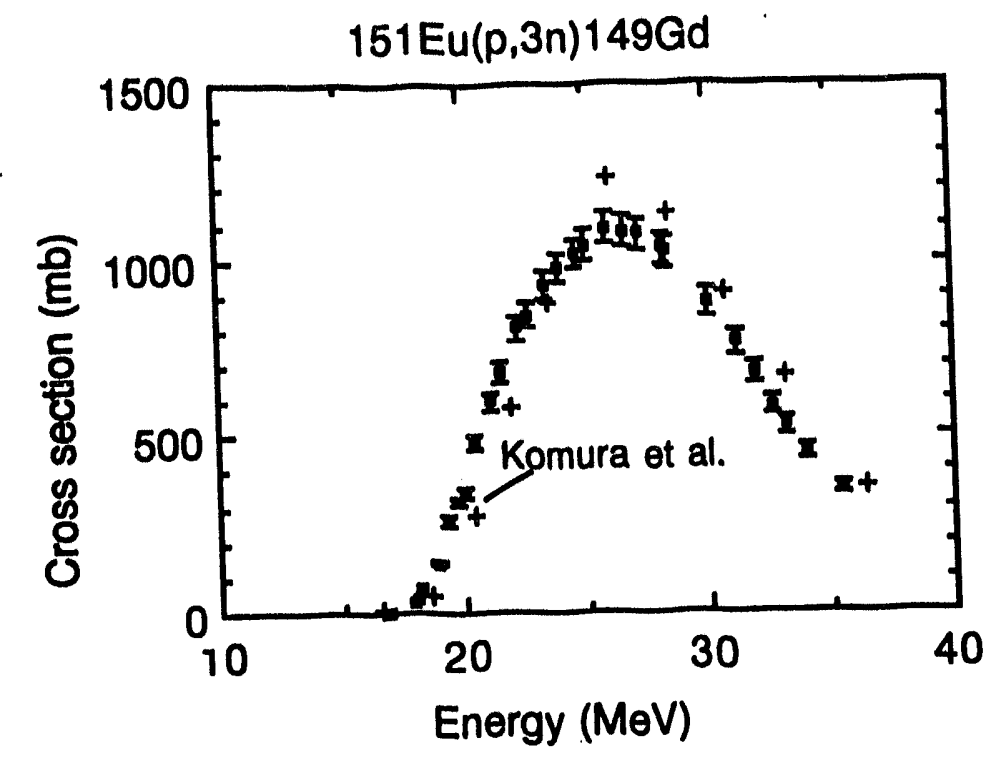

FIG. 3. Excitation function for ${ }^{151} \mathrm{Eu}(\mathrm{p}, 3 n)^{149} \mathrm{Gd}$. See Table 5 .

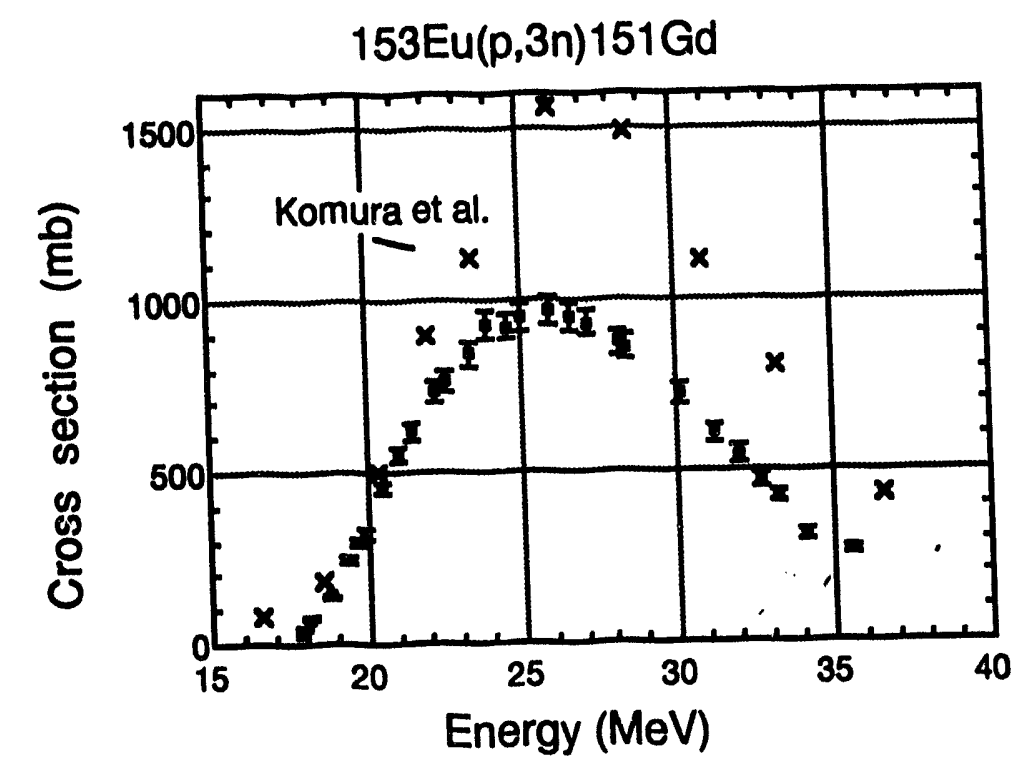

FIG. 4. Excitation function for ${ }^{153} \mathrm{Eu}(p, 3 n)^{151} \mathrm{Gd}$. See Table 5. 


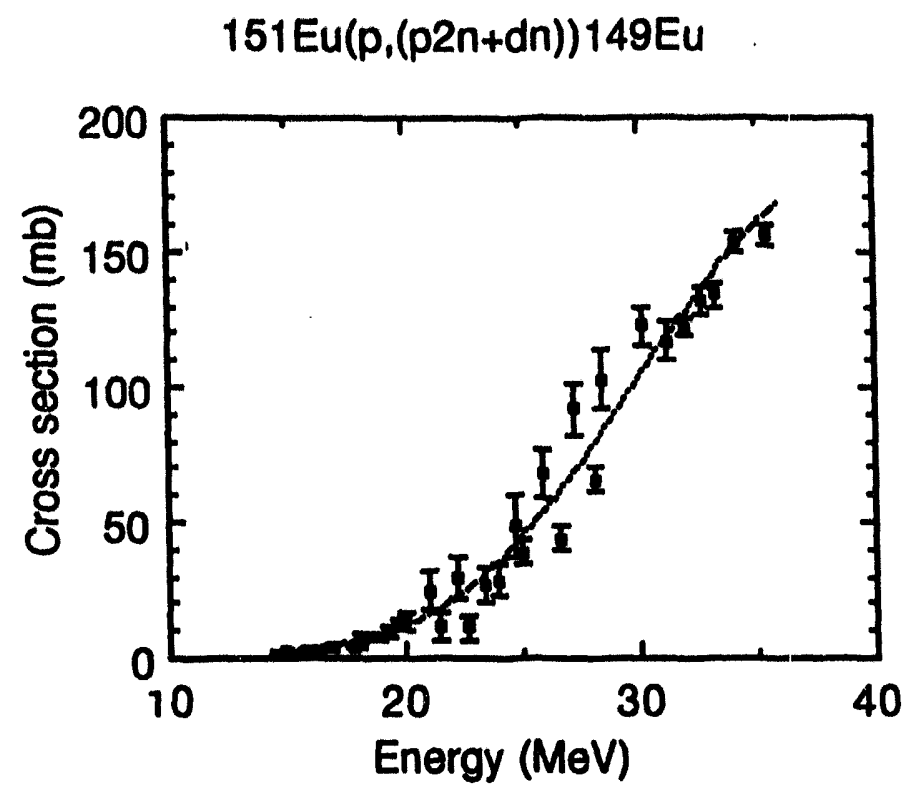

FIG. 5. Excitation function for ${ }^{151} \mathrm{Eu}[\mathrm{p},(\mathrm{p} 2 \mathrm{n}+\mathrm{dn})]^{149} \mathrm{Eu}$. See Table 5. The dotted curve is the result of a least squares fit to a polynomial.

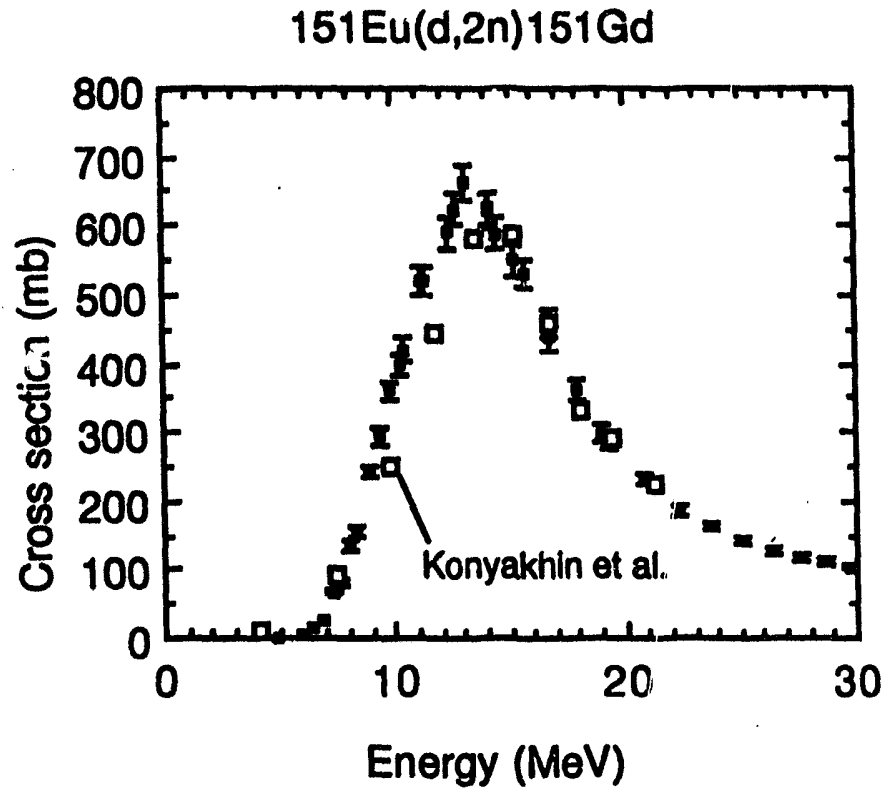

FIG. 6. Excitation function for ${ }^{151} \mathrm{Eu}(\mathrm{d}, 2 \mathrm{n}){ }^{151} \mathrm{Gd}$. The tail at $>20 \mathrm{MeV}$ was determined using high energy from the ${ }^{153} \mathrm{Eu}(\mathrm{d}, 2 \mathrm{n})^{153} \mathrm{Gd}$ excitation function. See text and Table 6. 


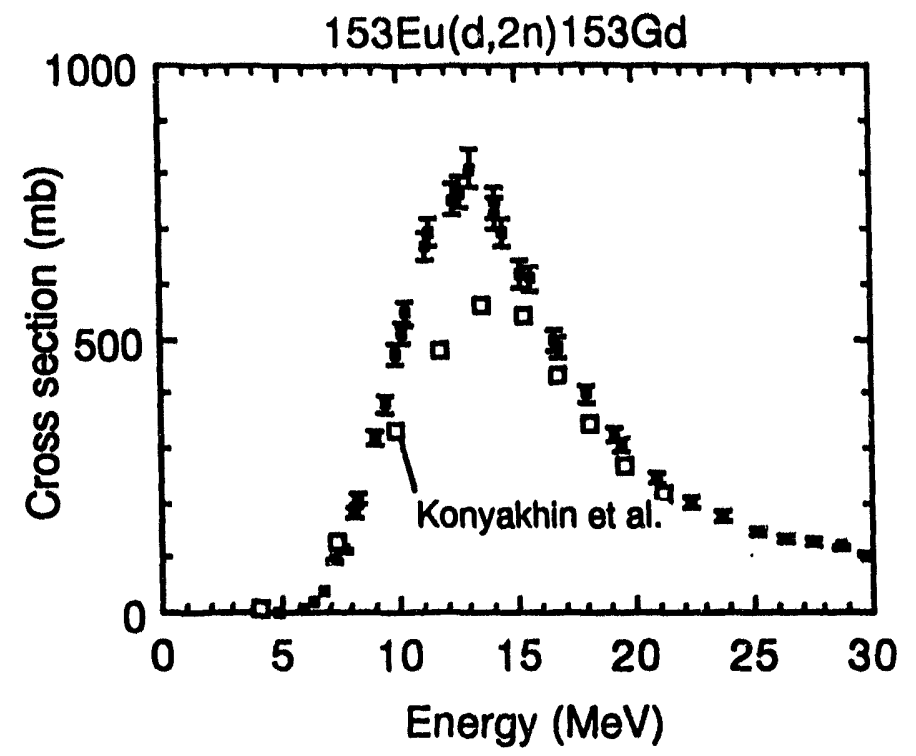

FIG. 7 Excitation function for ${ }^{153} \mathrm{Eu}(\mathrm{d}, 2 \mathrm{n})^{153} \mathrm{Gd}$. See Table 6.

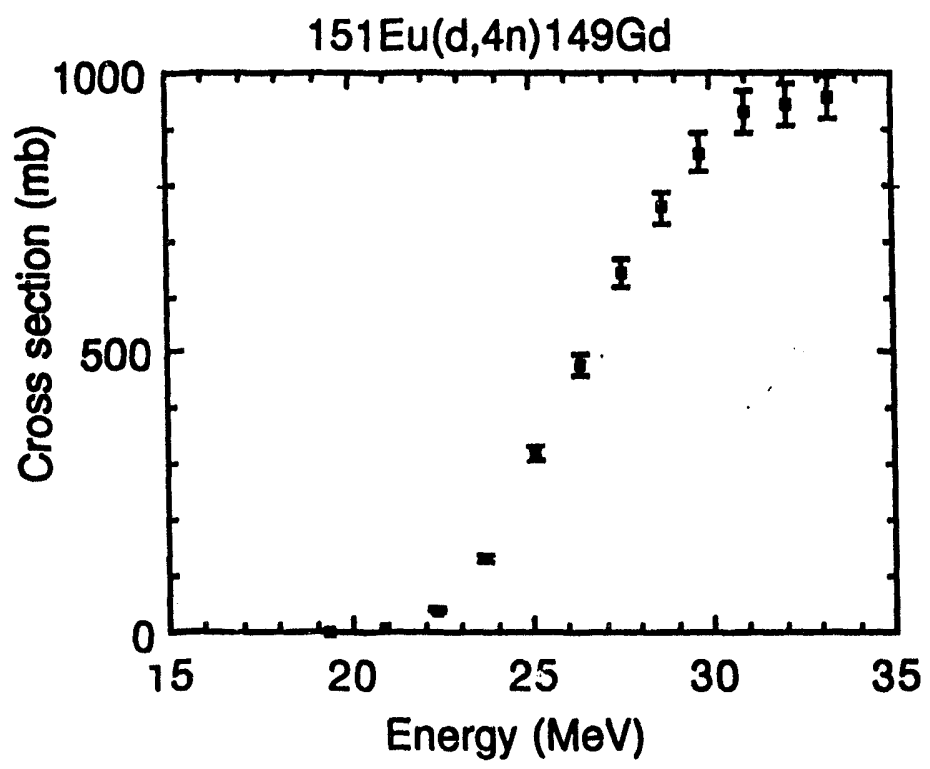

FIG. 8 Excitation unction for ${ }^{151} \mathrm{Eu}(\mathrm{p}, 4 \mathrm{n})^{149} \mathrm{Gd}$. See Table7. 


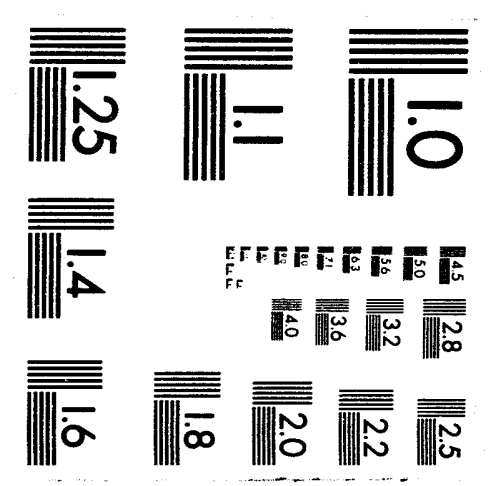



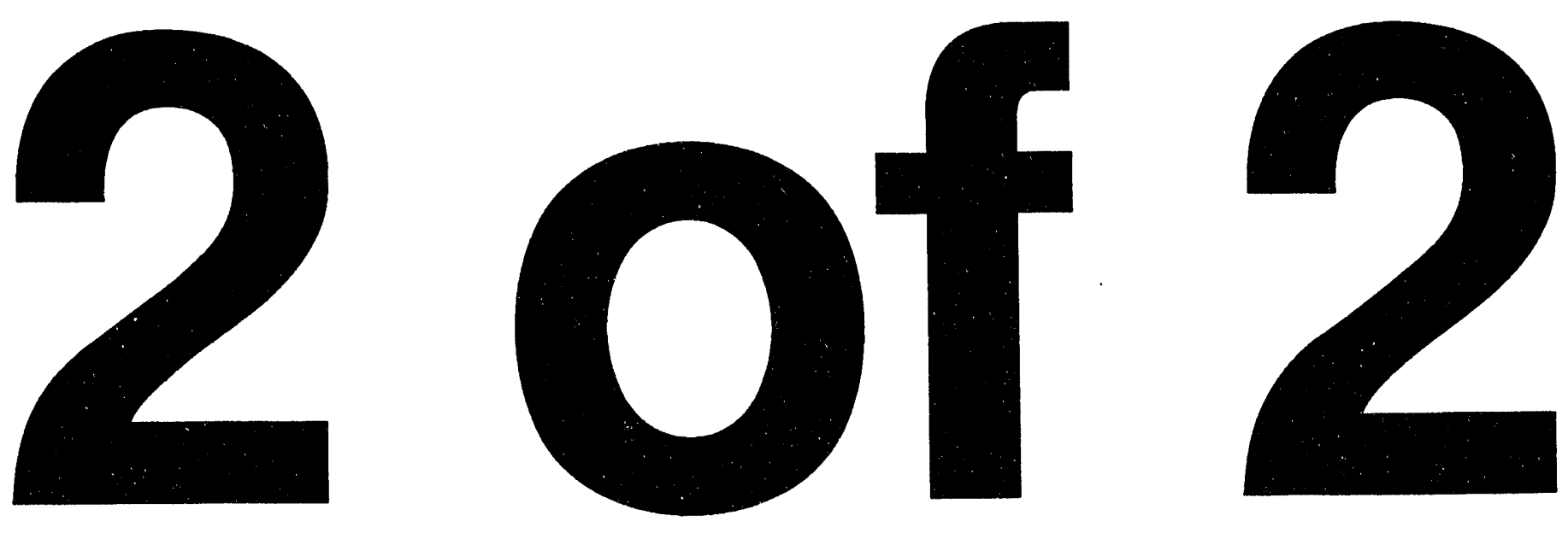


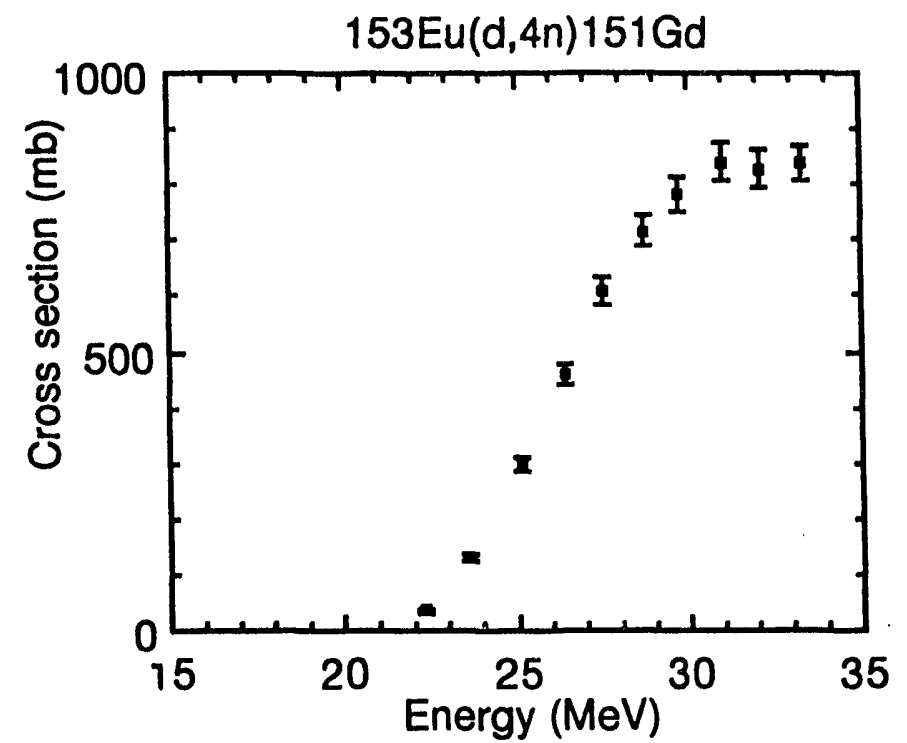

FIG. 9 Excitation function for ${ }^{153} \mathrm{Eu}(\mathrm{d}, 4 \mathrm{n})^{151} \mathrm{Gd}$. See Table 7.

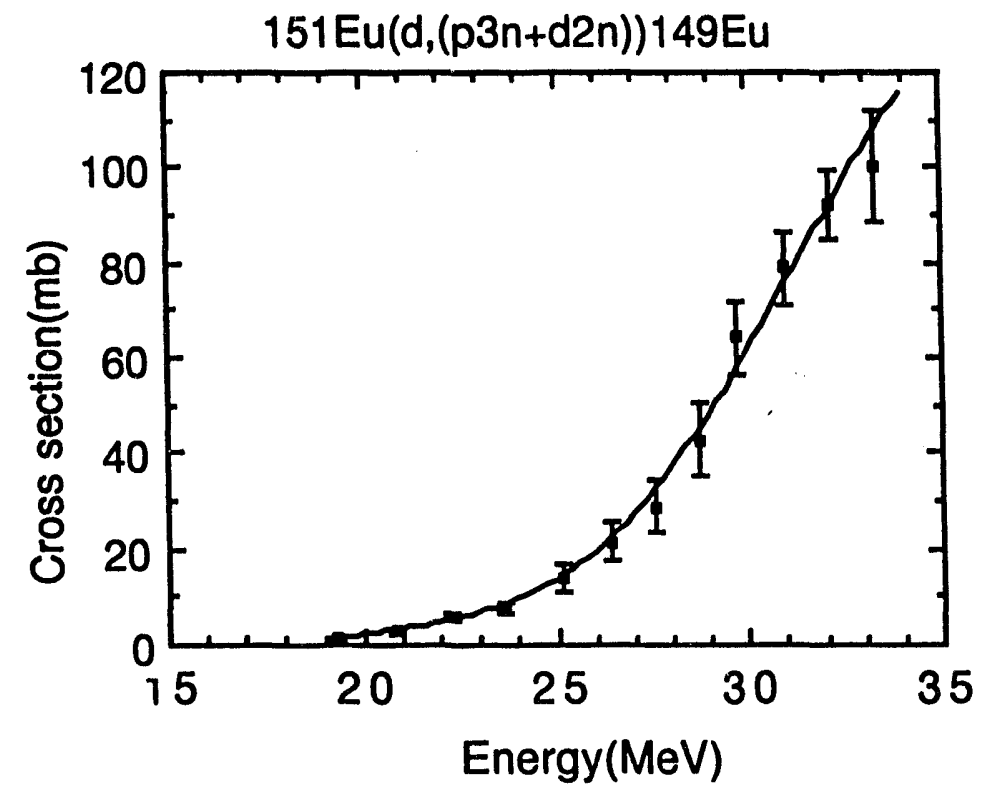

FIG. 10 Excitation function for ${ }^{151} \mathrm{Eu}[\mathrm{d},(\mathrm{p} 3 \mathrm{n}+\mathrm{d} 2 \mathrm{n})]^{149} \mathrm{Eu}$. It would appear that most of the cross sections are due to the $(d, p 3 n)$ reaction. See Table 7. 


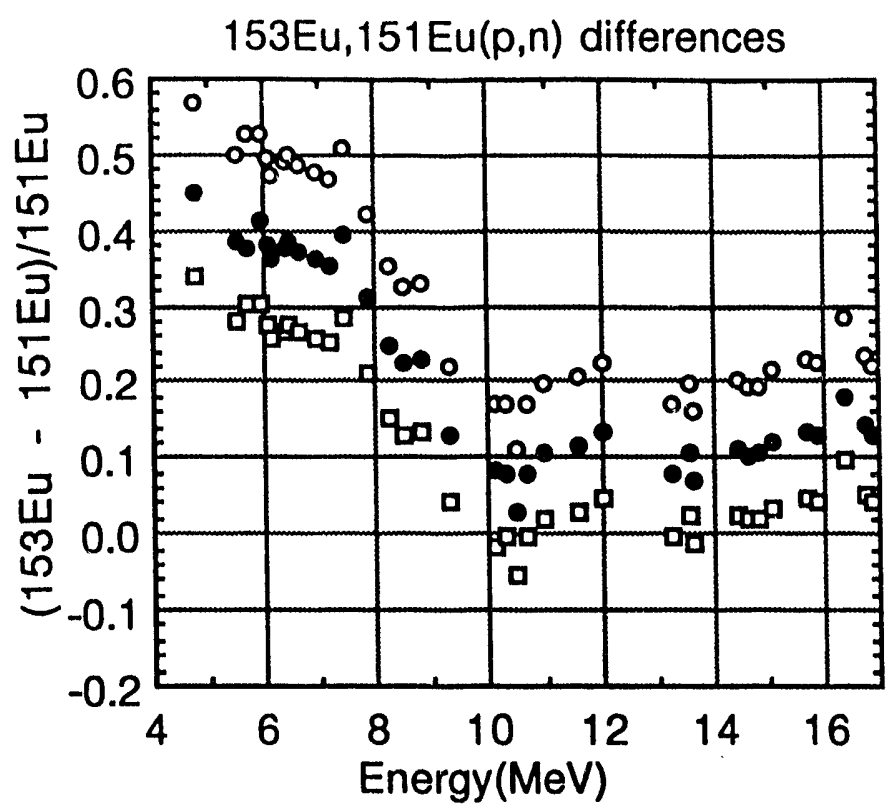

FIG. 11 Differences for the $(p, n)$ reaction for $\sigma(151 \mathrm{Eu})$ and $\sigma(153 \mathrm{Eu})$ expressed as $[\sigma(153 \mathrm{Eu})-\sigma(151 \mathrm{Eu})] / \sigma(151 \mathrm{Eu})$. The upper and lower sets of data represent the extremes for possible errors in the $I \gamma$ 's.

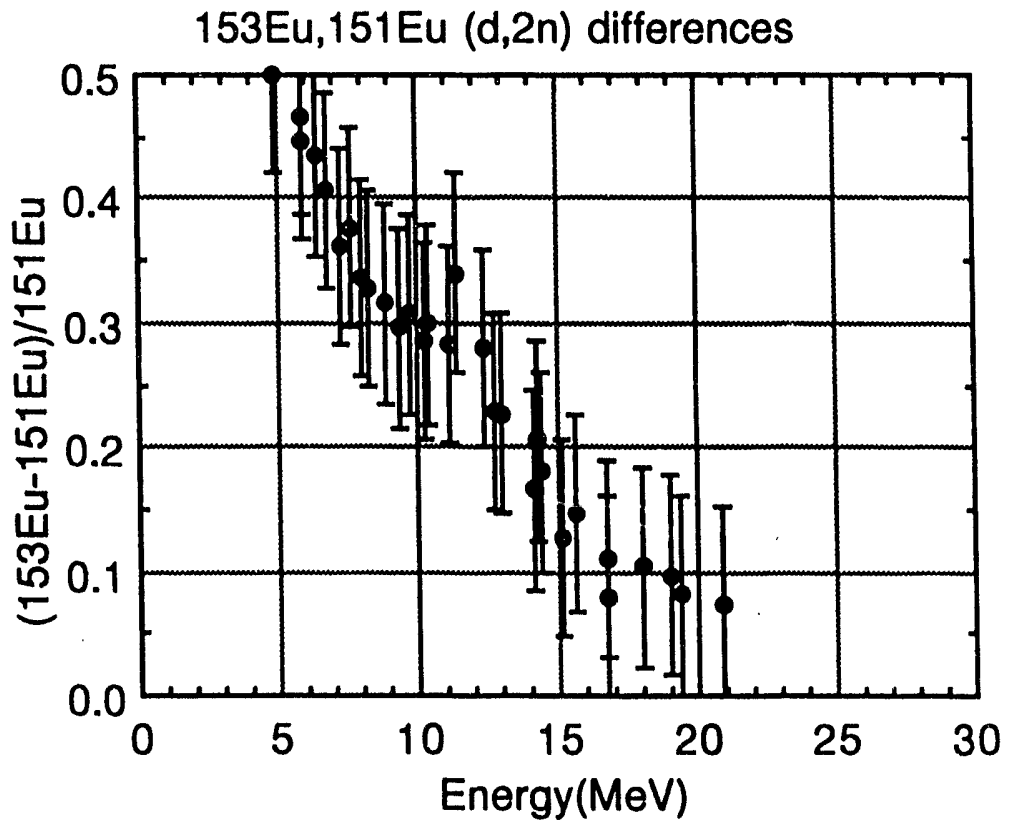

FIG.12 Differences for the $(\mathrm{d}, 2 \mathrm{n})$ reaction for $\sigma(151 \mathrm{Eu})$ and $\sigma(153 \mathrm{Eu})$ expressed as $[\sigma(153 \mathrm{Eu})-\sigma(151 \mathrm{Eu})] / \sigma(151 \mathrm{Eu})$. The error bars give the possible extremes for errors in the I $\gamma^{\prime} \mathrm{s}$ 

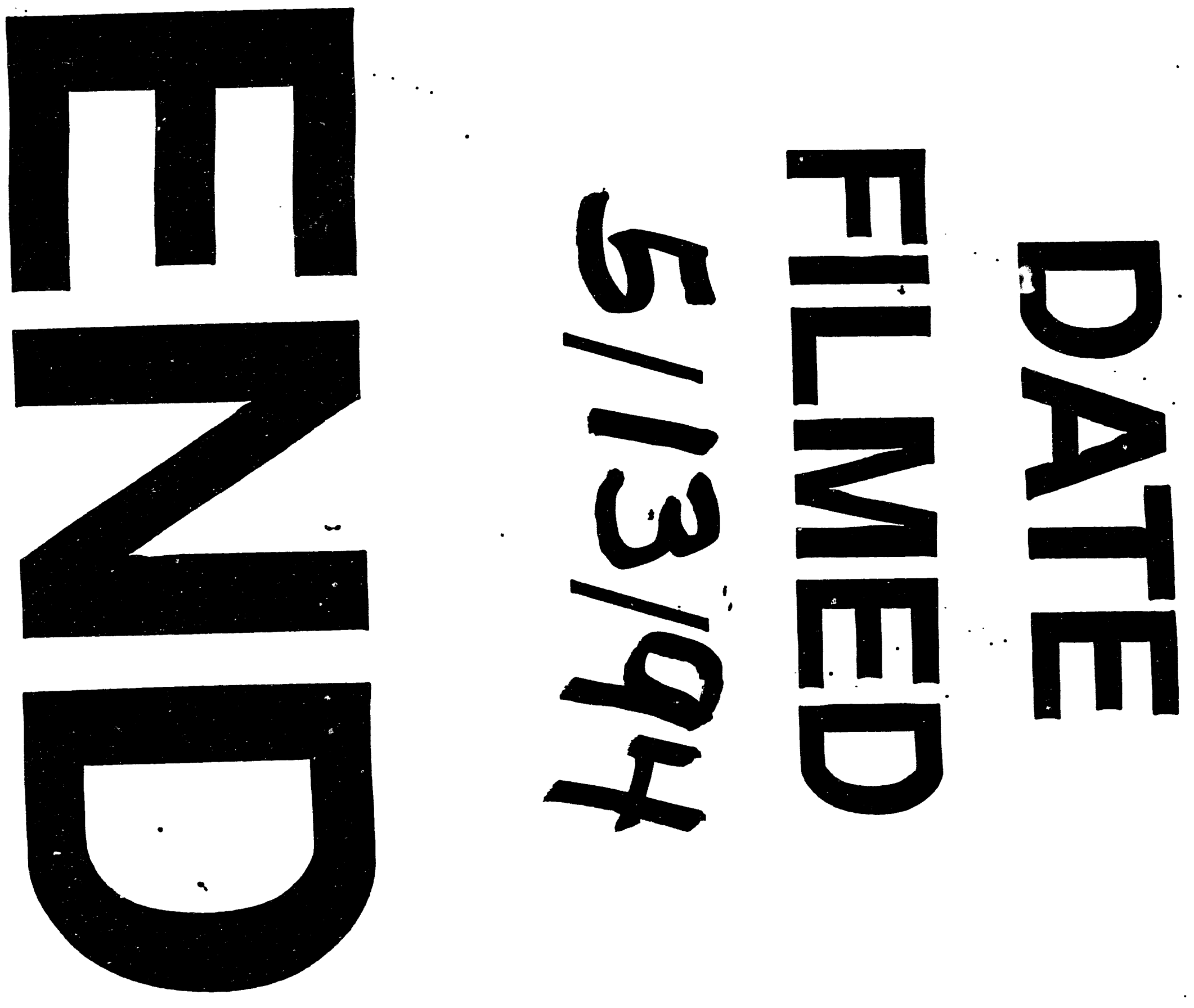
